\title{
Role of amyloid beta protein modulation in Alzheimer's disease
}

\author{
Doctoral Thesis \\ In partial fulfillment of the requirements for the degree \\ "Doctor rerum naturalium (Dr. rer. nat.)” \\ in the Molecular Medicine Study Program \\ at the Georg-August University Göttingen
}

submitted by

Antje Hillmann

born in

Halberstadt, Germany

Göttingen 2012 


\title{
Members of the Thesis Committee:
}

Supervisor

\author{
Prof. Dr. Thomas A. Bayer \\ Department for Psychiatry \\ University Medicine of Göttingen
}

Second member of the thesis committee

Prof. Dr. Uwe-Karsten Hanisch

Department of Neuropathology

University Medicine of Göttingen

Third member of the thesis committee

Prof. Dr. Mikael Simons

Max Planck Institute for Experimental Medicine Göttingen

Date of Disputation: 


\section{Affidavit}

Here I declare that my doctoral thesis entitled "Role of amyloid beta protein modulation in Alzheimer's disease” has been written independently with no other sources and aids than quoted.

Antje Hillmann

Göttingen, May 2012 


\section{Related publication}

Hillmann A, Hahn S, Schilling S, Hoffmann T, Demuth H-U, Bulic B, Schneider-Axmann T, Bayer TA, Weggen S, Wirths O (2012)

No improvement after chronic ibuprofen treatment in the 5XFAD mouse model of Alzheimer's disease. Neurobiology of aging 33:833.e39-50 


\section{Table of Contents}

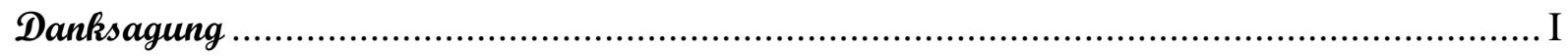

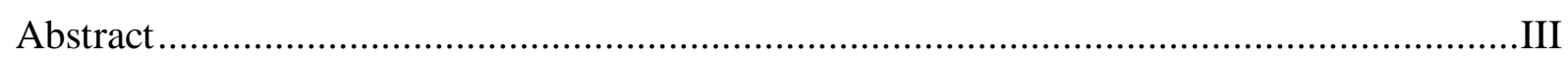

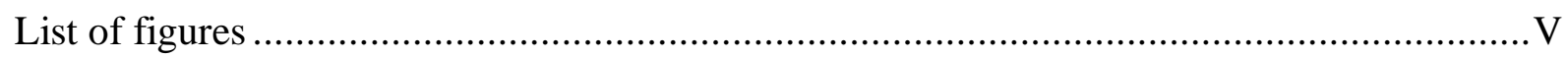

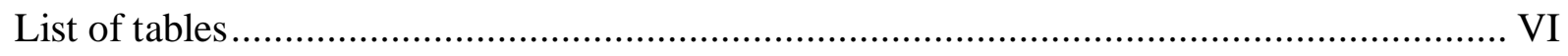

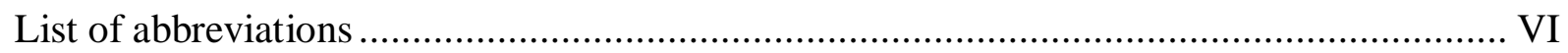

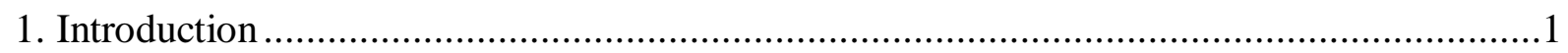

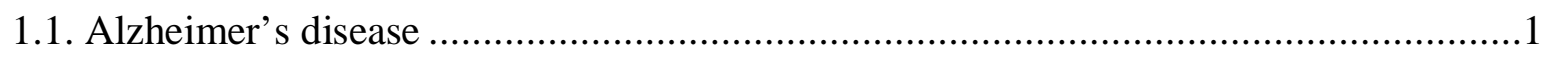

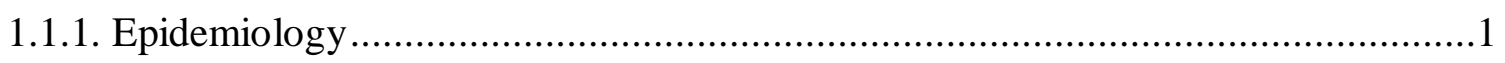

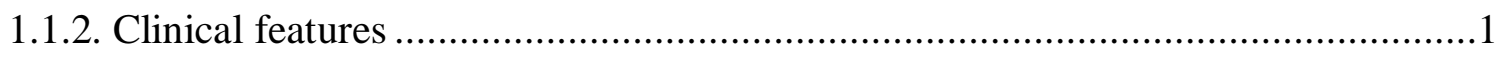

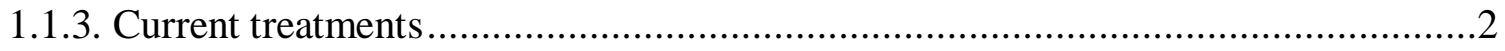

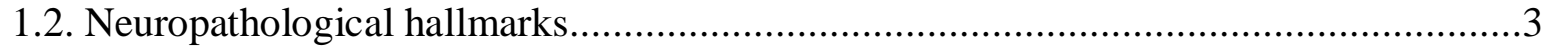

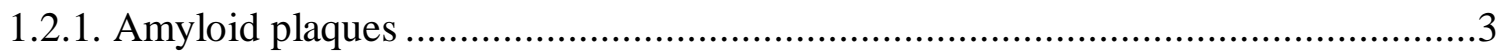

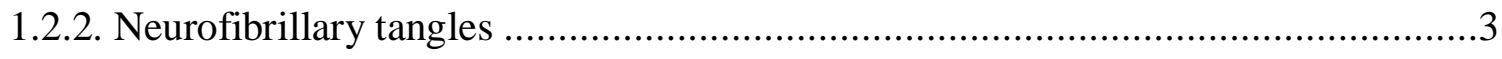

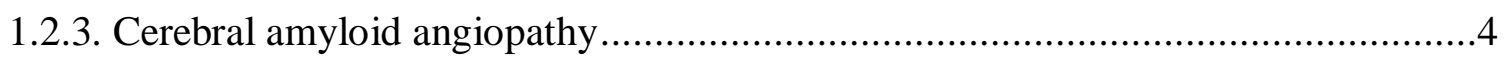

1.2.4. Synaptic deficits and neuron loss............................................................... 5

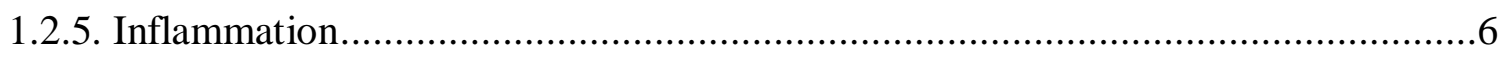

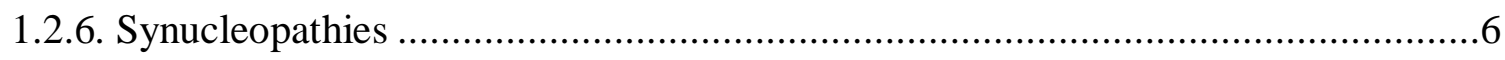

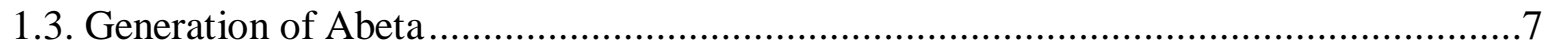

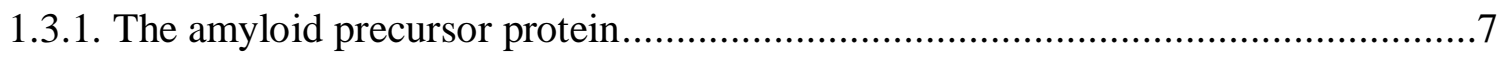

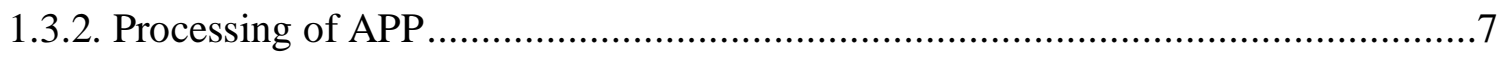

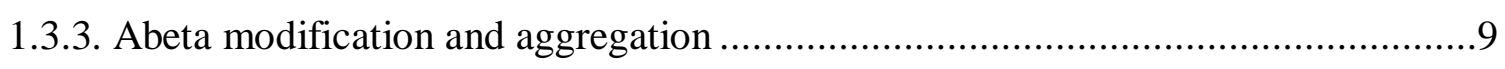

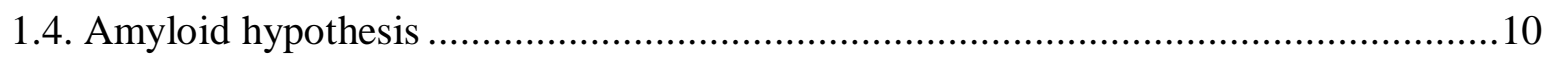

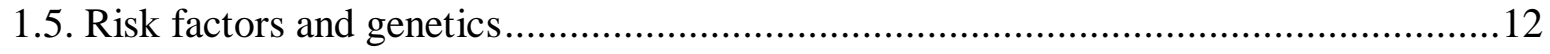

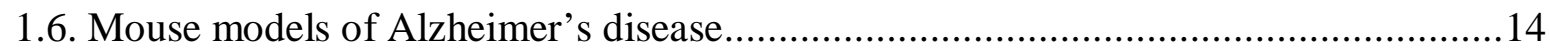

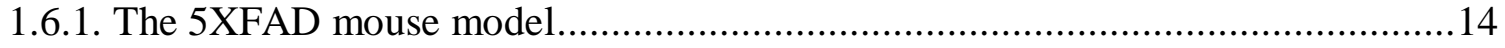

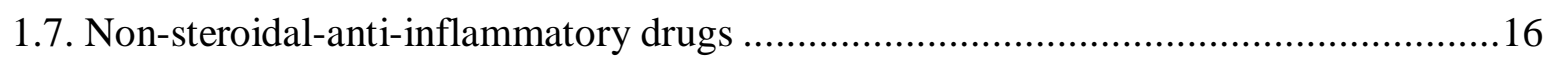

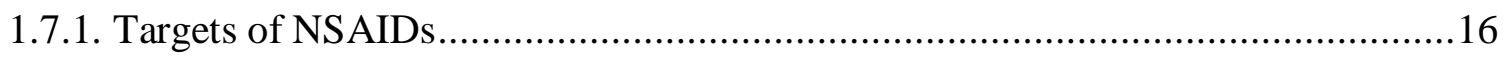

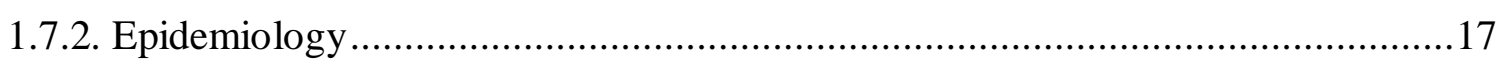

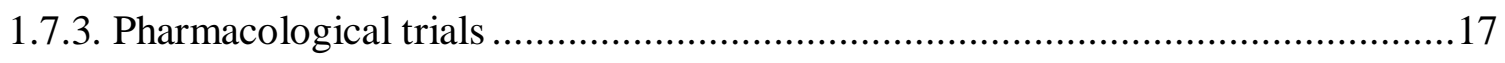

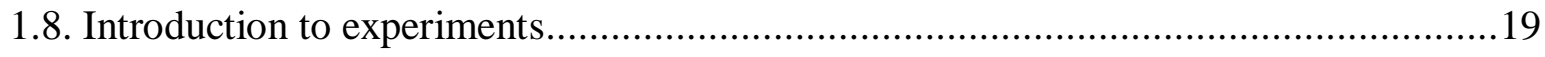

1.8.1. Project I: Chronic ibuprofen treatment in the 5XFAD mouse model....................19 
1.8.2. Project II: Analysis of oligomeric pyroglutamate Abeta in CAA. 20

1.8.3. Project III: Study of synuclein and A $\beta$ interaction in the cortex of 5XFAD mice .21

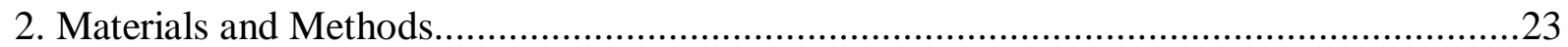

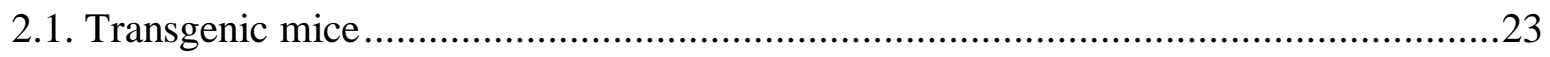

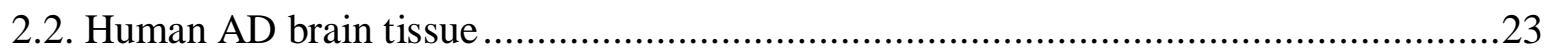

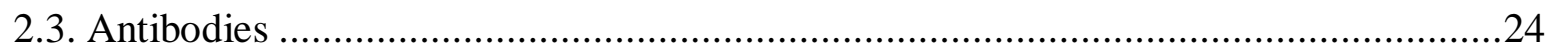

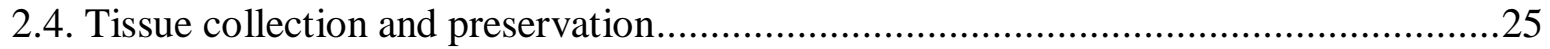

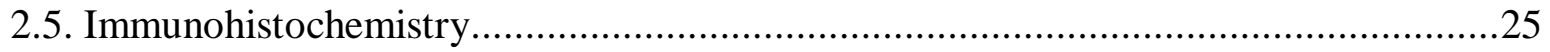

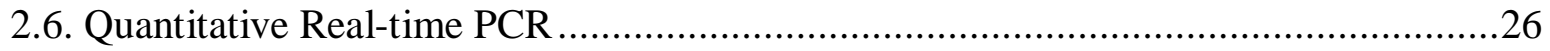

2.7. In vitro dose-response experiments with ibuprofen................................................27

2.8. Quantification of $A \beta$ plaque load and GFAP staining ...........................................28

2.9. Morphometric assessment of $\mathrm{A} \beta$ deposits in CAA ..............................................28

2.10. Enzyme-linked immunosorbent assay (ELISA) of $A \beta$ levels ................................29

2.11. Measurement of MCP-1 concentrations in brain...............................................29

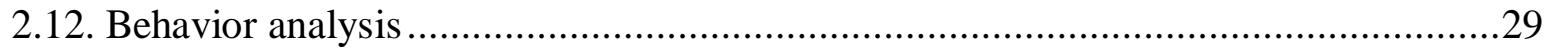

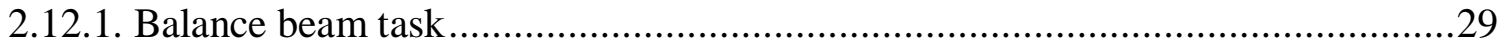

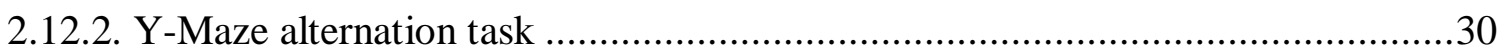

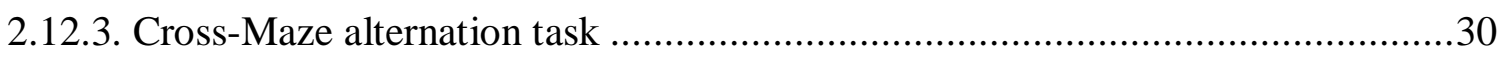

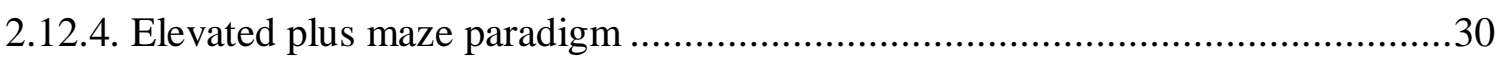

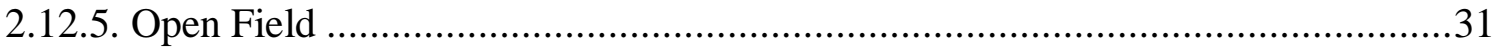

2.13. Stereotaxic injection of Adeno Associated Virus (AAV) .......................................31

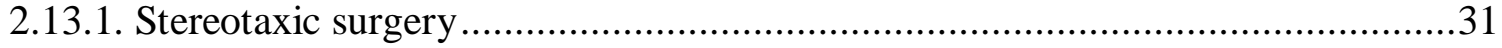

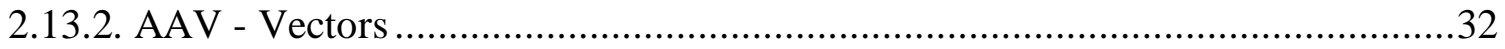

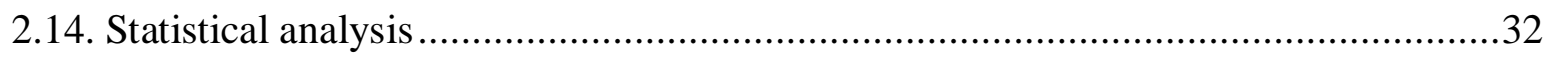

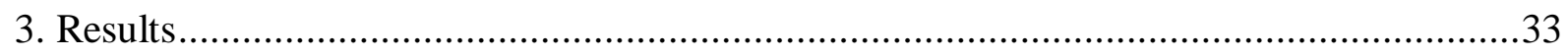

3.1. Project I: Chronic ibuprofen treatment in the 5XFAD mouse model........................33

3.1.1. Inflammatory processes in the 5XFAD mouse model .......................................33

3.1.2. Effect of ibuprofen treatment on transcript levels and protein levels of

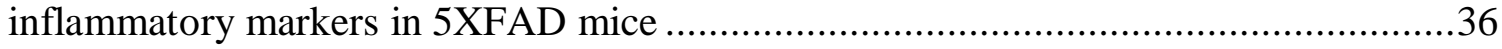

3.1.3. CHO-5XFAD cells are resistant to the A $\beta 42$-lowering activity of ibuprofen.........39

3.1.4. No effect of ibuprofen treatment on extracellular plaque pathology in 5XFAD

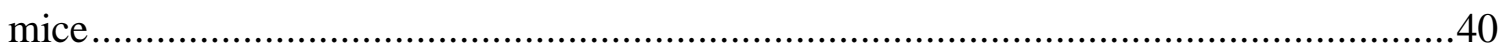

3.1.5. Effect of ibuprofen on $A \beta$ levels in 6-month-old 5XFAD mice...........................41

3.1.6. Effect of ibuprofen-treatment on behavioral performance in 5XFAD mice ..........42 
3.2. Project II: Analysis of oligomeric pyroglutamate Abeta in CAA …..........................46

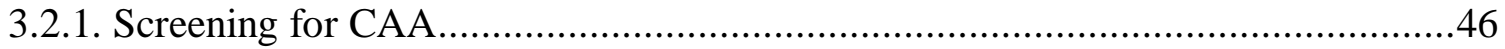

3.2.2. Comparative CAA staining of 9D5 versus NT244 ...........................................47

3.2.3. Quantitative analysis of blood vessels stained by diverse $A \beta$-specific antibodies 48

3.3. Project III: Study of synuclein and A $\beta$ interaction in the cortex of 5XFAD mice........50

3.3.1. Establishment of stereotactic injection of AVV into mouse brain .......................50

3.3.2. Analysis of specificity of synuclein antibody used in the study ..........................51

3.3.3. Expression of different synuclein variants in 5XFAD and wild-type mice ...........52

3.3.4. Colocalization analysis of $\alpha$-synuclein aggregates with APP and A $\beta$.................53

3.3.5. No influence of synuclein expression on extracellular plaque deposition in 5XFAD

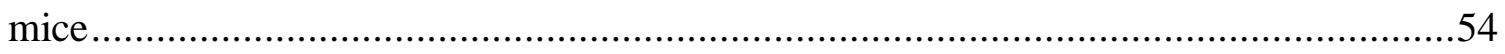

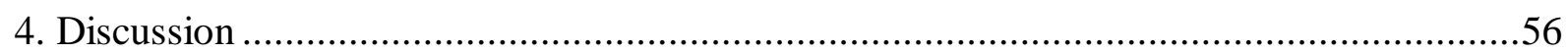

4.1. Project I: Chronic ibuprofen treatment in the 5XFAD mouse model.........................56

4.1.1. Inflammatory processes in the 5XFAD mouse model ......................................56

4.1.2. Ibuprofen treatment reduces gliosis in the 5XFAD mouse model........................59

4.1.3. 5XFAD mutations attenuate $A \beta 42$ lowering activity of ibuprofen .......................60

4.1.4. Ibuprofen treatment influences $A \beta$ levels but not the deposition in the 5XFAD

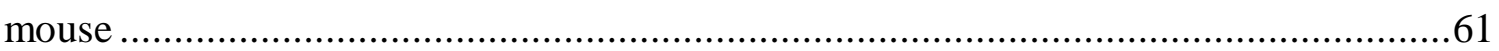

4.1.5. Decline in behavioral performance after ibuprofen treatment............................61

4.1.6. Detrimental effects in 5XFAD mice might be caused by increase of soluble A $\beta 42$

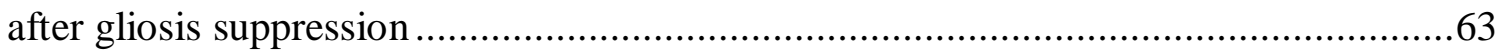

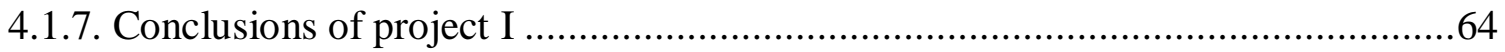

4.2. Project II: Analysis of oligomeric pyroglutamate Abeta in CAA ..............................65

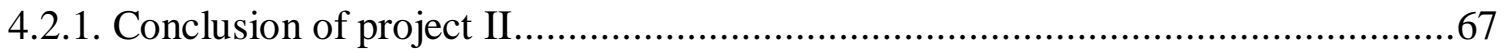

4.3. Project III: Study of synuclein and A $\beta$ interaction in the cortex of 5XFAD mice........68

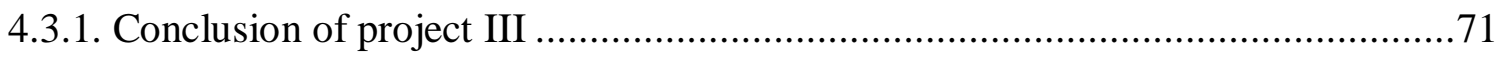

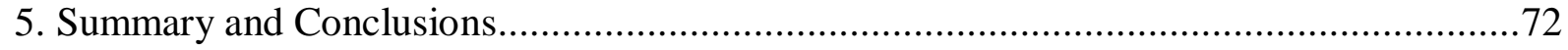

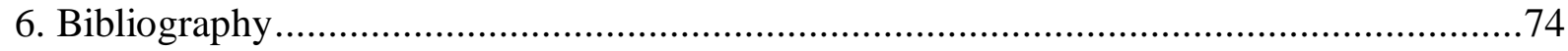

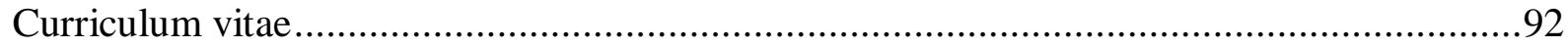


Dulium sapientiae initium.

Zweifel ist der Weisheit Anfang.

René Descartes 


\section{Danksagung}

Ich danke Prof. Thomas Bayer für seine immerwährende Unterstützung meiner wissenschaftlichen Arbeit, das in mich gesetzte Vertrauen und die Ermöglichung aktiv am internationalen Forschungsgeschehen teilnehmen zu können.

Dr. Oliver Wirths danke ich für zahlreiche wissenschaftliche Diskussionen und praktische Anregungen. Seine geduldigen Erklärungen und aufschlussreichen Kommentare haben entscheidend zum Gelingen dieser Doktorarbeit beigetragen.

Ebenso möchte ich mich bei Prof. Uwe-Karsten Hanisch und Prof. Mikael Simons für die Teilnahme an meinem Thesis-Komitee bedanken.

Der Arbeitsgruppe von Prof. Sebastian Kügler gebührt Dank für die geduldige Einweisung in das Gebiet der stereotaktischen Operationen.

Ein Dank geht auch an alle ehemaligen und aktuellen Mitglieder der AG Bayer. Ditte Z. Christensen, Marie-Caroline Cotel, Andrea Marcello, Vivek Venkataramani, Anika Saul, Katharina Dietrich und Yvonne Bouter. Es war eine Freude mit euch zu arbeiten.

Petra Tucholla danke ich für eine hervorragende technische Unterstützung meiner Arbeit. Danke dafür, dass du nie aufgegeben hast, Ordnung in unser Chaos zu bringen und immer zum richtigen Zeitpunkt deinen Notfall-Schokoladenvorrat mit uns geteilt hast.

Was wäre diese Arbeit ohne meine Mädels aus dem vorderen Büro? Sadeem Jawhar und Jessica Wittnam danke ich für zahlreiche Gespräche und Diskussionen über Wissenschaft, Gott und die Welt, einige abenteuerliche Reisen durch Europa und dafür, dass sie Freud und Leid in den letzten 3 Jahren mit mir geteilt haben.

Sadeem, meine „Schwester“: ich danke dir für deine bedingungslose moralische und fachliche Unterstützung und dafür, dass du nie den Glauben an mich verloren hast. Jess, dir danke ich dafür, dass du deinen unerschütterlichen Glauben an die Wissenschaft mit uns geteilt hast. Dein Enthusiasmus und deine Hilfsbereitschaft waren ein unverzichtbarer Teil der letzten 3 Jahre.

Ein großer Dank gebührt euch beiden ebenfalls für das Korrekturlesen dieser Arbeit. 
Ebenso sollen die Bachelor-, Master- und Rotationsstudenten nicht unerwähnt bleiben, die ich während meiner Doktorarbeit mitbetreuen durfte: Anna, Ziqiang, Annika, Katja und Freddy. Eure Motivation und eure Wissbegierde haben es mir erleichtert euch zu betreuen. Es war ein Lernprozess für beide Seiten.

Viele Menschen haben mich auf meinem Weg in Göttingen begleitet und wissentlich oder unwissentlich dazu beigetragen, dass ich heute an diesem Punkt angekommen bin.

Besonderer Dank gilt dabei „meinen Juristen“: Katja Kuplich, Verena Wernscheid und Michael Funke. Ich danke euch für eure fortwährenden Versuche naturwissenschaftliche Forschung zu verstehen. Eure Unterstützung, insbesondere in der letzten Phase dieser Arbeit, hat mir sehr geholfen.

Falk Kalamorz danke ich für eine wunderschöne Zeit am anderen Ende der Welt und dafür, dass er dieses Mal mein „Jammern auf hohem Niveau“ ertragen hat.

All dies wäre ohne meine Familie nicht möglich gewesen. Ich danke euch dafür, dass ihr mich auf jedem Schritt meines Weges begleitet und mir auch während schwieriger Zeiten zur Seite gestanden habt. 


\section{Abstract}

Alzheimer's disease (AD) is the most common neurodegenerative disease in the elderly. It is mainly characterized by the deposition of amyloid plaques and neurofibrillary tangles. In addition, inflammatory processes in the brain are a well described feature of AD. The contribution of inflammation to the pathological progression is still under debate. Epidemiological studies have shown that the use of non-steroidal-anti-inflammatory drugs (NSAIDs) delayed the onset, slowed the cognitive decline, and decreased the incidence of $\mathrm{AD}$. However, so far the results of pharmacological studies in both mice and humans are inconsistent.

In this thesis, inflammatory processes in the 5XFAD mouse model were characterized before using it to study the effect of ibuprofen. Assessment of inflammatory changes in the mice, revealed an upregulation of a broad range of microglial and astroglial markers, validating the suitability of the model for studying anti-inflammatory therapeutics.

The influence of long-term treatment with the NSAID ibuprofen on neuroinflammation, amyloid pathology and cognitive functions in the 5XFAD mouse model was analyzed. Treatment with ibuprofen resulted in suppression of inflammation in the 5XFAD mouse model. Surprisingly, an increase in soluble A $\beta 42$ levels and an aggravation of some behavioral parameters were also noted, raising the question of whether suppression of inflammation is beneficial in $\mathrm{AD}$.

In addition to plaque development, $\mathrm{AD}$ patients often demonstrate an accumulation of $\mathrm{A} \beta$ in blood vessels (cerebral amyloid angiopathy, CAA). Occurrence of CAA is associated with increased number of hemorrhages during passive immunizations due to direct binding of anti-A $\beta$ antibody to cerebral amyloid. For safer therapeutic approaches, it is therefore necessary to study the association of promising antibodies with the vasculature in the human brain.

Our group has generated a conformation-dependent monoclonal antibody, 9D5, that selectively recognizes low-molecular weight pyroglutamate $\mathrm{A} \beta \mathrm{pE} 3$ oligomers, and demonstrated its diagnostic and therapeutic potential. In this work, the CAA staining pattern of the 9D5 antibody was assessed and the question was addressed whether the 9D5 antibody recognizes the same amount of CAA as other A $\beta$ antibodies. The 9D5 antibody exhibited a limited detection of CAA, indicating that passive immunization with 9D5 antibodies will likely yield fewer side effects due to possible cerebral hemorrhages in sporadic AD patients. 
Up to two-thirds of the AD patients also develop $\alpha$-synuclein positive Lewy bodies and Lewy neurites, the major pathological hallmarks of Parkinson's disease. The interaction of $\alpha$-synuclein with $A \beta$ and the impact of $\alpha$-synuclein on pathology progression has been a matter of scientific debate.

In a pilot study, the effect of $\alpha$-synuclein overexpression on $A \beta$ pathology in the 5XFAD mouse model was analyzed. Stereotactic injection of $\alpha$-synuclein AAV constructs led to development of Lewy neurites. Only a minor degree of overlap between $A \beta$ and $\alpha$ synuclein pathology was seen, arguing against an interaction of both proteins. 


\section{List of figures}

Fig. 1 Plaques and tangles in the cerebral cortex in Alzheimer's disease

Fig. 2 APP processing

Fig. $3 \gamma$-secretase complex

Fig. $4 \mathrm{~A} \beta$ aggregation

Fig. 5 Schematic representation of the intraneuronal $A \beta$ hypothesis

Fig. 6 Familial mutations and their location within the APP gene

Fig. 7 Schematic overview of COX inhibition

Fig. 8 Analysis of gene expression of various inflammatory markers by quantitative RT-PCR

Fig. 9 Quantitative RT-PCR analysis of ibuprofen treated mice

Fig. 10 Effect of ibuprofen treatment on protein levels of inflammatory markers

Fig. 11 Cells with stable expression of the 5XFAD combination of APP and PS1 mutations are resistant to the A $\beta 42$-lowering activity of ibuprofen

Fig. 12 Unchanged hippocampal and cortical plaque load in 5XFAD mice

Fig. 13 Effect of 3 months of ibuprofen-treatment on $A \beta 40$ and $A \beta 42$ levels in 6-month-old 5XFAD mice

Fig. 14 Effect of ibuprofen-treatment on behavioral performance in 5XFAD mice

Fig. 15 Influence of ibuprofen-treatment on behavioral performance in 5XFAD mice

Fig. 16 Comparative CAA staining of 9D5 versus NT244

Fig. 17 Representative images of various $A \beta$ antibodies staining CAA and quantitative analysis of positively stained areas in blood vessels

Fig. 18 Representative images of the expression pattern of injected AVV in the frontal cortex of 5XFAD mice

Fig. 19 Analysis of LB509 antibody specificity

Fig. 20 Representative images of the cortices of 5XFAD mice injected with different synuclein variants

Fig. 21 Representative images of the expression of different synuclein variants in WT mice

Fig. $22 \alpha$-synuclein WT and $\alpha$-synuclein A30P only partially colocalize with APP in injected 5XFAD mice

Fig. $23 \alpha$-synuclein WT and $\alpha$-synuclein A30P show no colocalization with A $\beta$ in injected 5XFAD mice

Fig. 24 Plaque load analyses revealed no differences between injected and non-injected 5XFAD groups 


\section{List of tables}

Table 1 Details for primary antibodies used in this thesis

Table 2 Details for secondary antibodies used in this thesis

\section{List of abbreviations}

AAV

AD

AICD

APH-1

APLP

ApoE

APP

$\mathbf{A} \boldsymbol{\beta}$

AßpE3-x

BACE

BBB

CAA

CHO

COX

CTFa

CTF及

DAB

DLB

DS

EGFP

FA

FAD

FCS

GFAP

GSM

MCI

MCP-1

NFTs
Adeno-Associated-Virus

Alzheimer's disease

APP intracellular domain

Anterior pharynx-defective-1

Amyloid precursor like proteins

Apolipoprotein E

Amyloid precursor protein

Amyloid beta

Pyroglutamate-modified amyloid beta

Beta site APP-cleaving enzyme

Blood-brain barrier

Cerebral amyloid angiopathy

Chinese hamster ovary

Cyclooxygenase

C-terminal fragment generated by alpha secretase

C-terminal fragment generated by beta secretase

Diaminobenzidine

Dementia with Lewy bodies

Down syndrome

Enhanced green fluorescent protein

Formic acid

Familial Alzheimer’s disease

Fetal calf serum

Glial fibrillary acidic protein

Gamma-secretase modulator

Mild cognitive impairment

Monocyte chemotactic protein-1

Neurofibrillary tangles 
NMDA

NSAIDs

PBS

PD

PEN-2

PFA

PS

Syn

WT

$\alpha$-secretase

$\beta$-secretase

$\gamma$-secretase
N-Methyl-D-Aspartate

Non-steroidal-anti-inflammatory drugs

Phosphate buffered saline

Parkinson's disease

Presenilin enhancer -2

Paraformaldehyde

Presenilin

Synuclein

Wildtype

Alpha secretase

Beta secretase

Gamma secretase 


\section{Introduction}

\subsection{Alzheimer's disease}

Alzheimer's disease (AD) is a neurodegenerative disease which represents the most common form of dementia in the elderly population today. The disease, that is characterized by extracellular plaques, neurofibrillary tangles and brain atrophy, was documented more than 100 years ago by the German psychiatrist Dr. Alois Alzheimer.

\subsubsection{Epidemiology}

In 2010, 35.6 million people worldwide suffered from dementia with $\mathrm{AD}$, accounting for 60 to 80 percent of the cases. Due to the international increase in life expectancies, the number of AD patients is predicted to increase dramatically in the near future, reaching 115 million by 2050 (Thies and Bleiler, 2011).

Today, 1.2 million people suffer from dementia in Germany. This number is expected to increase to 1.4 million by 2020 and to 2 million by 2050. Two thirds of these cases are caused by AD (Deutsche Alzheimer Gesellschaft, 2010).

According the World Alzheimer Report 2010, worldwide costs of dementia exceed 1\% of global gross domestic product. By 2030, worldwide social costs will increase by $85 \%$ (Wimo and Prince, 2010).

\subsubsection{Clinical features}

It is believed that the neurodegenerative processes of $\mathrm{AD}$ are already ongoing for 20 to 30 years before the appearance of clinical symptoms. In this preclinical phase, plaques and tangles accumulate, and, after reaching a certain threshold, the first symptoms appear. In the mild cognitive impairment (MCI) phase, patients demonstrate a memory loss to a greater extent than one would expect for normal aging (Arnáiz and Almkvist, 2003). MCI patients often display subtle problems with attention and executive function, abstract thinking and impairments in semantic memory, even though their daily living is not affected by it (Bäckman et al, 2004). 
With progression of the disease, other cognitive domains are affected, leading to more severe symptoms including confusion, irritability, aggression and mood swings. The progressive impairment of learning and memory in the patients requires a close supervision of their daily lives as they are unable to plan, judge, and organize tasks (Förstl and Kurz, 1999). Up to $20 \%$ of the patients also develop hallucinations (Perry et al., 1990). At the late disease stage, the memory is impaired to a degree that even biographical memories cannot be recalled. Also, language is severely impaired, with patients using only simple sentences or even just words to articulate their needs (Förstl and Kurz, 1999). Occurrence of motor impairments is also commonly observed in AD patients, ranging from poor facial expression, rigidity and posture/gait to bradykinesia (Scarmeas et al., 2004).

\subsubsection{Current treatments}

Despite tremendous efforts in clinical research, there is currently no treatment for AD. All of the approved drugs are only for symptomatic treatment and cannot change the natural course of the disease. The development of these drugs was based on the neurotransmitter disturbances apparent in AD.

Current symptomatic drugs include the acetylcholinesterase inhibitors, donepezil, galantamine and rivastigmine. These drugs aim to overcome the loss of cholinergic neurons seen in $\mathrm{AD}$ by increasing the availability of acetylcholine through inhibition of its degradation in the synaptic cleft. Furthermore, N-methyl-D-aspartate (NMDA)-receptor antagonists are used for therapy. They protect neurons from glutamate-mediated excitotoxicity without preventing physiological activation of the NMDA receptor. Memantine is the only approved drug out of this group (Scarpini et al., 2003). Acetyl cholinesterase inhibitors have been proven to be effective in mild to moderate AD (Birks, 2006).

In addition, antipsychotic drugs like risperidone and olanzapine can be used to reduce behavioral symptoms such as aggression and psychosis in the patients. However, the drugs are associated with serious side effects, and their use is only advised in severe cases (Ballard and Waite, 2006). 


\subsection{Neuropathological hallmarks}

\subsubsection{Amyloid plaques}

Amyloid plaques are spherical protein accumulations that can be divided into two types: neuritic and diffuse plaques.

Neuritic plaques consist of microscopic foci of extracellular filamentous amyloid beta (A $\beta$ ) protein displaying a cross-sectional diameter ranging from 10 to $120 \mu \mathrm{m}$. Dystrophic neurites, containing enlarged lysosomes, degenerating mitochondria and paired helical filaments, are found in the vicinity of the plaques (Fig.1). Also, inflammatory markers, such as microglia and astrocytes, are commonly associated with neuritic plaques (Selkoe, 2001)

In contrast, diffuse plaques harbor less immunoreactivity and their diameters differ from $50 \mu \mathrm{m}$ to several hundred $\mu \mathrm{m}$. This type of plaque has been found largely in nondemented subjects and may represent a precursor to neuritic plaque generation (Duyckaerts et al., 2009).

\subsubsection{Neurofibrillary tangles}

Another pathological hallmark of $\mathrm{AD}$ is the occurrence of neurofibrillary tangles (NFTs) in the cell body and in apical dendrites (Fig.1). NFTs consist of hyperphosphorylated tau formed into paired helical filaments. The tau protein belongs to the group of microtubuleassociated proteins and is associated with axonal stabilization processes (Dixit et al., 2008). However, under pathological conditions, tau gets hyperphosphorylated and accumulates in the somatodendritic compartment of neurons (Ballatore et al., 2007).

In the human brain, six tau isoforms are derived by alternative mRNA splicing from a single gene (Goedert et al., 1989). Phosphorylation takes place in a post-translational step, mainly at serine and threonine residues of the protein (Chen et al., 2004). Several kinases have been identified to be involved in this step, such as glycogen synthase kinase 3 (GSK-3), cyclin-dependent kinase 5 (CDK-5) and mitogen-activated protein kinase (MAPK) (Baumann et al., 1993; Mandelkow et al., 1993).

Tau pathology has been found to correlate better with the cognitive decline in patients than the plaque pathology and is therefore commonly used for post-mortem staging of $A D$ (Braak and Braak, 1991). 


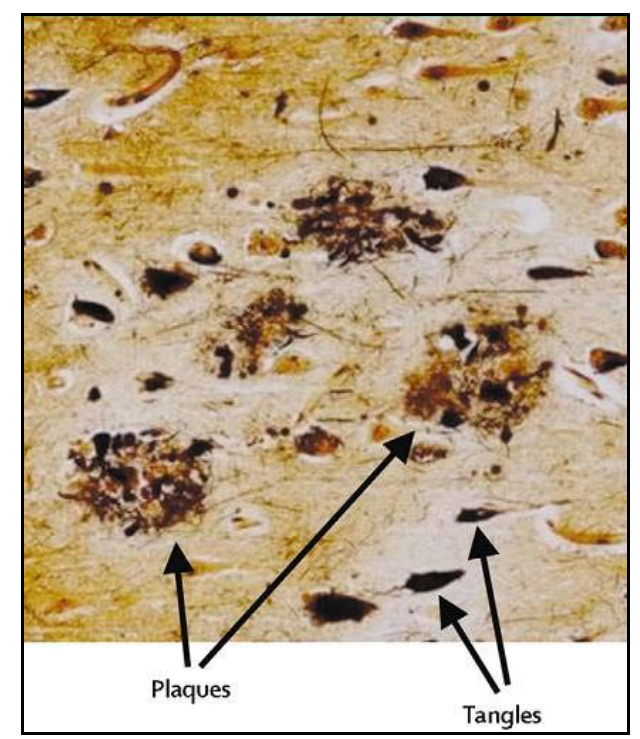

Fig. 1 Plaques and tangles in the cerebral cortex in Alzheimer's disease: Plaques are extracellular deposits of $\mathrm{A} \beta$ surrounded by dystrophic neurites, reactive astrocytes, and microglia, whereas tangles are intracellular aggregates composed of a hyperphosphorylated form of the microtubule-associated protein tau (Blennow et al., 2006).

\subsubsection{Cerebral amyloid angiopathy}

$\mathrm{AD}$ patients often display a third pathological hallmark. In addition to extracellular amyloid deposits and NFTs, these patients show cerebral amyloid angiopathy (CAA), an accumulation of $A \beta$ in blood vessels in the cerebral and cerebellar cortex (Ellis et al., 1996).

CAA is present in the brains of the elderly with an age-related prevalence from $10 \%$ to $40 \%$. However, its incidence in Alzheimer disease is much higher ranging from 25\% to $80 \%$ (Tomimoto et al., 1999; Herzig et al., 2006).

Meningeal and cerebral ateries, and to a lesser degree capillaries and veins, are affected by CAA, while white matter blood vessels are usually spared (Jellinger, 2002). Deposition of vascular amyloid can result in cerebral blood flow dysregulation, breakdown of the blood-brain barrier (BBB) and microhemorrhages (Zlokovic, 2011).

The contribution of CAA to the cognitive decline in $\mathrm{AD}$ is still unclear. Minor CAA seems to be without effect on the cognitive decline in severe Alzheimer pathology, while both mild Alzheimer pathology and small vessel disease may interact synergistically. However, severe amyloid angiopathy has an important role in the cognitive symptoms in AD patients (Jellinger, 2007). 


\subsubsection{Synaptic deficits and neuron loss}

Synapse and synaptic protein loss has been shown to be a key feature in memory dysfunction. AD patients show a reduction of synaptic markers in the temporal and frontal cortices (Davies et al., 1987). However, in the majority of cases, the hippocampus seems to be more affected compared with other brain regions (Honer, 2003).

Synaptic loss is currently one of the best neurobiological correlates with the cognitive deficits seen in AD. Decrease in synapse numbers significantly correlate with the mini mental state examination performance of the patients (DeKosky and Scheff, 1990). A more detailed comparison of neuropsychological tests with structural and neurochemical measurements revealed neocortical synapse density as a major correlate to the cognitive performance. While plaques and tangles only demonstrated weak connections (Terry et al., 1991), the severity of synapse loss depends on the disease stage. Patients with MCI had synapse reductions of 18\%, whereas mild AD patients demonstrated a loss of 55\% in comparison to healthy controls (Scheff et al., 2007).

Another important marker for cognitive decline in $\mathrm{AD}$ is neuron loss. $\mathrm{AD}$ patients show a prominent reduction in neuron numbers, especially in the temporal cortex and the CA1 region of the hippocampus (West et al., 1994). In addition, studies have also revealed neuron loss in the locus coeruleus, nucleus basalis, substantia nigra and raphe nucleus, with the degree of neuron loss differing between the regions (Hoogendijk et al., 1995; Zarow et al., 2003; Lyness et al., 2003). The nucleus basalis of Mynert undergoes a profound neuron loss which may exceed 75\% (Whitehouse et al., 1982). In comparison, unbiased stereological counting revealed a neuron loss of approximately 50\% in the superior temporal cortex (Gómez-Isla et al., 1997).

Brains of $\mathrm{AD}$ patients exhibit a prominent atrophy represented by enlargement of the ventricles, widening of the sulci and shrinkage of the gyri. The most pronounced atrophic changes are found in the hippocampus. An MRI-based analysis revealed a reduction of hippocampal volume of about 30\% in comparison to healthy controls (Bobinski et al., 1996). In addition, changes in the entorhinal cortex and the amygdala can also appear (Bottino et al., 2002). 


\subsubsection{Inflammation}

Inflammatory processes in the brain are a well described feature of AD. However, their contribution to the pathological progression is still under debate, as there have been reports demonstrating toxic or even beneficial effects (Boche and Nicoll, 2008). Inflammation is thought to be a downstream process appearing after $A \beta$ plaques, NFTs and neuron degeneration (Arnaud et al., 2006).

Increased astrogliosis, measured by glial fibrillary acidic protein (GFAP) concentration, is found in cortex, thalamus, brainstem and cerebellum in AD brains (Delacourte, 1990). Aggregation of $\mathrm{A} \beta$ results in activated microglia and induces the production of reactive-oxygen species, pro-inflammatory cytokines, chemokines and prostaglandines leading to degenerative changes in neurons (Akiyama et al., 2000). On the other hand, microglia cells have been demonstrated to mediate soluble $\mathrm{A} \beta$ macropinocytosis and efficient degradation in endolysosomal compartments (Mandrekar et al., 2009).

Epidemiological studies demonstrated that patients with rheumatoid disease taking anti-inflammatory drugs have a lower prevalence of $\mathrm{AD}$, a finding that underlines the influence of inflammatory processes in AD pathology (in t' Veld et al., 2001). In addition, a recent study demonstrated that cognitive function was inversely associated with GFAP load in the occipital, parietal and temporal lobes independent of NFT deposition (Kashon et al., 2004).

\subsubsection{Synucleopathies}

$\alpha$-synuclein is a ubiquitous presynaptic protein of unknown function, which plays a role in neurodegenerative diseases, termed synucleopathies. Disruption of axonal transport leads to aggregation of the protein in the cell body and dystrophic neurites (Murphy et al., 2000).

$\alpha$-synuclein is a major component of Lewy bodies and Lewy neurites, the neuropathological hallmarks of Parkinson's disease (PD) (Hamilton, 2000). Interestingly, $60 \%$ of $\mathrm{AD}$ cases show an accumulation of $\alpha$-synuclein in Lewy bodies in the amygdala, cortex and cerebellum (Hamilton, 2000; Kotzbauer et al., 2001). Furthermore, an increasing number of cases with overlapping $\mathrm{AD}$ and $\mathrm{PD}$ pathologies have been identified, coined dementia with Lewy bodies (DLB) (Lippa et al., 2007). DLB patients exhibit more severe symptoms and have a faster rate of cognitive decline than AD patients (Kraybill et al., 2005). 


\subsection{Generation of Abeta}

\subsubsection{The amyloid precursor protein}

$\mathrm{A} \beta$ is derived from a larger precursor protein, the amyloid precursor protein (APP), which is a single-transmembrane glycoprotein located on chromosome 21 (Goldgaber et al., 1987; Kang et al., 1987). APP belongs to a gene family consisting of three members: APP and two amyloid precursor like proteins (APLP). APLP-1 and 2 are also type- 1 transmembrane proteins demonstrating a significant sequence homology to APP in their ectodomains; though, only APP possesses the A $\beta$ sequence (Thinakaran and Koo, 2008).

The APP gene contains 19 exons, of which three can be alternatively spliced resulting in the expression of three APP isoforms: APP695, APP751 and APP770 (Tanzi et al., 1988). The APP isoforms 751 and 770 are widely expressed in non-neuronal cells, but can also occur in neurons. APP695 is predominantly expressed in neurons and is the most abundant form in the human brain. In neurons, APP occurs in the perikaya, nerve terminals, dendrites and synapses in which it undergoes fast anterograde axonal transport (Koo et al., 1990).

The physiological function of APP remains largely undetermined. Roles in neurite outgrowth, synaptogenesis, neuronal protein trafficking, transmembrane signal transduction, cell adhesion and calcium metabolism have been suggested (Zheng et al., 1995). Furthermore, APP 751 and 770 are believed to play a role in the blood coagulation (Smith et al., 1990).

\subsubsection{Processing of APP}

The processing of APP occurs in two distinct pathways: the amyloidogenic and the non-amyloidogenic pathway. The three secretases active in the processing are: alpha-secretase ( $\alpha$-secretase), beta-secretase ( $\beta$-secretase) and gamma-secretase ( $\gamma$-secretase) (Fig. 2$)$.

In the non-amyloidogenic pathways, $\alpha$-secretase cleaves APP twelve amino acids from the transmembrane domain at the N-terminal, liberating a large soluble fragment (sAPP $\alpha$ ) from the membrane. The remaining membrane-bound C-terminal Fragment of 83 amino-acids $(\mathrm{CTF} \alpha)$ is then processed by $\gamma$-secretase to release the short p3 fragment and the APP intracellular domain (AICD). 


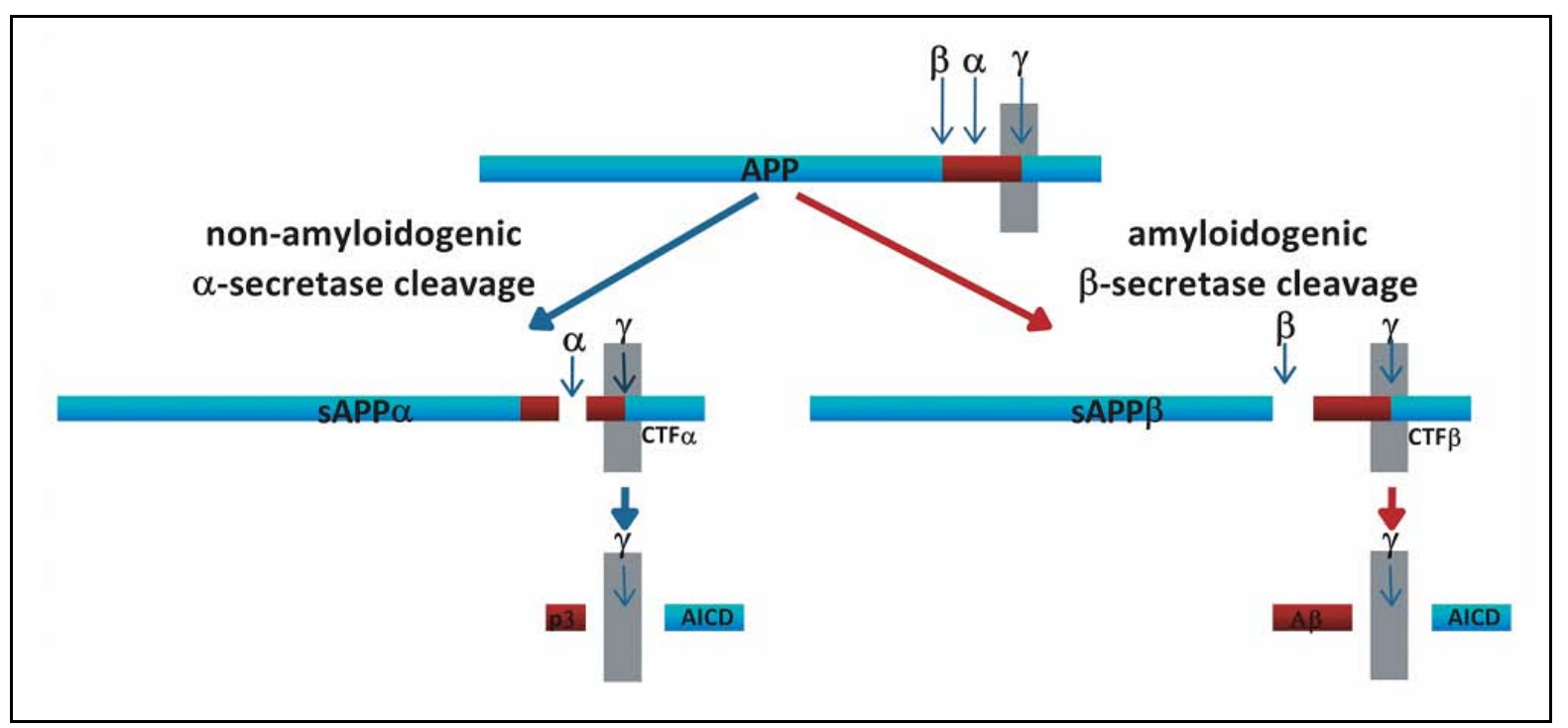

Fig. 2 APP processing: Schematic overview of proteolytic processing of the amyloid precursor protein by $\alpha-, \beta$ and $\gamma$-secretase (Xu, 2009).

The amyloidogenic processing starts with $\beta$-secretase cleavage 16 amino acids upstream from the $\alpha$-secretase cleavage site, generating a soluble amino terminal APP derivative (sAPP $\beta$ ) and a membrane inserted C-terminal fragment that is 99 amino acids long $(\mathrm{CTF} \beta)$. The CTF $\beta$ fragment is further cleaved in a sequential manner by $\gamma$-secretase, yielding A $\beta$ peptides of varying lengths from 38 - 43 amino acids and an additional ACID fragment (Xu, 2009).

Intensive research on the nature of the involved secretases led to the identification of several putative enzymes; however, the underlying cleavage processes are not yet fully understood.

$\alpha$-secretase is a single zinc dependent transmembrane type- 1 protein. Studies suggest that $\alpha$-cleavage is mediated by members of the ADAM (a disintegrin and metalloproteinase) family such as ADAM 9, ADAM 10 and ADAM 17 (Allinson et al., 2003).

The beta site APP-cleaving enzyme (BACE) for $\beta$-secretase cleavage was identified by several research groups (Sinha et al., 1999; Vassar et al., 1999). BACE1 is a type 1 membrane protease with a single transmembrane domain near its C-terminus. It cleaves $A \beta$ at known positions, the aspartate at position 1 or the glutamate at position 11 (Vassar et al., 1999).

$\gamma$-secretase is an enzyme complex consisting of at least four subunits: presenilin (PS, PS1 or PS2), presenilin enhancer-2 (PEN-2), nicastrin and anterior pharynx-defective-1 (APH-1) (Fig. 3). The presenilin subunit bears the $\gamma$-secretase active site catalyzing the intramembrane sequential processing of APP. It is known that $\gamma$-secretase also cleaves other substrates such as notch, cadherin, tyrosine, ErbB4 and CD44 (Wolfe, 2009). 


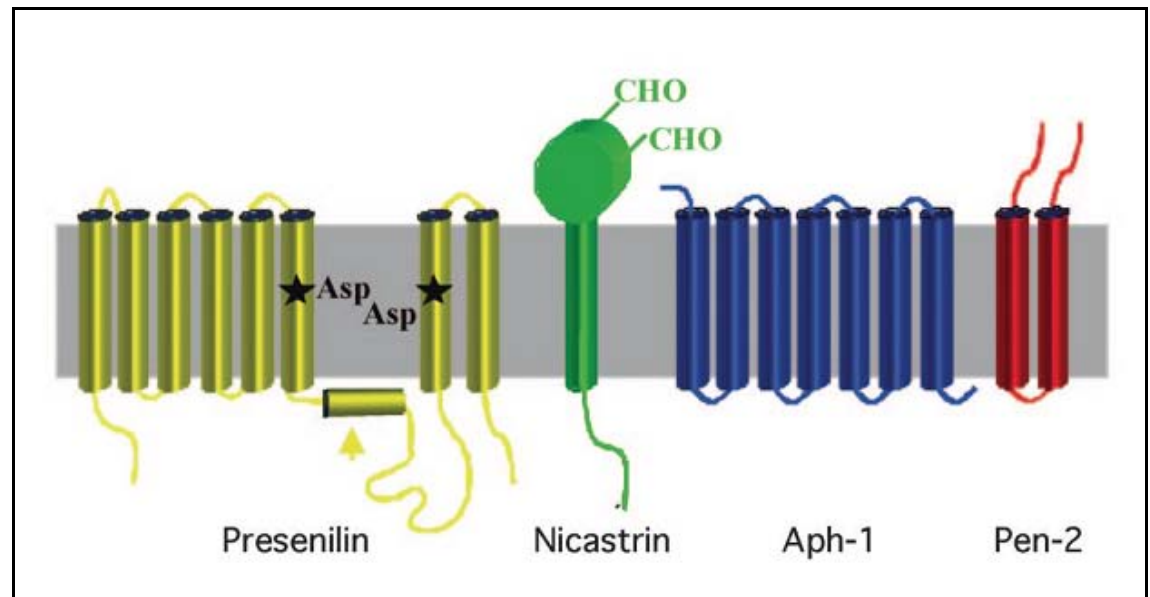

Fig. $3 \gamma$-secretase complex: Schematic drawing of the predicted transmembrane helices of the four component proteins of the $\gamma$-secretase (Lazarov et al., 2006).

\subsubsection{Abeta modification and aggregation}

Analysis of $A \beta$ deposits in human brains revealed the abundance of heterogeneous $A \beta$ peptides, harboring N- and C-terminal modifications (Harigaya et al., 2000; Portelius et al., 2010). C-terminal heterogeneity is caused by $\gamma$-secretase, which cleaves APP at different positions yielding peptides such as $A \beta 42, A \beta 40, A \beta 38$ and $A \beta 37$.

Studies with C-terminal specific antibodies have shown that the parenchymal deposits mostly consist of $A \beta 42$ in contrast to the vascular amyloid which is predominantly composed of Aß40 (Gravina et al., 1995; Herzig et al., 2004). Increased C-terminal length seems to influence toxicity of the peptide. A $\beta 1-42$ exhibits a rapidly increased aggregation in comparison to the shorter peptide of $A \beta 1-40$ and is therefore believed to promote peptide depositions and neurotoxicity in the brain (Jarrett et al., 1993; Suzuki et al., 1994).

Moreover, $\mathrm{A} \beta$ peptides are known which possess N-terminal truncations and modifications generated by aminopeptidases, glutaminyl cyclase and isomerases. Peptides with N-terminal deletions exhibit enhanced levels of aggregation in comparison with fulllength $A \beta$ peptides (Pike et al., 1995). This holds true especially for pyroglutamate-modified $\mathrm{A} \beta(\mathrm{A} \beta \mathrm{pE} 3-\mathrm{x})$, a highly abundant peptide in $\mathrm{A} \beta$ plaques, which promotes an increased aggregation propensity, stability and cellular toxicity (Jawhar et al., 2011a).

$\mathrm{A} \beta$ is a self-aggregating peptide that is able to form dimers and trimers and larger oligomers of more than $100 \mathrm{kDa}$. It is hypothesized that monomeric $\mathrm{A} \beta$ exists in a complex equilibrium with oligomers and other $\mathrm{A} \beta$ conformations. When the equilibrium is disturbed by reaching a certain threshold amount of monomers, a nucleation-dependent polymerization 
process is initiated. Monomeric A $\beta$ then self-associates into oligomers which are polymerized into larger protofibrils and ultimately to $A \beta$-fibers, the major constituents of plaques (Fig. 4). Protofibrils are metastable intermediate structures that can form fibrils or dissociate again into monomers (Walsh and Selkoe, 2007; Roychaudhuri et al., 2009). Oligomers are described as soluble peptides as they are soluble in aqueous buffer and remain in solution following high speed centrifugation, while $A \beta$ fibers are insoluble (Walsh et al., 1997).

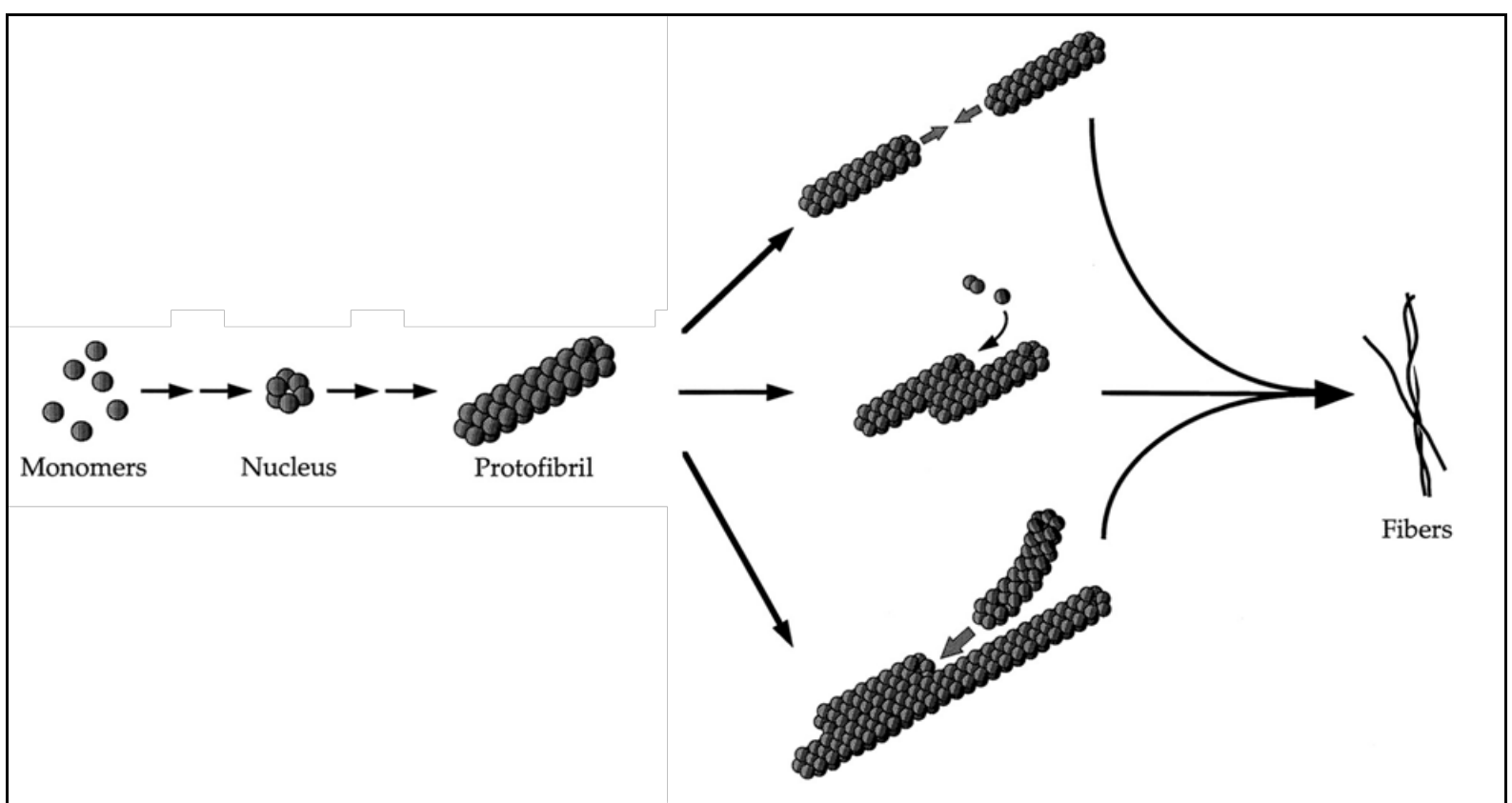

Fig. 4 A $\beta$ aggregation: $A \beta$ is a natively disordered protein, existing in the monomeric state as an equilibrium mixture of many conformers. Self-association leads to the formation of oligomeric nuclei, which are prolonged into a protofibrils. Maturation of protofibrils yields the classical amyloid-fibrils found in plaques. Adpated from (Walsh et al., 1997).

\subsection{Amyloid hypothesis}

The amyloid hypothesis considers accumulation of $\mathrm{A} \beta$ in the brain as the causative event driving $\mathrm{AD}$ pathogenesis. The rest of the disease pathology, including NTFs, and neuron loss is believed to occur as downstream events (Hardy and Allsop, 1991). Several observations have supported the hypothesis since its development 20 years ago. One major argument for the hypothesis arose from studies showing that mutations in APP and PS1 lead to enhanced levels of $\mathrm{A} \beta 42$ peptides resulting in an early-onset forms of $\mathrm{AD}$ (Bertram et al., 2010). The triplication of chromosome 21, the location of the APP gene, leads to the development of AD pathology at a young age in Down Syndrome (DS) patients (Heston and Mastri, 1977). Moreover, transgenic mouse models overexpressing mutant APP variants exhibit an age-dependent AD pathology (Morrissette et al., 2009). In addition, it was shown 
that the apolipoprotein E ع4-polymorphism (ApoE4), which represents the most important genetic risk factor for the sporadic forms of $\mathrm{AD}$, is associated with increased $\mathrm{A} \beta$ accumulation and reduced clearance (Strittmatter et al., 1993) .

However, an argument challenging this hypothesis is the fact that only a weak correlation between the appearance of plaques and the cognitive status of the patient could be observed and also non-demented patients can exhibit a high abundance of amyloid plaques (Snowdon, 1997; Wirths et al., 2010a). Moreover, it has been demonstrated that soluble oligomeric $\mathrm{A} \beta 42$, and not amyloid plaques, correlates better with cognitive dysfunction in $\mathrm{AD}$ (McLean et al., 1999).

This discrepancies lead to modification of the amyloid hypothesis, taking into account emerging evidence for the importance of intraneuronal $A \beta$ in the disease development. The occurrence of intraneuronal $\mathrm{A} \beta$ in $\mathrm{AD}$ has been known for long time. Already in 1985, using immunohistochemical analyses Masters et al hypothesized that amyloid is first deposited in the neuron and later in the extracellular space (Masters et al., 1985). Interestingly, it was shown that intraneuronal $A \beta x-42$ accumulates in $A D$ vulnerable regions and seems to precede deposition of extracellular plaque and NFTs (Gouras et al., 2000). This finding was supported by a study in DS patients, which showed intraneuronal A $\beta$ immunostaining many years before the development of senile plaques (Gyure et al., 2001). Several studies demonstrated a correlation between intraneuronal $\mathrm{A} \beta$, neuron loss and cognitive impairment (Bayer and Wirths, 2010).

Taken together, it is now hypothesized that aggregation of soluble $A \beta$ inside the neuron is triggering the disease cascade leading to subsequent events such as neuron loss and brain atrophy (Wirths et al., 2004) (Fig. 5). 


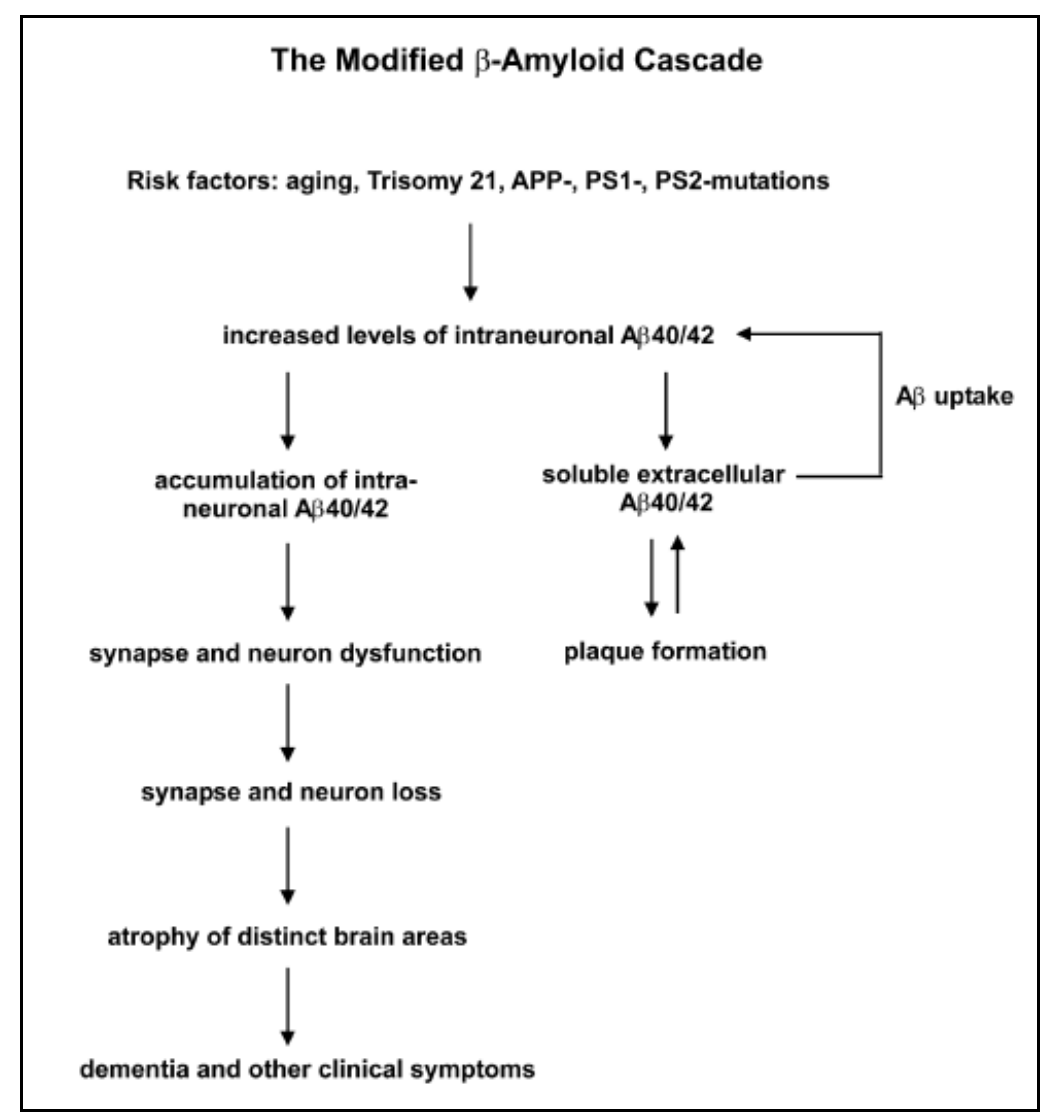

Fig. 5 Schematic representation of the intraneuronal $\mathbf{A} \boldsymbol{\beta}$ hypothesis: The increase in intraneuronal $A \beta$ leads to aggregation of the protein, triggering the disease cascade. In parallel, increased secretion and deposition of A $\beta 42$ leads to extracellular plaque formation (Wirths et al., 2004).

\subsection{Risk factors and genetics}

$\mathrm{AD}$ can be subdivided into the sporadic type and the familial type. Most cases of AD are sporadic with a late onset, affecting people above the age of 65 years. The major risk factor for developing $\mathrm{AD}$ remains aging. After 65 years of age, the prevalence of $\mathrm{AD}$ doubles approximately every 5 years (Ferri et al., 2005). Furthermore, epidemiological studies found low educational attainment and low mental ability in early life to be associated with an increased risk of $\mathrm{AD}$ (Mortimer et al., 2003). Moreover, severe head trauma and traumatic brain injury is also correlated to AD development (Van Den Heuvel et al., 2007). Other risk factors are vascular diseases including high cholesterol, high blood pressure, smoking and obesity (Mayeux, 2003).

Furthermore, ApoE4 has been reported to be associated with sporadic AD. The presence of the ApoE4 allele is suggest to increase the risk of the disease by more than 4 times and decrease the age of onset (Corder et al., 1993). Recent genome wide association studies also found links for sporadic AD with clustrin (CLU) and complement receptor 1 
(CR1) genes involved in $A \beta$ clearance, and phosphatidylinositol-binding-clathrin-assemblyprotein (PICALM) affecting intracellular trafficking (Lambert et al., 2009; Kok et al., 2011).

The familial AD (FAD) cases only account for $5 \%$ of the cases, with an early-onset before the age of 65 years. Familial forms are caused by mutations in single genes that are inherited in an autosomal-dominant fashion. So far, studies revealed mutations in three genes: APP, PS1 and PS2.

Mutations in the APP gene were the first ones to be detected and currently there are 32 missense mutations identified (Goate et al., 1991; Cruts and Van Broeckhoven, 1998). The majority of APP mutations cluster primarily around the secretase processing sites influencing the APP processing (Fig. 6). Mutations near the $\beta$-secretase site, such as the Swedish mutation, enhance $\beta$-secretase cleavage and increase the overall $\mathrm{A} \beta$ levels (Citron et al., 1992; Mullan et al., 1992). The London and Florida mutations near the $\gamma$-secretase site specifically increase $A \beta 42$ over $A \beta 40$ ratio without affecting overall $A \beta$ levels (Goate et al., 1991; Eckman et al., 1997). In contrast, mutations within the $A \beta$ sequence have been shown to alter the aggregation pattern or fibril formation or increase cerebral amyloid angiopathy, as seen in the Dutch and Arctic mutations (Van Broeckhoven et al., 1990; Basun et al., 2008).

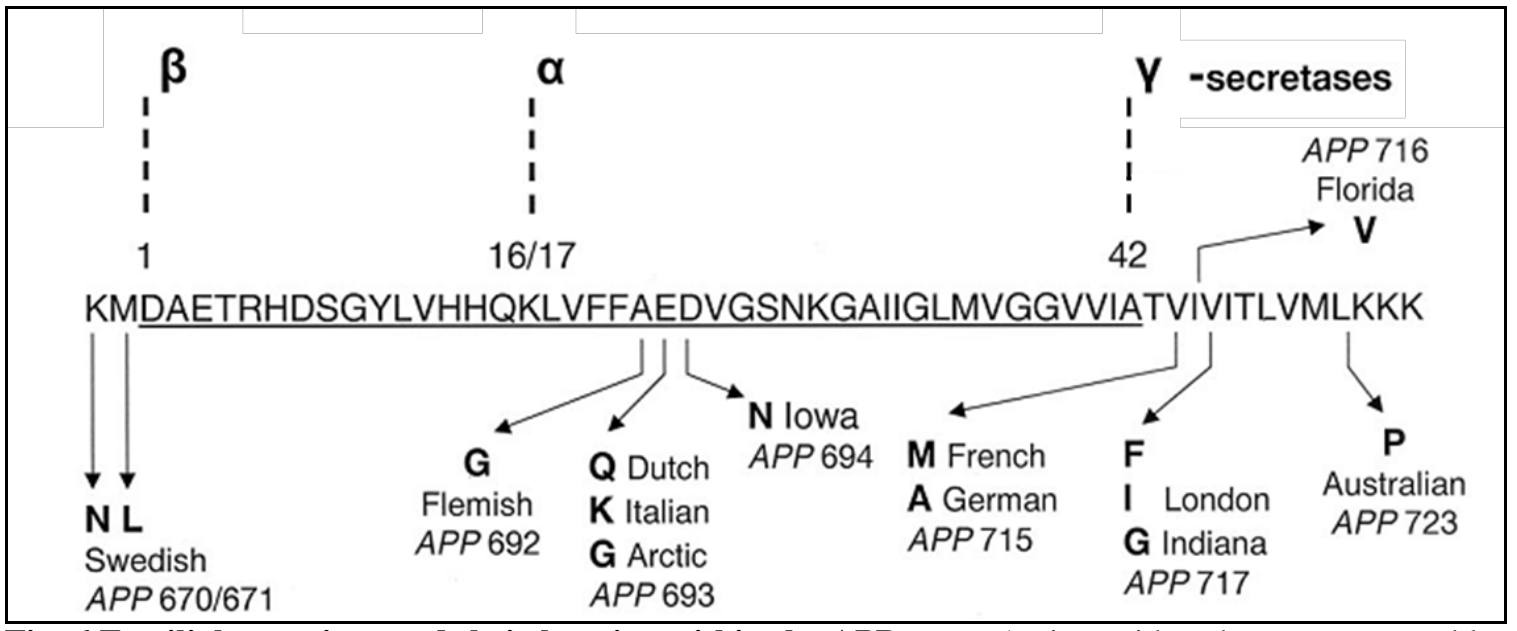

Fig. 6 Familial mutations and their location within the APP gene: Amino acid exchange, name and location of the mutation are given. $A \beta$ sequence is underlined. Adapted from (Janssen et al., 2003).

Mutations in the PS1 gene, on chromosome 14, are responsible for the most aggressive forms of $\mathrm{AD}$ and account for $18-50 \%$ of all early-onset $\mathrm{AD}$ cases (Sherrington et al., 1995). So far, 185 mutations have been identified. Moreover, changes in the PS2 gene, on chromosome 1 were found; however, only 13 mutations were described until now (Cruts and Van Broeckhoven, 1998). 
PS1 and PS2 mutations are believed to alter the biochemical character of the $\gamma$ secretase complex and its interaction with APP, thereby promoting the generation of more $A \beta 42$ peptides, altering the $A \beta 42$ to $A \beta 40$ ratio (De Strooper et al., 2012).

\subsection{Mouse models of Alzheimer's disease}

Despite the availability of invertebrate organisms, like Drosophila melanogaster and Caenorhabditis elegans for $\mathrm{AD}$ research, vertebrate models have given the most insight in $\mathrm{AD}$ research, as they are evolutionary closer to humans. Advanced genetic modifications made mice the most commonly used vertebrates for transgenic modeling. Transgenic mouse models generally are designed based on gene mutations found in FAD. Various attempts have been made to generate models that harbor typical human $\mathrm{AD}$ features such as $\mathrm{A} \beta$ aggregation and deposition, NFTs formation, neuron loss and synaptic deficits.

In general, APP transgenic mice show increased production of $A \beta$ and plaque deposition and only limited neuron loss. The Tg2576 model expressing the Swedish APP mutation is one of the most extensively studied mouse models. It shows a 5-fold increase in $\mathrm{A} \beta 40$ and a 14-fold increase in A $\beta 42$. Plaque deposition starts around 9-12 months of age and is accompanied by impairments in spatial and working memory (Hsiao et al., 1996).

The use of PS1 mutations for single transgenic mouse lines resulted in increased levels of $A \beta 42$ in the mice but no plaque formation or behavioral deficits were found (Duff et al., 1996; Guo et al., 1999). However, crossing PS1 models to APP transgenic models resulted in an accelerated AD pathology progression in the mice (Holcomb et al., 1998).

Current mouse models are able to represent various features of $\mathrm{AD}$ pathology; however there are still some drawbacks. Transgenic APP and PS1 models fail to generate NFTs. Only introduction of tau mutations from frontal temporal dementias facilitates NFTslike pathology (Oddo et al., 2003). Furthermore, only a minority of the models display neuron loss (Wirths and Bayer, 2010).

\subsubsection{The 5XFAD mouse model}

The 5XFAD mouse model is double transgenic APP/PS1 model harboring 5 FAD mutations, three in the APP gene and two in the PS1 gene. It was generated by introducing APP K670N/M671L (Swedish), I716V (Florida), V717I (London) and PS1 M146L, L286V mutations into APP695 and PS1 cDNAs via site directed mutagenesis and subcloning of the 
genes into the Thy- 1 transgene cassette. The mice showed stable transmission and expression of both transgenes for more than 10 generations, demonstrating that the 5XFAD mice breed as single transgenic model (Oakley et al., 2006).

The 5XFAD mouse model was originally described by the group of Robert Vassar. Later on, these findings were extended in a more detailed analysis by our laboratory with mice backcrossed to C57BL/6J genetic background; a more commonly used genetic background in $\mathrm{AD}$ research. As the current thesis is based on experiments performed with mice on C57BL/6J genetic background, the following description will focus mainly on the findings of our group.

Due to the mutations used in the 5XFAD model, the mice show a dramatic increase in $\mathrm{A} \beta 42$ in comparison to $A \beta 40$. This results in an early pathology onset with plaque deposition seen as early as 2-3 months and increasing in an age-dependent manner over time (Oakley et al., 2006; Jawhar et al., 2012).

Furthermore, the mice display neuroinflammatory features, as the number of reactive astrocytes and microglia increases proportionally to amyloid burden in the brain (Oakley et al., 2006; Kalinin et al., 2009).

The 5XFAD model exhibits two cardinal features of AD: accumulation of intraneuronal $A \beta$ and neuron loss. A strong intraneuronal $A \beta$ signal was found in the fifth cortical layer at the age of 3 months, decreasing with age and being almost absent at 12 months of age. Interestingly, the amount of cortical neurons in layer 5 was significantly decreased in the 5XFAD mice at the age of 12 months, demonstrating a possible link between the two properties (Jawhar et al., 2012).

This extensive pathology also leads to changes on the behavioral level. 5XFAD mice show impairment in spatial working memory at the age of 6 months and display a reduced anxiety starting around the same time. Motor performance started to deteriorate at the age of 9 months; however no effect on general locomotor activity was observed (Jawhar et al., 2012).

Taken together, the 5XFAD mouse model displays a variety of AD hallmarks similar to the human situation in a short amount of time. This made it a valuable tool for therapeutic approaches (Kalinin et al., 2009; Wirths et al., 2010c; Jawhar et al., 2011b). 


\subsection{Non-steroidal-anti-inflammatory drugs}

\subsubsection{Targets of NSAIDs}

Non-steroidal-anti-inflammatory drugs (NSAIDs) have analgesic, antipyretic and, in higher doses, anti-inflammatory features. The major targets of NSAIDs are the cyclooxygenases (COX) 1 and 2 that catalyze the formation of inflammatory prostaglandins from arachidonic acid (Fig. 7). COX 1 is a constitutively expressed enzyme, responsible for maintenance of the gastric mucosa, while COX 2 expression is inducible and upregulated at sites of inflammation (Vane and Botting, 1998). Just recently, COX-3 was identified as a splice variant of COX-1 (Chandrasekharan et al., 2002), though its role in the production of inflammatory mediators needs further elucidation.

There are two classes of NSAIDs: non-selective and selective inhibitors. Non-selective inhibitors, inhibit COX-1 and COX-2 isoenzymes. Aspirin, ibuprofen, naproxen, indomethacin and sulindac are examples of this group. Furthermore, selective NSAIDs have been developed, only inhibiting COX-2, such as celecoxib and rofecoxib.

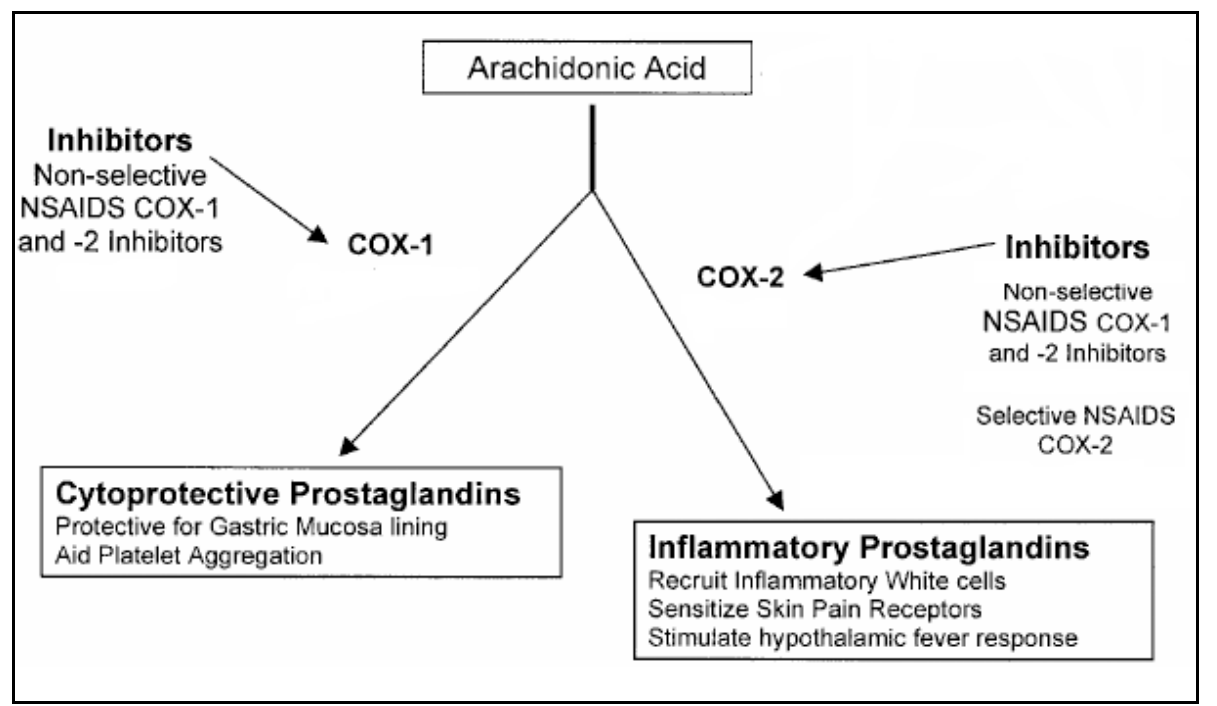

Fig. 7 Schematic overview of COX inhibition: COX-1 is involved in normal physiological functions including maintenance of the gastric mucosa. COX-2 is induced by inflammation. Non-selective NSAIDs can inhibit both enzymes, while selective NSAIDs only target COX-2. Adapted from (Maroon et al., 2006).

However, it has also been suggested that NSAIDs directly influence APP processing and $A \beta$ production, as it has been demonstrated that a subset of NSAIDs could selectively alter the generation of $A \beta$ peptides. In cell based assays, treatment with ibuprofen, sulindac sulfide, or indomethacin led to a $70 \%-80 \%$ reduction of $A \beta 42$ peptides with a parallel 
increase of the less toxic $A \beta 38$ peptides, while $A \beta 40$ levels remained unchanged. This effect was independent of inhibition of the COX enzymes (Weggen et al., 2001).

The exact mechanism of this shift in $A \beta$ production is not fully understood. Analysis suggested that the change in $A \beta$ production is due to a direct interaction of NSAIDs with the $\gamma$-secretase complex. Small molecules with this activity have now been termed $\gamma$-secretase modulators (GSMs) (Weggen et al., 2003; Richter et al., 2010).

\subsubsection{Epidemiology}

In 1990, McGeer and colleagues observed that patients with rheumatoid arthritis receiving a NSAID therapy had a lower prevalence of $\mathrm{AD}$. This led to the hypothesis that NSAID intake is associated with a reduced risk of AD (McGeer et al., 1990). Since then several epidemiological studies have supported this idea, showing that the use of NSAIDs delayed the onset, slowed the cognitive decline, and decreased the incidence of AD by $25 \%-$ 80\% (Szekely and Zandi, 2010). In addition, several studies demonstrated that the relative risk for AD decreased with increasing duration of NSAID use (Stewart et al., 1997; in t' Veld et al., 2001; Zandi et al., 2002). Neuropathological analysis of postmortem brain tissue revealed that NSAID intake caused a reduction of activated microglia but did not change the overall number of extracellular plaques. This might indicate that, in humans, NSAIDs mainly acted by suppressing irflammation rather than by inhibiting plaque or tangle formation (Mackenzie and Munoz, 1998).

\subsubsection{Pharmacological trials}

The combined anti-inflammatory and $\gamma$-secretase modulating activities of some NSAIDs appeared to be a promising approach for treatment of AD. However, the results of pharmacological studies in both mice and humans have been inconsistent (Imbimbo, 2009).

Long-term treatment studies with ibuprofen have revealed beneficial effects in several mouse models of AD (McGeer and McGeer, 2007; Imbimbo, 2009). Use of ibuprofen in the Tg2576 mouse model led to a decrease in insoluble $A \beta$ deposits, activated microglia and inflammatory markers, resulting in improved behavior that is comparable to wild-types (Lim et al., 2000, 2001). Similar results were reported from double or triple transgenic mouse models, showing a significant reduction in $A \beta$ load after the use of ibuprofen and an improvement in spatial working memory (Jantzen et al., 2002; McKee et al., 2008). Furthermore, other studies utilizing a non-selective inhibitor like indomethacin or selective COX-2 inhibitors such as 
Celecoxib or an derivat of flurbiprofen also demonstrated positive treatment effects (Jantzen et al., 2002; Sung et al., 2004; Melnikova et al., 2006).

However, clinical trials using NSAIDs revealed controversial outcomes. Smaller initial pilot studies using indomethacin seemed to show beneficial effects. Unfortunately, a high dropout rate and the small number of subjects made the results less reliable (Rogers et al., 1993; de Jong et al., 2008). Larger studies with several NSAIDs produced completely negative results. Long-term treatment with COX-2 selective NSAID celecoxib, rofecoxib and naproxen, a non-selective NSAID, showed no benefit or even detrimental effects. The supposed positive effect of high-dose Tarenfluribil seen in mildly affected $\mathrm{AD}$ patients lead to the largest-ever study in patients with AD; yet the study came out negative (Aisen et al., 2003; Soininen et al., 2007).

The reasons for the discrepancy between mouse and human trials are still under debate. The failure could be explained by issues such as timing and duration of treatment, dose and class of the chosen drugs. Also, the role of inflammation in the brain should be taken into account, as it might harbor protective features, which have so far been neglected. 


\subsection{Introduction to experiments}

\subsubsection{Project I: Chronic ibuprofen treatment in the 5XFAD mouse model}

Several NSAIDs demonstrate anti-inflammatory and $\gamma$-secretase modulating activities, making them valuable candidates for $\mathrm{AD}$ treatment. However, the results of pharmacological studies in both mice and humans have been inconsistent. Preventative effects could be seen in mice, while in humans there was no beneficial outcome.

It is not yet clear whether the beneficial effects of NSAIDs are due to theirs influences on $\gamma$-secretase modulation and subsequent reduction of $A \beta$ load or if the anti-inflammatory properties of the drugs lead to an enhancement of the overall cognitive status of the mice. This needs to be further elucidated.

Recently, it has been shown that many PS1 mutations associated with FAD impede the A 342 -reducing effects of NSAIDs and other GSMs both in vitro and in vivo (Weggen et al., 2003; Czirr et al., 2007; Page et al., 2008). Consequently, AD mouse models incorporating such PS1 mutations present an opportunity to study the effects of NSAIDs onflammatory processes and cognitive function independent of their anti-amyloidogenic properties.

Interestingly, the PS1 double mutation M146L and L286V, used in the 5XFAD mouse model, has been shown to render cultured cells completely resistant to the A $\beta 42$-reducing activity of the potent GSM BB25 (Hahn et al., 2011). This makes the 5XFAD mouse model a valuable tool in studying the exclusive effects of ibuprofen on inflammation.

In the present study, we evaluated the long-term treatment effects of ibuprofen in the 5XFAD mice. Treatment started at the age of 3 months and lasted until 6 months of age. Progression of amyloid pathology, flammation and cognitive changes in the mice were assessed.

Aims of the project:

- Analyze the inflammation status of the 5XFAD model at 3 and 6 months of age.

- Assess the influence of ibuprofen treatment on amyloid levels and depositions in the brain.

- Elucidate the effects of ibuprofen treatment on inflammatory markers in terms of RNA and protein levels.

- Unravel whether ibuprofen treatment can rescue behavior deficits seen in the 5XFAD mice. 


\subsubsection{Project II: Analysis of oligomeric pyroglutamate Abeta in CAA}

Immunotherapy has gained considerable attention in the last years as it was shown that active and passive $A \beta$ immunization lower cerebral $A \beta$ levels and improve cognition in animal models of AD. In 1999, Schenk et al. first reported that active immunization using full-length $A \beta 1-42$ prevented the development of plaque formation in young mice and reduced the extent and progression of plaques in aged PDAPP mice (Schenk et al., 1999). Similar beneficial effects were seen with passive immunization (Janus et al., 2000).

A clinical trial using active immunization with A $\beta 1-42$ (AN1792) resulted in cognitive benefit and amyloid clearance in some cases but also demonstrated a strong autoimmune reaction in a subset of patients (Orgogozo et al., 2003; Gilman et al., 2005)

Neuropathological analysis of an $\mathrm{AD}$ patient brain revealed extensive areas of the neocortex with only very few plaques, although tangles, neuropil threads and CAA were apparently unchanged. However, T-lymphocyte meningoencephalitis and cerebral white matter infiltration by macrophages was also observed. This side-effect was also seen in other patients who received the same antibody (Nicoll et al., 2003). Due to these side effects the phase II clinical trial of the $A \beta$ vaccine was stopped when approximately $6 \%$ of the immunized patients developed meningoencephalitis.

In addition, passive immunization decreased plaque burden in a transgenic mouse model, but resulted in an increase in the occurrence of microhemorrhages in areas with CAA (Pfeifer et al., 2002). Since then, microhemorrhages within the brain vasculature have been a matter of concern and are believed to be caused by anti-A $\beta$ antibody binding to CAA (Racke et al., 2005).

Our group has recently developed a conformational specific pyroglutamate $A \beta$ antibody 9D5, which only recognizes low molecular weight pyroglutamate $\mathrm{A} \beta$ oligomers (410mers) and not monomers, dimers or higher molecular fibrillar forms of pyroglutamate $\mathrm{A} \beta$. Passive immunization for 10 weeks (one treatment per week) stabilized the behavioral deficit of the transgenic $\mathrm{AD}$ mouse model and $\mathrm{AD}$-associated neuropathology. This is of special interest, as the antibody detects only a small subpopulation of the $A \beta$ variants present in the 5XFAD mouse brain (Wirths et al., 2010c). Therefore, the 9D5 antibody might be a safe, promising tool for therapeutic intervention.

In the current work, the CAA staining pattern of the 9D5 antibody was assessed and the question was addressed whether the 9D5 antibody recognizes the same amount of CAA as 
other $A \beta$ antibodies. In addition, a possible correlation between CAA staining and gender, age, Braak stage and ApoE genotype was studied.

Aims of the project:

- Analysis of the correlation of CAA staining with gender, age, Braak stage and ApoE genotype.

- Qualitative and quantitative assessment of the 9D5 CAA staining pattern in comparison with other $A \beta$ antibodies.

\subsubsection{Project III: Study of synuclein and $A \beta$ interaction in the cortex of 5XFAD mice}

In addition to plaques, $60 \%$ of $\mathrm{AD}$ cases show an accumulation of Lewy bodies in the amygdala, cortex and cerebellum (Kotzbauer et al., 2001). Lewy bodies and Lewy neurites have been shown to consist mostly of aggregated $\alpha$-synuclein and are the major pathological hallmarks of PD. An increasing number of reports demonstrated the occurrence of an overlapping pathology of $\mathrm{AD}$ and $\mathrm{PD}$, the so called dementia with Lewy bodies (Lippa et al., 2007). DLB patients have been shown to exhibit a faster rate of cognitive decline than AD patients (Kraybill et al., 2005).

It is believed that $A \beta$ and synuclein have synergistic effects on each other, promoting aggregation and pathology. Over expression of $\alpha$-synuclein in $\mathrm{AD}$ mouse models resulted in an increased neurodegeneration and congnitive decline. In one study, mice exhibiting accumulation of intraneuronal $\mathrm{A} \beta$ were crossed to $\alpha$-synuclein over-expressing mice. Double transgenic animals demonstrated an enhanced accumulation of intraneuronal synuclein and an accelerated development of motor deficits in comparison to synuclein single transgenic mice (Masliah et al., 2001). Furthermore, Clinton et al. demonstrated that over expression of mutant $\alpha$-synuclein in the $3 \times \mathrm{Tg}$ mouse model resulted in a change of $\mathrm{A} \beta$ solubility and accumulation with an dramatic increase in A $\beta 42$ (Clinton et al., 2010).

In vitro NMR studies showed that both $\mathrm{A} \beta 40$ and $\mathrm{A} \beta 42$ can interact with $\alpha$-synuclein (Mandal et al., 2006). Furthermore, studies in vitro cell-free conditions demonstrated that A $\beta$ directly interacts with $\alpha$-synuclein forming hybrid pore-like oligomers which can alter neuronal activity (Tsigelny et al., 2008). 
Based on these findings, the study of the coexistence of Lewy bodies, $A \beta$ plaques and intraneuronal deposition in $\mathrm{AD}$ seems to be an interesting approach to gain more insight about the disease processes.

The first objective of this pilot study was to establish the stereotactic surgery procedure in the lab. After achieving this, adeno-associated-viruses (AAV) serotype 1/2 carrying wild-type $\alpha$-synuclein, mutant $\alpha$-synuclein and $\beta$-synuclein constructs were injected into a small cohort of 5XFAD mice. Injections were performed into the frontal-cortex aiming for the fifth cortical layer. Mice were injected at the age of 3 months, when a high abundance of neuronal $A \beta$ accumulation can be seen in the designated cortical layer and sacrificed at the age of 7 months.

The question raised by this project is whether an additional intraneuronal expression of synuclein variants might lead to the development of Lewy bodies in the neurons harboring intraneuronal $A \beta$ and if the synuclein overexpression influences the $A \beta$ pathology in the mice.

Aims of the pilot study:

- Establishment of stereotactic surgery protocol for injection of AVV into mouse brains.

- Analysis of expression pattern of different synuclein constructs.

- Assessment of AD pathology and synuclein pathology in the injected region. 


\section{Materials and Methods}

\subsection{Transgenic mice}

The generation of 5XFAD mice has been described previously (Oakley et al., 2006). In brief, 5XFAD mice express the 695 amino acid isoform of the human APP (APP695) carrying the Swedish/London/Florida mutations under the control of the murine Thy1promoter. In addition, human PS1 carrying the M146L/L286V mutations is expressed under the control of the murine Thy1-promoter. 5XFAD mice used in the current thesis were backcrossed for more than 5 generations to C57BL/6J wild type mice to obtain an incipient congenic line on a C57BL/6J genetic background (Jawhar et al, 2010). All animals were handled according to German guidelines for animal care.

Only female 5XFAD mice were used for chronic ibuprofen treatment. Mice were fed either a standard chow or standard chow containing ibuprofen (50mg/kg bw/day). Treatment of the mice started at 3 months of age and lasted for 3 months.

For stereotactic surgery and injection of AVV, male 5XFAD and WT mice were used. Injections were applied at 3-4 months of age and mice were sacrifced 3.5 months after being injected. All animal experiments were performed according to the German guidelines for animal care and approved by the local legal authorities.

\subsection{Human AD brain tissue}

Human brain samples of the gyrus temporalis superior were obtained from the Netherlands Brain Bank (NBB), Amsterdam, Netherlands. Tissue was post-fixed in 4\% buffered formalin at $4^{\circ} \mathrm{C}$ for several weeks and then embedded into paraffin. 


\subsection{Antibodies}

Table 1 Details for primary antibodies used in this thesis:

\begin{tabular}{|c|c|c|c|c|}
\hline $\begin{array}{l}\text { Primary } \\
\text { antibody }\end{array}$ & Target & Dilution & $\begin{array}{l}\text { Secondary } \\
\text { Antibody }\end{array}$ & Manufacturer \\
\hline 4G8 & $A \beta 17-24$ & $1: 10.000$ & Mouse & Covance, USA \\
\hline IC16 & generic $A \beta$ & 1:000 & Mouse & Gift of S. Weggen \\
\hline NT244 & generic $A \beta$ & $1: 1000$ & Mouse & $\begin{array}{c}\text { Synaptic Systems, } \\
\text { Germany }\end{array}$ \\
\hline Abeta[N] & $A \beta 1-x$ & $1: 500$ & Rabbit & IBL, Germany \\
\hline mab2-48 & $\mathrm{A} \beta \mathrm{pE} 3-\mathrm{x}$ & $1: 1000$ & Mouse & $\begin{array}{c}\text { Synaptic Systems, } \\
\text { Germany }\end{array}$ \\
\hline G2-10 & $\mathrm{A} \beta 40$ & $1: 1000$ & Mouse & Millipore, Germany \\
\hline G2-11 & $\mathrm{A} \beta 42$ & $1: 1000$ & Mouse & Millipore, Germany \\
\hline 23850 & APP & $1: 500$ & Rabbit & Gift of G. Multhaup \\
\hline OC & $\begin{array}{c}\text { Fibrillar A } \beta \\
\text { oligomers }\end{array}$ & $1: 1000$ & Rabbit & Gift of C. Glabe \\
\hline Iba1 & Activated microglia & $1: 1000$ & Rabbit & $\begin{array}{c}\text { Synaptic Systems, } \\
\text { Germany }\end{array}$ \\
\hline GFAP & GFAP & $1: 2000$ & Mouse & $\begin{array}{c}\text { Synaptic Systems, } \\
\text { Germany }\end{array}$ \\
\hline LB509 & human $\alpha$-synuclein & $1: 1000$ & Mouse & Invitrogen, Germany \\
\hline $\begin{array}{c}\alpha / \beta \text {-synuclein } \\
\text { (3B6) }\end{array}$ & $\begin{array}{c}\text { human } \\
\alpha \text { - and } \beta \text {-synuclein }\end{array}$ & $1: 1000$ & Mouse & Santa Cruz, USA \\
\hline
\end{tabular}

Table 2 Details for secondary antibodies used in this thesis:

\begin{tabular}{|c|c|}
\hline Antibody & Manufacturer \\
\hline Rabbit anti-mouse immunoglobulins, biotinylated & DAKO, Denmark \\
\hline Swine anti-rabbit immunoglobulins, biotinylated & DAKO, Denmark \\
\hline Alexa Fluor 488 donkey anti-mouse immunoglobulins & Invitrogen, Germany \\
\hline Alexa Fluor 568 donkey anti-rabbit immunoglobulins & Invitrogen, Germany \\
\hline Goat Anti-Rabbit immunoglobulins, Dylight ${ }^{\circledR} 488$ conjugated & Thermo scientific, USA \\
\hline Goat Anti-Mouse immunoglobulins, Dylight ${ }^{\circledR} 594$ conjugated & Thermo scientific, USA \\
\hline
\end{tabular}




\subsection{Tissue collection and preservation}

Mice were briefly anaesthetized by exposure to $\mathrm{CO}_{2}$ in a box with dry-ice and then killed by spinal dislocation. Brain and spinal cord tissue was removed and brains were divided at the midline. One half of the brain was snap frozen on dry ice and stored at $-80^{\circ} \mathrm{C}$ until further analysis. The other brain half was post fixed in $4 \% \operatorname{Roti}^{\circledR}$-Histofix solution (Roth, Germany) at $4^{\circ} \mathrm{C}$.

For analysis of AAV injections, perfused tissue was used. Mice were anesthetized by $10 \mathrm{~mL} / \mathrm{kg}$ intraperitonal injection of $1 \%$ ketamine (Medistar, Germany) and $0.1 \%$ zylazine (Riemser, Germany) in aqua ad injectabilia. Transcardial perfusion was performed through the left ventricle of the heart with $30 \mathrm{~mL}$ ice-cold phosphate buffered saline (PBS) followed by $30 \mathrm{~mL} \mathrm{4 \%}$ paraformaldehyde (PFA) dissolved in PBS. The brain was taken out, cut in coronal blocks and also post fixed in $4 \% \operatorname{Roti}^{\circledR}$-Histofix (Roth, Germany) at $4{ }^{\circ} \mathrm{C}$.

After a post fixation interval of at least 2 days, the tissue was placed in the TP 1020 Automatic Tissue Processor (Leica, Germany). The tissue was dehydrated and paraffin fixated according to the following protocol: $5 \mathrm{~min}$ in 4\% formalin, $30 \mathrm{~min}$ in tap water, 1 hour each in ethanol of $50 \%, 60 \%, 70 \%, 80 \%, 90 \%$, and 2x $100 \%$ followed by 1 hour of xylol treatment and a final emersion in liquid paraffin for 2 hours. Afterwards, tissue was embedded in solid paraffin blocks using an EG1140 H Embedding Station (Leica, Germany).

\subsection{Immunohistochemistry}

The paraffin-embedded tissues were cut into $4 \mu \mathrm{m}$ thick paraffin sections using a microtome (Microm, Germany). Sections were mounted on coated SuperFrost ${ }^{\circledR}$ Plus glass slides (Menzel-Gläser, Germany) and dried overnight at $37^{\circ} \mathrm{C}$.

Sections were deparaffinized in xylol ( $2 \times 5 \mathrm{~min}$ ) and rehydrated using a series of ethanol baths (EtOH): $10 \mathrm{~min}$ 100\% EtOH, $5 \mathrm{~min}$ 95\% EtOH, $5 \mathrm{~min}$ 70\% EtOH and $1 \mathrm{~min}$ $\mathrm{ddH}_{2} \mathrm{O}$. Endogenous peroxidases were blocked by incubation of the slides in $0.3 \% \mathrm{H}_{2} \mathrm{O}_{2}$ in 0.01M PBS. Antigen retrieval was achieved by boiling sections in $0.01 \mathrm{M}$ citrate buffer $\mathrm{pH}$ 6.0, followed by $15 \mathrm{~min}$ incubation at room-temperature (RT) to cool down. This was followed by a washing step of $1 \mathrm{~min}$ in $\mathrm{dd}_{2} \mathrm{O}$ and afterwards sections were incubated for $3 \mathrm{x}$ 5 minutes in $0.1 \%$ Triton $\mathrm{X}-100$ in $0.01 \mathrm{M}$ PBS to permeabilize the membrane. In the case of intracellular $A \beta$ staining, sections were then incubated for 3 minutes in $88 \%$ formic acid (FA). Non-specific binding sites were blocked by 1 hour treatment with $4 \%$ skim milk and $10 \%$ 
fetal calf serum (FCS) in 0.01M PBS, prior to the addition of the primary antibodies. Primary antibody dilutions were prepared in 0.01M PBS solution containing 10\% FCS (PBS-FCS). Incubation for primary antibodies was performed overnight in a humid chamber at RT.

On the second day, sections were washed 3 x 5 min in $0.1 \%$ Trition $\mathrm{X}-100$ in $0.01 \mathrm{M}$ PBS followed by $1 \mathrm{~min}$ in 0.01M PBS. Biotinylated secondary antibodies were diluted 1:200 in PBS-FCS and applied to the sections. Incubation occurred for $1 \mathrm{~h}$ at $37^{\circ} \mathrm{C}$. Sections were then washed in $0.01 \mathrm{M}$ PBS and incubated for $1 \mathrm{~h}$ with ABC-solution prepared from the Vectastain Elite ABC Kit (Vector Laboratories).

Section were washed 3 x 5min in PBS and visualized using diaminobenzidine (DAB) as a chromagen. DAB developing solution $(0.5 \mathrm{mg} / \mathrm{mL}$ DAB solution in Tris/HCL) was added to the section and a red brown staining pattern could be seen after 1-5 min. Afterwards, sections were washed $3 \times 5 \mathrm{~min}$ in $0.01 \mathrm{M}$ PBS and counterstained with hematoxylin solution (Roth, Germany) for $40 \mathrm{sec}$, followed by $5 \mathrm{~min}$ of tap water. In the last step, sections were dehydrated in a series of EtOH baths: 1 min 70\%, 5 min 95\%, 10 min 100\% and 2 x 5min xylol, and embedded by adding Roti-Histokitt mounting medium (Roth, Germany).

For fluorescent staining, the same protocol was followed; however, the peroxidase blocking step was omitted. After primary antibody incubation, AlexaFluor or Dylight conjugated secondary antibodies were diluted in PBS-FCS solution and applied for $1.5 \mathrm{~h}$. Afterwards, the sections were washed $3 \times 5 \mathrm{~min}$ in $0.01 \mathrm{M}$ PBS and counterstained for $1 \mathrm{~min}$ in a solution of $1.5 \mathrm{mg} / \mathrm{L}^{\prime}, 4$-Diamidin-2-phenylindol (DAPI, Sigma) in $\mathrm{ddH}_{2} \mathrm{O}$. After an additional washing step of 1 min in PBS, sections were embedded with fluorescent mounting medium (DAKO, Denmark) and stored in the dark.

\subsection{Quantitative Real-time PCR}

Deep frozen brain hemispheres were homogenized in $1 \mathrm{ml}$ of Trizol® reagent (Invitrogen, Darmstadt, Germany) per 100 mg tissue using a glass-Teflon® homogenizer (10 strokes, $800 \mathrm{rpm})$. RNA extraction was performed according to the protocol of the manufacturer. Reverse transcription of the purified RNA samples was carried out using the First Strand cDNA Synthesis Kit (Fermentas, St. Leon-Rot, Germany) according to the protocol of the supplier. 
Quantitative Real-time PCR (RT-PCR) was performed using a Stratagene MX3000P Real-Time Cycler (Agilent, Santa Clara, USA). The SYBR-green based DyNAmo Flash SYBR Green qPCR Kit (Finnzymes, Espoo, Finland) containing ROX as an internal reference dye was used for amplification. Generated cDNA was diluted 1:10 in $\mathrm{ddH}_{2} \mathrm{O}$ and used as the sample template. Undiluted cDNA from all samples was pooled and serially diluted in ddH2O to create a standard curve for assessing amplification efficiency.

Primers were purchased from Qiagen as intron-spanning validated primer sets (QuantiTect Primer Assays, Qiagen, Hilden, Germany), except for the following primers:

- MCSF-R (Wirths et al., 2010b): forward 5'-GACCTGCTCCACTTCTCCAG-3'

reverse 5'-GGGTTCAGACCAAGCGAGAAG-3'

- Interleukin-1ß (Li et al., 2008): forward 5'-AAGGAGAACCAAGCAACGACAAAA-3' reverse 5'-TGGGGAACTCTGCAGACTCAAACT-3'

Statistical analysis of quantitative RT-PCR measurements was done by using the Relative Expression Software Tool V1.9.6 (REST) (Pfaffl et al., 2002). The expression ratio results of the studied transcripts were tested for significance by the Pair Wise Fixed Reallocation Randomization Test. Levels of significance were as follows: ${ }^{* * *} p<0.001$; ${ }^{* *} p$ $<0.01 ;{ }^{*} p<0.05$.

\subsection{In vitro dose-response experiments with ibuprofen}

Experiments were carried out by the group of Prof. Sascha Weggen at the University of Düsseldorf, Germany.

Chinese hamster ovary (CHO) cell lines with stable expression of wild-type human APP751 (CHO-APPwt cells) or stable co-expression of human APP751 harboring the “Swedish” (K670N/M671L), "London" (V717I), and "Florida" (I716V) mutations together with PS1 harboring the double mutation M146L/L286V (CHO-5XFAD cells) have been described previously (Hahn et al., 2011). All cell lines were maintained in Dulbecco’s modified Eagle's medium with $10 \%$ fetal bovine serum, $1 \mathrm{mM}$ sodium pyruvate and 100 units/ml penicillin/streptomycin (Invitrogen, Germany). A $\beta$ secretion of individual cell lines after ibuprofen treatments was compared in dose-response experiments as described earlier (Czirr et al., 2007; Hahn et al., 2011). All cell lines intended for comparison were cultured and treated in parallel at similar cell densities. Cells were cultured in serum-containing 
medium and treated for $24 \mathrm{~h}$ with indicated concentrations of ibuprofen (Sigma-Aldrich, Munich, Germany) or DMSO vehicle. $A \beta 40$ and $A \beta 42$ levels in conditioned media were determined by a previously described sandwich ELISA assay. Triplicate measurements from each drug concentration were averaged and normalized to DMSO control conditions. Doseresponse experiments were repeated at least three times, and results were analyzed by twoway ANOVA with Bonferroni post-hoc tests.

\subsection{Quantification of $A \beta$ plaque load and GFAP staining}

Extracellular $\mathrm{A} \beta$ plaque load was evaluated in the cortex and the hippocampus using an Olympus BX-51 microscope equipped with an Olympus DP-50 camera (Olympus, Hamburg, Germany) and the ImageJ software (V1.41, NIH, Bethesda, USA). Serial images of $4 \mathrm{x}$ magnification (hippocampus) and 10x (cortex) were captured on four sections per animal which were $30 \mu \mathrm{m}$ apart from each other. Using ImageJ, the pictures were binarized to 16-bit black and white images and a fixed intensity threshold was applied defining the DAB staining. Measurements were performed for the percentage of area covered by DAB staining (Breyhan et al., 2009). For GFAP staining, the astrocyte-covered area in the dentate gyrus was quantified accordingly.

For plaque load quantification of coronal sections, pictures were taken at 20x magnification following the same protocol was applied.

\subsection{Morphometric assessment of $A \beta$ deposits in $C A A$}

$\mathrm{A} \beta$ deposits were evaluated in blood vessels using an Olympus BX-51 microscope equipped with an Olympus DP-50 camera (Olympus, Hamburg, Germany) and the ImageJ software (V1.41, NIH, Bethesda, USA). Serial images of stained blood vessels were taken at 40x magnification. The number of blood vessels analyzed per patient remained unchanged for each antibody $(n=4-9)$. Using ImageJ, the outer and inner border of the blood vessels were delineated so that only the region in between was assessed. The pictures were binarized to 16-bit black and white images and a fixed intensity threshold was applied defining the percentage of DAB staining. 


\subsection{Enzyme-linked immunosorbent assay (ELISA) of A $\beta$ levels}

Experiments were carried out by the group of Hans-Ulrich Demuth at Probiodrug AG in Halle/Saale, Germany.

To analyze soluble $\mathrm{A} \beta$ levels, frozen brains were homogenized in a Douncehomogenizer in TBS $[120 \mathrm{mM} \mathrm{NaCl}, 50 \mathrm{mM}$ Tris $\mathrm{pH} 8.0$ containing complete protease inhibitor (Roche, Mannheim, Germany)], and subsequently centrifuged at $27.000 \mathrm{~g}$ for $20 \mathrm{~min}$ at $4{ }^{\circ} \mathrm{C}$. To analyze the insoluble $\mathrm{A} \beta$ fraction, brains were weighted in frozen state and directly homogenized in a Dounce-homogenizer in $2.5 \mathrm{ml}$ 2\% SDS, containing complete protease inhibitor (Roche, Mannheim, Germany). Homogenates were sonicated for $30 \mathrm{~s}$ and subsequently centrifuged at $80.000 \mathrm{~g}$ for $1 \mathrm{~min}$ at $4{ }^{\circ} \mathrm{C}$. Supernatants were directly frozen at $80{ }^{\circ} \mathrm{C}$. The resulting pellets were resuspended in $0.5 \mathrm{ml} \mathrm{70 \%} \mathrm{formic} \mathrm{acid} \mathrm{and} \mathrm{sonicated} \mathrm{for} 30$ seconds. Formic acid was neutralized with $9.5 \mathrm{ml} 1 \mathrm{M}$ Tris and aliquots were directly frozen at $-80{ }^{\circ} \mathrm{C}$. Both $\mathrm{A} \beta 40$ - and A $\beta 42-$ ELISA measurements were performed according to the protocol of the manufacturer (IBL Co. Ltd., Japan).

\subsection{Measurement of MCP1 concentrations in brain}

Experiments were performed by the group of Hans-Ulrich Demuth at Probiodrug AG in Halle/Saale, Germany.

MCP-1 concentrations were analyzed in the TBS fraction of the brain using a mouse cytokine Milliplex ${ }^{\mathrm{TM}}$ MAP Kit (Merck Millipore, USA). The assay was performed according to the manufacturers' protocol using $25 \mu \mathrm{l}$ of undiluted brain sample. The bead-based ELISA was analyzed using a Bioplex 200 (BioRad, Munich, Germany) multiplex array reader.

\subsection{Behavior analysis}

\subsubsection{Balance beam task}

Balance and general motor function were assessed using the balance beam task. A one cm dowel beam was attached to two support columns $44 \mathrm{~cm}$ above a padded surface. At either end of the $50 \mathrm{~cm}$ long beam, a $9 \times 15 \mathrm{~cm}$ escape platform was attached. The animal was placed on the center of the beam and released. Each animal was given three trials during a single day of testing. The time the animal remained on the beam was recorded and the resulting latencies to fall of in all three trials were averaged. If an animal remained on the 
beam for the whole $60 \mathrm{sec}$ trial period or escaped to one of the platforms, the maximum time of $60 \mathrm{sec}$ was recorded (Arendash et al., 2001; Wirths et al., 2008).

\subsubsection{Y-Maze alternation task}

Y-maze test was used to assess the spontaneous alternation percentage by a triangular Y-shaped maze built from a black plastic material (arms size: $30 \mathrm{~cm}$ length, $8 \mathrm{~cm}$ width, 15 cm height). For $10 \mathrm{~min}$, each mouse was placed in the first arm and allowed to discover the maze freely. An entry was defined as successful only when the mouse entered the arm with four paws. Alternation was considered successful when entries into three different arms in overlapping triplet sets were made (for example $1,2,3$ or 2, 3, 1 but not 1, 2, 1). The alternation percentage was calculated as the percent of the actual alternations relative to the total possible arm entries. Possible entries were calculated by subtracting 2 from the total arm entries. In order to diminish odor cues, the maze was cleaned with $70 \%$ ethanol solution (Oakley et al., 2006; Jawhar et al., 2011b).

\subsubsection{Cross-Maze alternation task}

Spontaneous alternation rates were assessed using a cross-maze built from black plastic material which had 4 arms arranged at $90^{\circ}$ extending from a central space measuring 8 x $8 \mathrm{~cm}$ (arm sizes: $30 \mathrm{~cm}$ length, $8 \mathrm{~cm}$ width, and $15 \mathrm{~cm}$ height). This test is based on the same principle and protocol as the Y-maze. During 10 min test sessions, each mouse was randomly placed in one arm and allowed to move freely through the maze. Alternation was defined as successive entries into the four arms in overlapping quadruple sets (e.g. 1, 3, 2, 4 or 2, 3, 4, 1 but not 1, 2, 3, 1). The alternation percentage was calculated as the percentage of actual alternations to the possible number of arm entries. In order to diminish odor cues, the maze was cleaned with 70\% ethanol solution (Jawhar et al., 2012)

\subsubsection{Elevated plus maze paradigm}

Behavior in this task (i.e. activity in the open arms) reflects a conflict between the mice's preference for protected areas (e.g., closed arms) and their innate motivation to explore novel environments (Karl et al., 2003).

The test setting consists of a plus-shaped apparatus with two open and two enclosed arms (15 cm long), each with an open roof, elevated $72 \mathrm{~cm}$ above the ground. The mice were 
placed in the center facing the open arms and allowed to discover the maze freely for 5 min. Monitoring was done by an automated tracking system (VideoMot2, TSE-Systems, Germany). By setting the software's parameters according to the manufacturer protocol, the software calculated the time spent in the closed and the opened arms and the central region. Anxiety levels were evaluated by calculating the percentage of time spent in the open arms realative to the total time in the maze (Wirths et al., 2010c; Jawhar et al., 2012).

\subsubsection{Open Field}

The open field test was used to asses both exploratory behavior and locomotor activity. The mice were tested using an open field box made of grey plastic with 50 x $50 \mathrm{~cm}$ surface area and $38 \mathrm{~cm}$-high walls. Monitoring was done by an automated tracking system (VideoMot2, TSE-Systems, Bad Homburg, Germany). The behavioral parameters registered during 5-min sessions were the percentage of time spent in the central part $(20 \mathrm{x} 20 \mathrm{~cm})$ versus total time, total traveled distance, speed and percentage of locomotor activity during the test period (Lim et al., 2001).

\subsection{Stereotaxic injection of Adeno Associated Virus (AAV)}

\subsubsection{Stereotaxic surgery}

Mice were anesthetized by intraperitonal injection of a mixture of ketamine ( 100 $\mu \mathrm{g} / \mathrm{g}$ animal weight) and xylazine ( $\sim 6.4 \mu \mathrm{g} / \mathrm{g}$ animal weight) in aqua ad injectabilia (Braun, Germany). When the mice no longer reacted to pain stimuli, their heads were shaved and the mice were secured in a stereotaxic frame with ear cups (Kopf Instruments, USA). After exposure of the skull, the coordinates of bregma and lambda were determined and the calculated position for injection was marked. The bone was thinned around the injection site with a drill and a portion of the skull was removed.

Pulled glass capillaries were used for injection (World Precision Instruments, USA). After lowering the glass capillary to the desired depth in the cortex, the tissue was given time to equilibrate for 4 minutes. Coordinates used for injection in the frontal cortex were bregma $+1.54 \mathrm{~mm}$, lateral $1.5 \mathrm{~mm}$ and $1.75 \mathrm{~mm}$ in depth. One microliter of virus, containing $1.0 \times 10^{8}$ transducing units, was delivered into the brain with a speed of $200 \mathrm{~nL} / \mathrm{min}$ controlled via a microliter injector (World Precision Instruments, USA). After injection of the virus, the 
capillary remained in the brain for another 4 minutes and was then slowly withdrawn. The scalp was sutured and the mice were placed in front of a heat lamp to recover. For each injection, a new capillary was used.

\subsubsection{AAV - Vectors}

Recombinant AAV1/2 vectors were provided by Prof. Sebastin Kügler, University Medicine Göttingen.

In brief, recombinant AAV were produced in HEK293 cells by transient cotransfection with helper plasmids pDG and PDP1 and the respective AAV genome plasmid. Forty-eight hours after transfection, cells were lysed using three rounds of freezing and thawing. Virus particles were pre-purifed by ultracentrifugation through an iodixanol step gradient. The $40 \%$ iodixanol fraction was further purified using heparin-affinity chromatography on an Äkta FPLC. The concentrated eluate was then dialyzed against PBS. The genome titer of the recombinant virus was determined by RT-PCR.

Vectors carried either the human $\alpha$-synuclein WT, human $\alpha$-synuclein A30P or human $\beta$-synuclein WT gene under control of the human synapsin 1 gene (hsyn) promoter. In addition, all vectors harbored an enhanced green fluorescent protein (EGFP) gene in a separate expression cassette also under the control of the hsyn promoter.

Viruses were transported on dry ice and stored at $-80^{\circ} \mathrm{C}$. Stability of the virus was ensured by avoiding repeated thawing.

\subsection{Statistical analysis}

Differences between groups were analysed using one-way ANOVA or unpaired t-tests. All data are shown as mean \pm standard error of the mean (SEM). Significance levels were as follows: ${ }^{* * *} p<0.001 ;{ }^{* *} p<0.01$; ${ }^{*} p<0.05$. All calculations were performed using GraphPad Prism version 5 (GraphPad Software, San Diego, USA). 


\section{Results}

\subsection{Project I: Chronic ibuprofen treatment in the 5XFAD mouse model}

Besides amyloid plaques and neurofibrillary tangles, neuroinflammation is a well described feature of $\mathrm{AD}$. So far no clear answer can be given about the influence of inflammation on disease progression, as both detrimental and beneficial effects have been described (Boche and Nicoll, 2008).

There is substantial epidemiological evidence that users of NSAIDs have a decreased risk of developing $\mathrm{AD}$. The exact mechanism has not been resolved but a number of possibilities have been suggested that could account for the protective effects, including antiinflammatory as well as anti-amyloidogenic activity by modulation of $\gamma$-secretase (Imbimbo, 2004).

In order to gain further insight into the mechanism of these drugs, a mouse model was chosen which expresses PS mutations that render it resistant to $\gamma$-secretase modulation (Hahn et al., 2011). This allows the effects of NSAIDs on filammatory processes and cognitive function to be studied without inference of anti-amyloidogenic properties.

In the present study, effects of 3 months of treatment with the NSAID ibuprofen were examined in the 5XFAD mice.

\subsubsection{Inflammatory processes in the 5XFAD mouse model}

As previous reports only briefly described the inflammatory pathology occurring in the 5XFAD mouse model (Oakley et al., 2006), it was first investigated if inflammatory marker transcripts were up-regulated in the mice in general. Therefore, we compared the expression levels of a variety of inflammatory mediators in 3- and 6-month-old 5XFAD and age-matched wildtype (WT) mice.

At 3 months of age, the majority of the genes tested showed no significant changes compared to WT animals. Only Tlr-2 (1.8-fold, $p<0.05)$, CD11B (1.4-fold, $p<0.05)$ and cathepsin D (2.2-fold, $p<0.01)$ were up-regulated, while IL-10 was significantly decreased 
(0.2-fold, $p<0.01$ ) (Fig. 8 A, B). The lack of severe brain inflammation at this early time point correlates with the mild pathology seen in the mice.

In contrast, at 6 months of age, when 5XFAD mice have developed a robust AD pathology including cognitive impairment, a broad range of inflammation markers were highly up-regulated. Six-month-old SXFAD mice showed a consistent increase of the interleukins IL-1 $\beta$ (3.2-fold, $p<0.05)$, IL-6 (1.7-fold, $p<0.05)$, IL-10 (4.0-fold, $p<0.01$ ) and TNF- $\alpha$ (2.5-fold, $p<0.05)$. Also, Toll-like receptor family members were up-regulated such as Tlr-2 (3.3-fold, $p<0.05$ ), Tlr-7 (3.3-fold, $p<0.05$ ) and Tlr-9 (2.4-fold, $p<0.01$ ) (Fig. 8 A). Expression levels of the microglia-associated markers CD11B (2.3-fold, $p<0.001$ ), F4/80 (4.1-fold, $p<0.01$ ), cathepsin D (CathD, 3.2-fold, $p<0.001$ ), macrophage colony-stimulating factor receptor (MCSF-R) (2.4-fold, $p<0.001)$ were similarly up-regulated (Fig. 8 B). The astrocytic marker, glial fibrillary acidic protein (GFAP), showed the highest increase (28 -fold, $p<0.001$ ) of all genes tested, indicating a severe astrogliosis in the mice in comparison to WT animals (Fig. 8 B). 
A

5XFAD 3 Months 5XFAD 6 Months

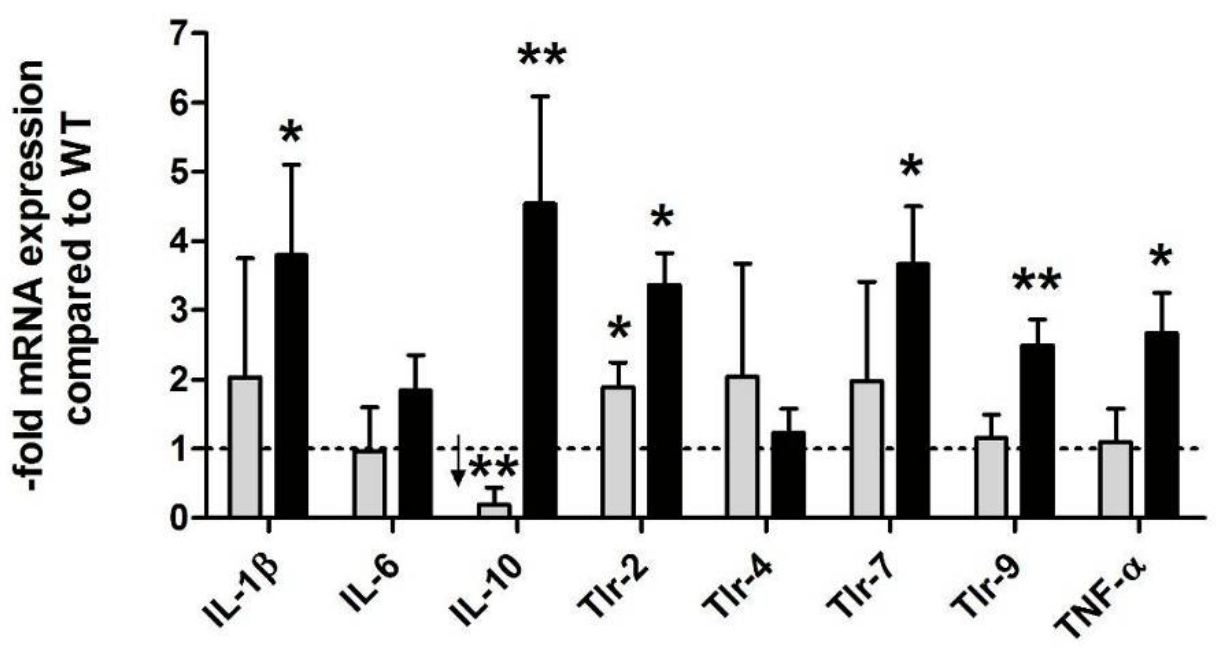

B

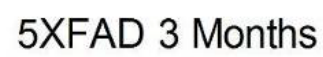

5XFAD 6 Months

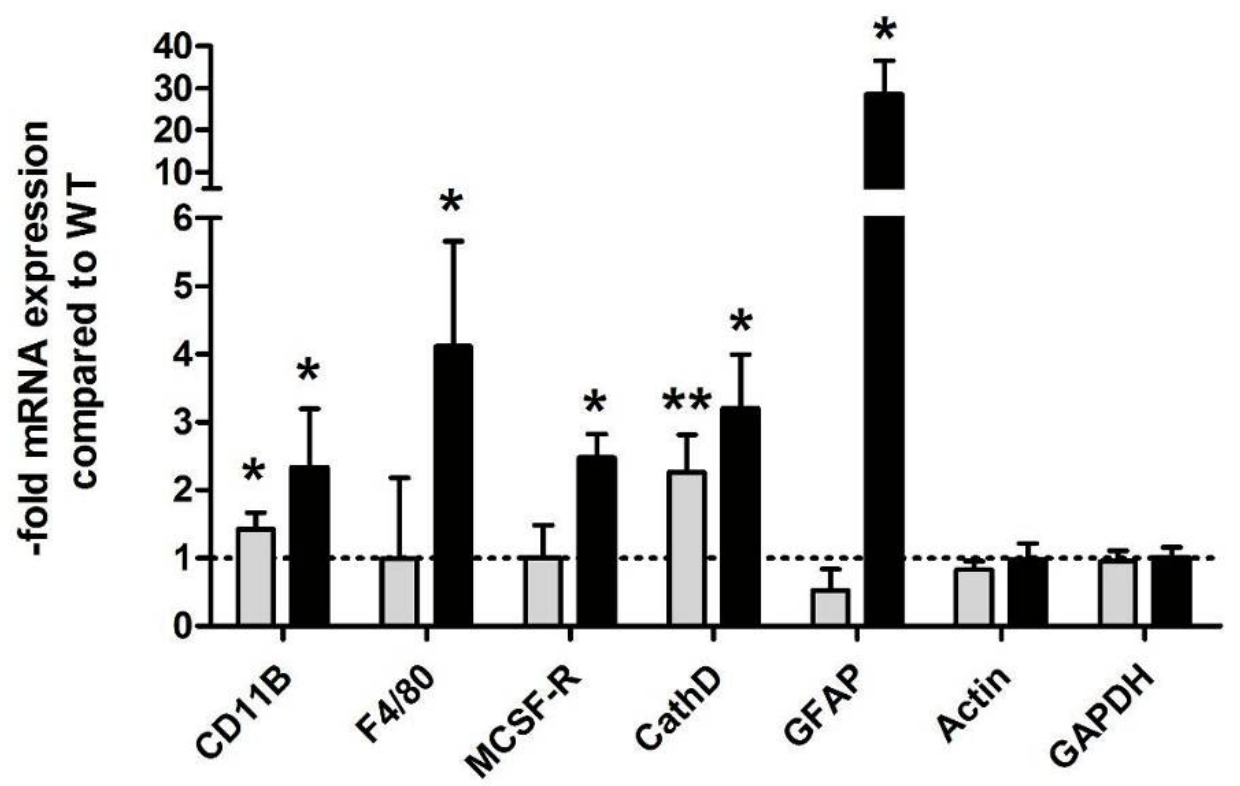

Fig. 8 Analysis of gene expression of various inflammatory markers by quantitative RT-PCR:

Expression levels of 5XFAD mice were compared to age-matched WT control animals. Normalization was performed against two housekeeping genes: Actin and glyceraldehyde 3-phosphate dehydrogenase (GAPDH). The expression of the housekeeping genes did not differ in the different age groups. Significance levels as calculated by REST program refer to 5XFAD mice compared to age-matched WT animals: ${ }^{* *}, p<0.01$; ${ }^{*} p<$ $0.05 ; \mathrm{n}=3-4$ per group. 


\subsubsection{Effect of ibuprofen treatment on transcript levels and protein levels of inflammatory markers in 5XFAD mice}

As described in the previous chapter, the 5XFAD mouse model shows an agedependent increase in inflammatory pathology. Between 3 and 6 months of age, a robust upregulation of microglial and astroglial markers occurs. Therefore, in an initial experiment, analysis of ibuprofen treatment's effect on expression levels of inflammatory markers was performed.

A comparison between ibuprofen-treated and untreated 5XFAD mice at the age of 6 months revealed a down-regulation of several inflammatory markers like interleukins IL-6 (0.7-fold, $p<0.05)$ and IL-10 (0.3-fold, $p<0.05)$, MCSF-R (0.8-fold, $p<0.05)$ and GFAP (0.3-fold, $p<0.001$ ). Furthermore, Tlr-7 (0.6-fold, $p=0.099$ ) and F4/80 (0.6-fold, $p=0.145$ ) showed a non-significant decrease in expression. Other markers like IL-1 $\beta$, Tlr-2, TNF $\alpha$ and CathD remained unchanged after ibuprofen treatment (Fig. 9).

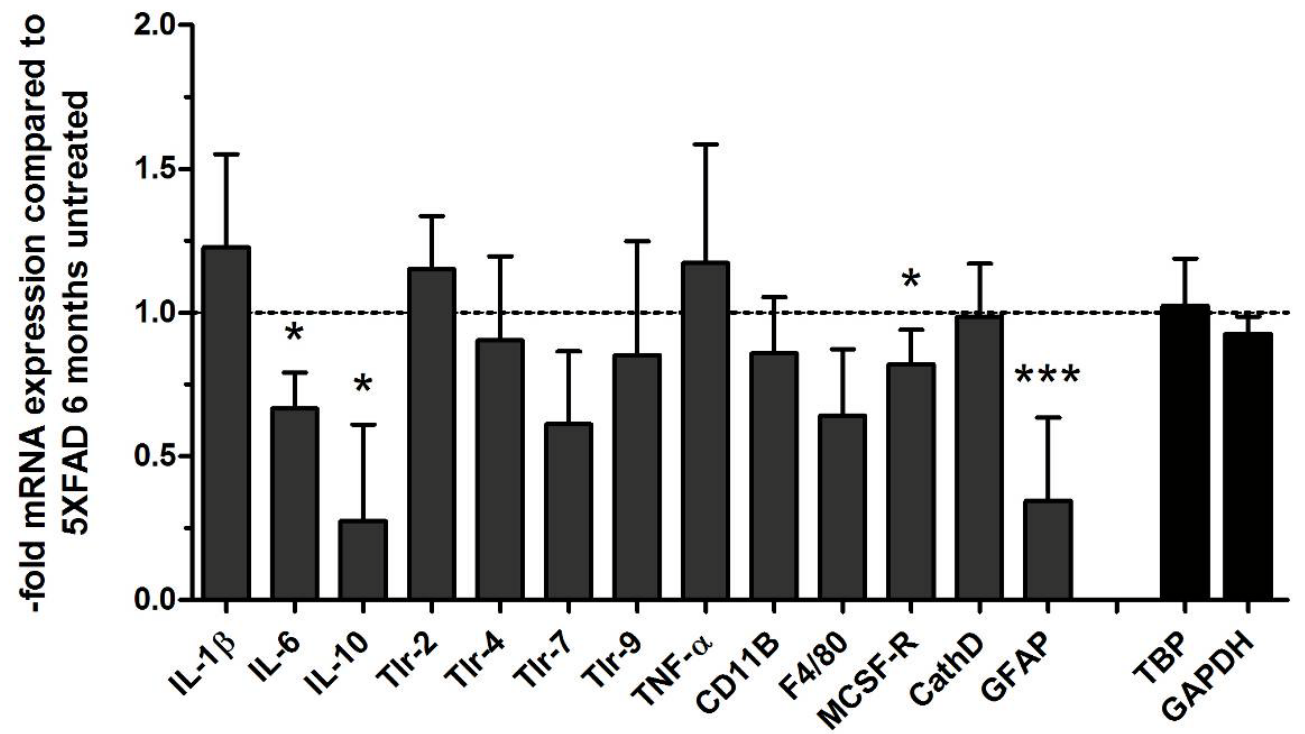

Fig. 9 Quantitative RT-PCR analysis of ibuprofen treated mice: Analysis showed significant downregulation of several inflammatory markers including IL-6, IL-10, MCSF-R and GFAP in ibuprofen treated mice in comparison to untreated age-matched controls. Significance levels as calculated by REST program refer to 5XFAD mice compared to age-matched WT animals: ${ }^{* *}, p<0.01 ;{ }^{*}, p<0.05 ; \mathrm{n}=3-4$ per group. 
To assess the effect of ibuprofen treatment on protein levels, qualitative doubleimmunostainings were performed using an $A \beta$ antibody (4G8-green) and microglial/ macrophage marker (Iba-1-red). A reduction of Iba-1 staining (in red) was observed in cortical samples of ibuprofen treated (Fig. $10 \mathrm{~B}$ ) compared to untreated 5XFAD mice (Fig. 10 A). To corroborate this finding, the levels of monocyte chemotactic protein-1 (MCP-1) were quantified by ELISA in TBS-soluble protein fractions. Strongly reduced MCP-1 levels were detected in ibuprofen treated 5XFAD mice $(2.81 \pm 0.73 \mathrm{pg} / \mathrm{ml})$ compared to untreated $5 X F A D$ mice $(8.63 \pm 1.59 \mathrm{pg} / \mathrm{ml}, p<0.01)$ (Fig. $10 \mathrm{~F})$.

To assess whether the strong down-regulation of GFAP expression was also reflected on the protein level, the astrocyte covered area was quantified in the dentate gyrus of ibuprofen treated and untreated control 5XFAD mice. Ibuprofen treated mice displayed a strong trend towards reduced GFAP load, which almost reached statistical significance ( $p=$ 0.055; Fig. 10 C-E). 

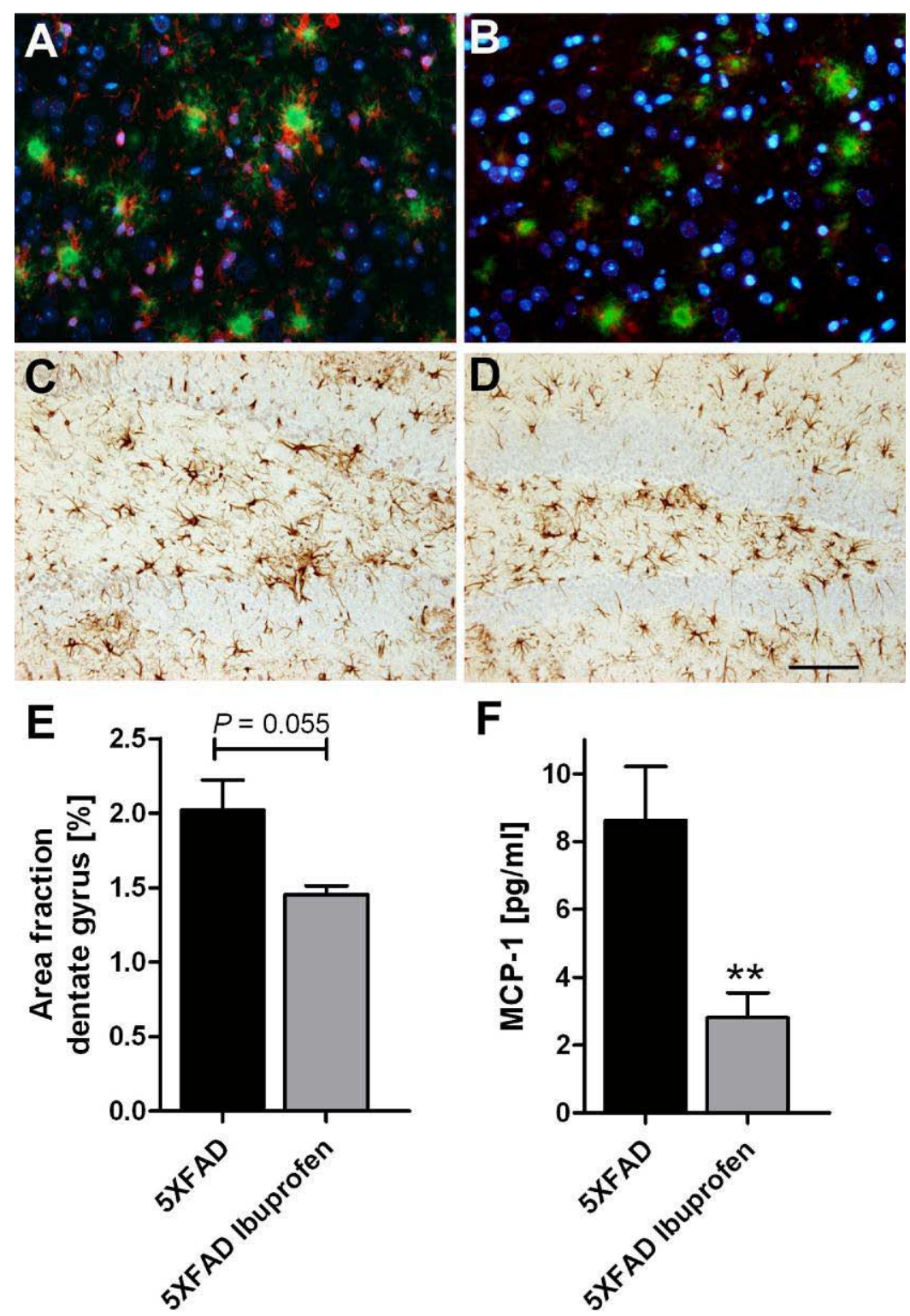

Fig. 10 Effect of ibuprofen treatment on protein levels of inflammatory markers: Immunohistochemical detection of $A \beta$ (red) and Iba-1 (green) revealed reduced macrophage/microglia staining in the cortex in ibuprofen treated mice (B) compared to untreated 5XFAD mice (A). Quantification of GFAP-positive astrocytes in the dentate gyrus showed a strong trend towards reduced astrogliosis in ibuprofen treated mice (D, E) compared to untreated 5XFAD mice (C). Quantification of the pro-inflammatory chemokine MCP-1 using ELISA revealed a substantial down-regulation after ibuprofen-treatment (F). MCP-1 ELISA was performed by the group of Hans-Ulrich Demuth, Probiodrug, Halle/Saale, Germany.

All error bars represent SEM. Unpaired t-test; **, $p<0.01 . \mathrm{n}=7$ (5XFAD) and 8 (5XFAD-Ibu) for MCP-1 ELISA. $n=4$ per group for GFAP quantification. Scale bar: A-D: $50 \mu \mathrm{m}$. 


\subsubsection{CHO-5XFAD cells are resistant to the A 342 -lowering activity of ibuprofen}

It was previously shown that CHO-cells expressing the 5XFAD combination of APP and PS1 mutations are completely resistant to the A $\beta 42$-lowering activity of the potent GSM BB25, indicating that this mouse model is insensitive to $\gamma$-secretase modulation (Hahn et al., 2011).

In order to confirm this result for ibuprofen, dose-response experiments were performed using the same cell lines. Cells with stable expression of the 5XFAD combination of APP (Swedish/London/Florida) and PS1 (M146L/L286V) mutations (CHO-5XFAD cells) displayed an 18-fold increase in the $A \beta 42 / A \beta 40$ ratio as compared to cells with stable expression of wild type APP (CHO-APPwt cells) demonstrating that the expression of 5 FAD mutations caused a dramatic shift to increased production of the amyloidogenic A $\beta 42$ peptide species (Fig. 11 A).

To compare the response of individual cell lines to ibuprofen, cells were treated with increasing concentrations of ibuprofen $(100-500 \mu \mathrm{M})$. A $\beta 42$ and $A \beta 40$ levels in cell culture supernatants were measured by sandwich ELISA. CHO-APPwt cells showed a dosedependent decrease in A $\beta 42$ levels (200 $\mu \mathrm{M}, p<0.05$; $300-500 \mu \mathrm{M}, p<0.001)$ (Fig. $11 \mathrm{C}$ ). In contrast, $A \beta 42$ reductions after ibuprofen treatment were strongly attenuated in CHO5XFAD cells (Fig. 11 C). A $\beta 40$ levels were not affected by ibuprofen treatment in both cell lines (Fig. 11 B). 
A

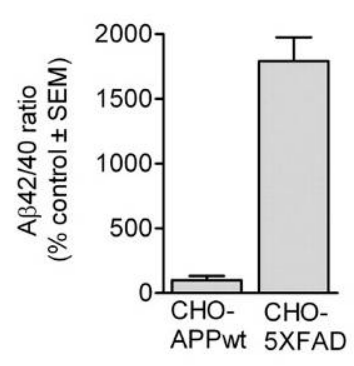

B
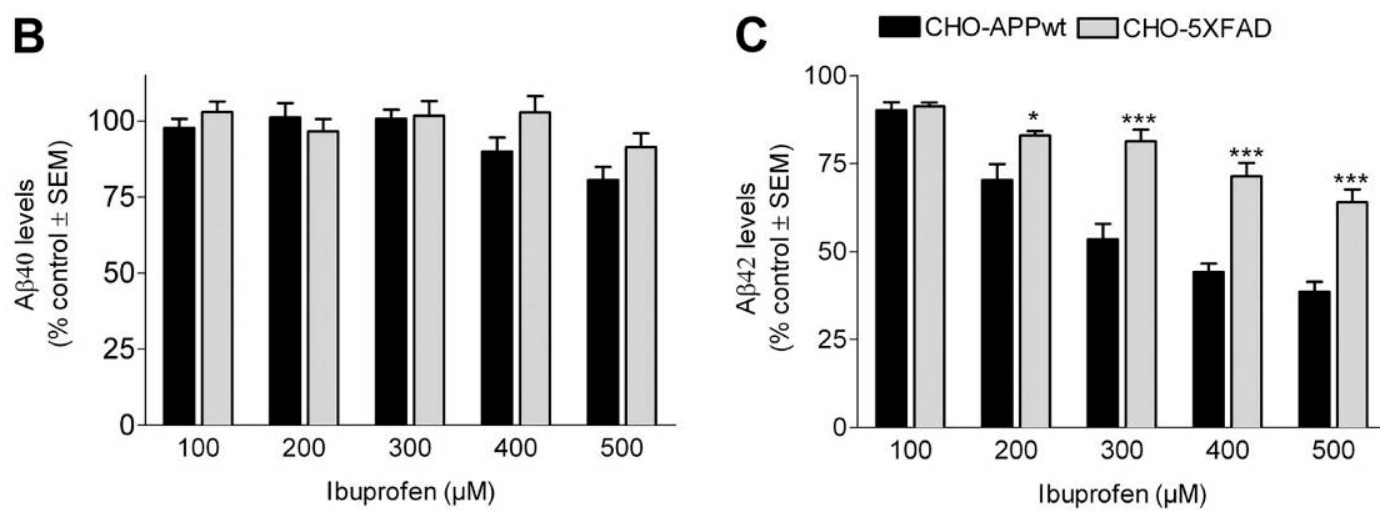

Fig. 11 Cells with stable expression of the 5XFAD combination of APP and PS1 mutations are resistant to the A $\beta 42$-lowering activity of ibuprofen: (A) Comparison of $A \beta 42 / A \beta 40$ ratios in cell lines with stable expression of wild type APP (CHO-APPwt cells) and the 5XFAD combination of APP and PS1 mutations (CHO-5XFAD cells) was performed. CHO-5XFAD revealed an 18-fold increase in the A $\beta 42 / A \beta 40$ ratio compared to CHO-APPwt cells. Response of individual cell lines to increasing ibuprofen concentration was measured in cell culture supernatants by sandwich ELISA. A $\beta 40$ levels remained unchanged (B). A $\beta 42$ levels showed a dose-dependent decrease in CHO-APPwt cell, while the effect was strongly attenuated in CHO5XFAD cells (C). Experiments were performed by the group of Prof. Sascha Weggen at the University of Düsseldorf, Germany. All error bars represent SEM. Two-way analysis of variance (ANOVA) with Bonferroni post tests; *, $p<0.05$; ***, $p<0.001$.

\subsubsection{No effect of ibuprofen treatment on extracellular plaque pathology in 5XFAD mice}

To assess the influence of ibuprofen treatment on the $A \beta$ plaque progression in the 5XFAD mice, plaque load analysis was performed. Sagittal brain sections of 6-month-old ibuprofen-treated and control $5 \mathrm{XFAD}$ mice were stained with two different $\mathrm{A} \beta$ antibodies detecting either overall $A \beta$ (4G8, $A \beta 17-24)$ or $A \beta x-42$ peptides (G2-11).

Using the 4G8 antibody, no significant differences were observed in the cortex (5XFAD: $5.67 \pm 0.76 \%$; 5XFAD-Ibu: $6.98 \pm 0.18 \%$ ) or the hippocampus (5XFAD: $3.7 \pm$ 0.18\%; 5XFAD-Ibu: $4.05 \pm 0.35 \%$ ) (Fig. $12 \mathrm{~A}$, B) of ibuprofen treated mice in comparison to untreated controls. 
Similar findings were obtained for $\mathrm{A} \beta$ peptides ending at amino acid 42 with no significant differences in cortex (5XFAD: $2.16 \% \pm 0.27 \%$; 5 XFAD-Ibu: $2.37 \% \pm 0.56 \%$ ) or hippocampus (5XFAD: 1.54\% \pm 0.22\%; 5XFAD-Ibu: 1.39\% \pm 0.36\%) (Fig. 12 C, D).

A

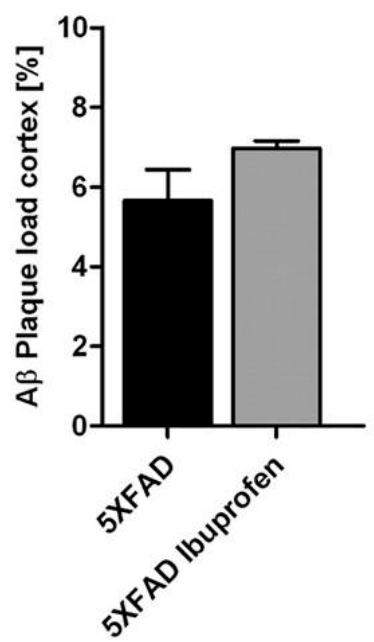

B

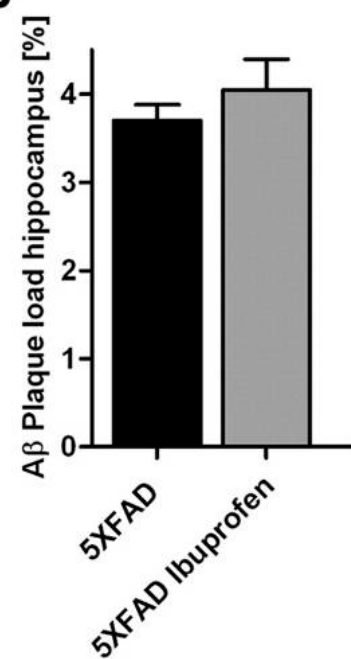

C

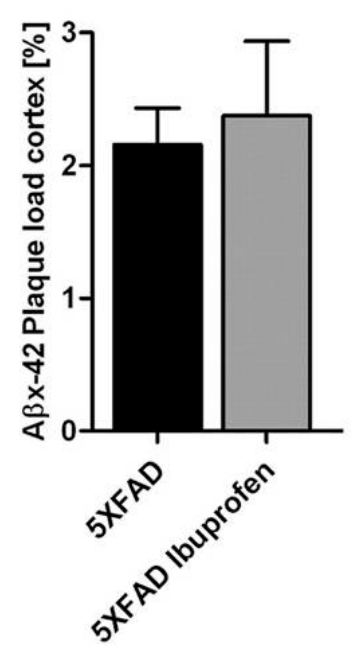

D 5

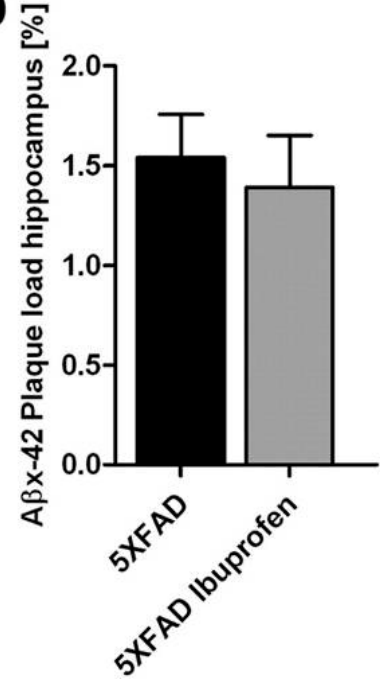

Fig. 12 Unchanged hippocampal and cortical plaque load in 5XFAD mice: No reduction in overall $A \beta(A$, $\mathrm{B}$ ) or $\mathrm{A} \beta 42$-plaque load $(\mathrm{C}, \mathrm{D})$ either in the cortex $(\mathrm{A}, \mathrm{C})$ or the hippocamous $(\mathrm{B}, \mathrm{D})$, could be detected following 3-months of ibuprofen-treatment. All error bars represent SEM. Unpaired t-test. $n=4$ per group.

\subsubsection{Effect of ibuprofen on $A \beta$ levels in 6-month-old 5XFAD mice}

ELISA quantification of $A \beta x-40$ and $A \beta x-42$ (mass $A \beta$ /gram brain weight) revealed no alteration in TBS-soluble A $\beta \mathrm{X}-40$ levels (5XFAD: $0.18 \pm 0.03 \mu \mathrm{g} / \mathrm{g}, 5 \mathrm{XFAD}-\mathrm{Ibu}: 0.12 \pm$ $0.02 \mu \mathrm{g} / \mathrm{g}$ ) of ibuprofen-treated 5XFAD mice in comparison to untreated controls (Fig. $13 \mathrm{~A}$ ). Interestingly, increased $\mathrm{A} \beta \mathrm{x}-42$ levels in the TBS-soluble fraction (5XFAD: $0.12 \pm$ 0.011 $\mu \mathrm{g} / \mathrm{g}, 5 X F A D-I b u: 0.25 \pm 0.015 \mu \mathrm{g} / \mathrm{g} ; p<0.001$ ) could be detected (Fig. $13 \mathrm{~B}$ ).

In the insoluble $A \beta$ fraction (combined SDS and FA fractions), no significant differences were detected for A $\beta x-40$ (5XFAD: $16.77 \pm 2.7 \mu \mathrm{g} / \mathrm{g}, 5 X F A D-I b u: ~ 12.94 \pm 0.74$ $\mu \mathrm{g} / \mathrm{g}$ ) or $\mathrm{A} \beta \mathrm{x}-42$ levels (5XFAD: $78.52 \pm 6.54 \mu \mathrm{g} / \mathrm{g}$, 5XFAD-Ibu: $75.08 \pm 4.3 \mu \mathrm{g} / \mathrm{g}$ ) comparing both test groups (Fig. 13 C, D). 


\section{A}

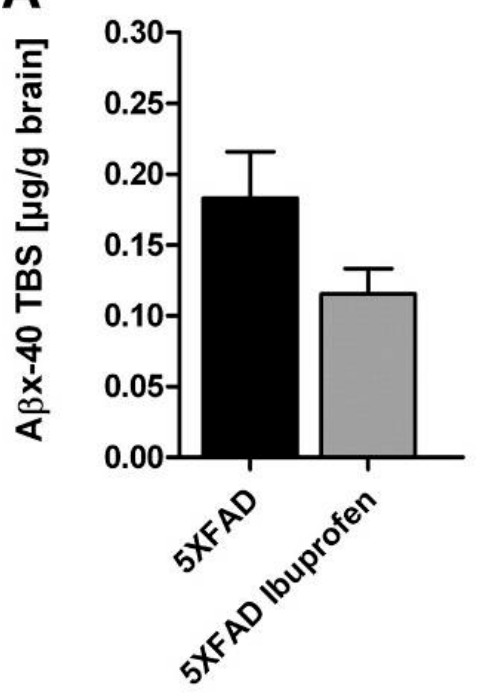

C

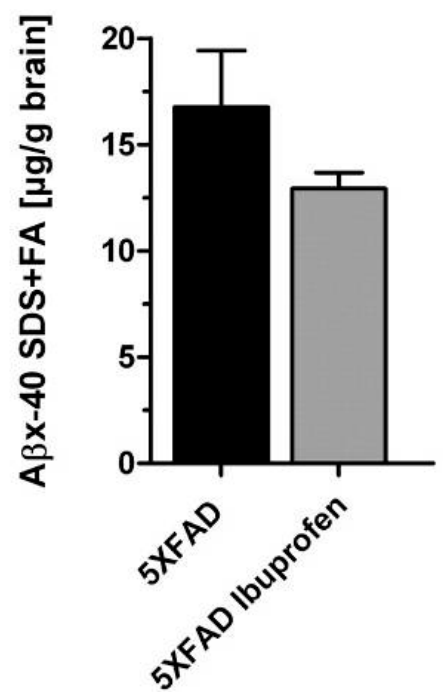

B

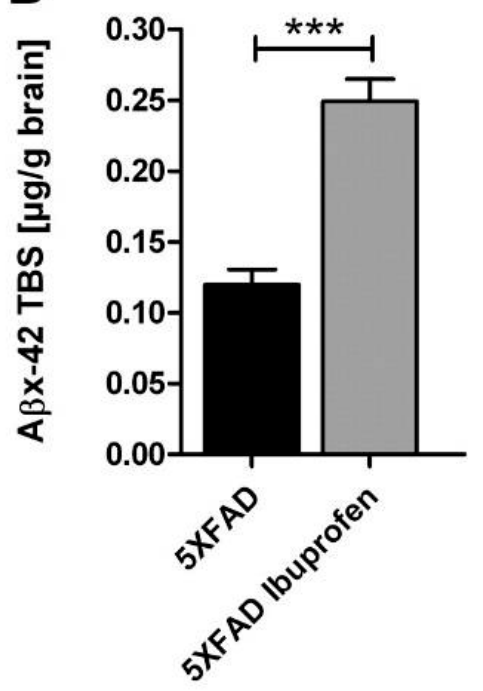

D

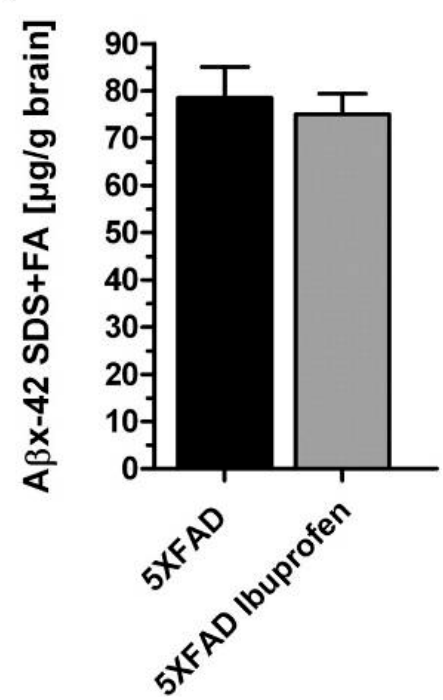

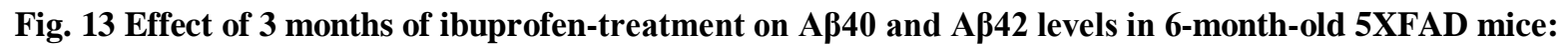
Quantification of $A \beta x-40$ and $A \beta x-42$ using ELISA showed increased TBS-soluble $A \beta x-42$ levels after ibuprofen-treatment (B), whereas $A \beta x-40$ levels remained unchanged (A). No differences were detected in SDSand FA-soluble $A \beta x-40$ and $A \beta x-42$ levels (C, D). Experiments were performed by the group of Hans-Ulrich Demuth, Probiodrug AG, Halle/Saale, Germany. All error bars represent SEM. Unpaired t-test; ${ }^{* * *}, p<0.001$. $\mathrm{n}=7$ (5XFAD-Ibu) and 8 (5XFAD).

\subsubsection{Effect of ibuprofen-treatment on behavioral performance in 5XFAD mice}

Motor coordination was assessed using the balance beam task (Fig. 14 A). Ibuprofen treated 5XFAD mice performed significantly worse than untreated mice $(p<0.001)$. Working memory was assessed using the Y-maze and the cross-maze alternation tasks. 
Performance in the Y-maze was similar in both the treated and untreated groups (Fig. $14 \mathrm{~B}, \mathrm{C})$. Analysis of the more difficult, and hence more sensitive, cross-maze task revealed a significantly reduced alternation frequency in ibuprofen treated 5XFAD mice compared to untreated 5XFAD (Fig. 14 D; $p<0.001$ ). Exploratory behavior of the mice was unchanged between the groups as the number of arm entries during the test period was not significantly different (Fig. 14 E).

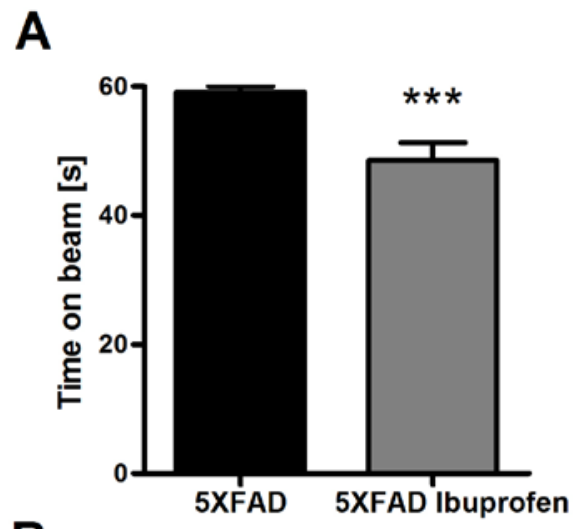

B

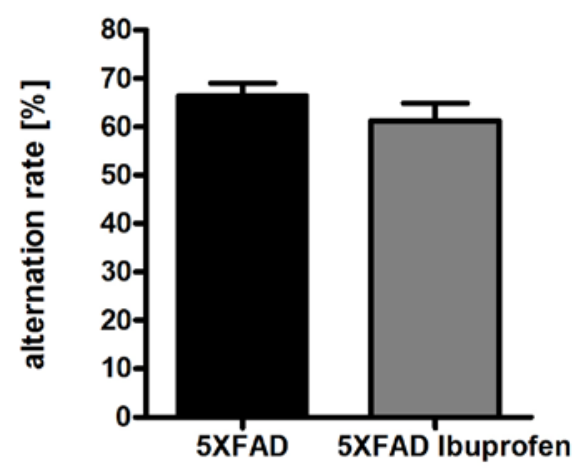

D

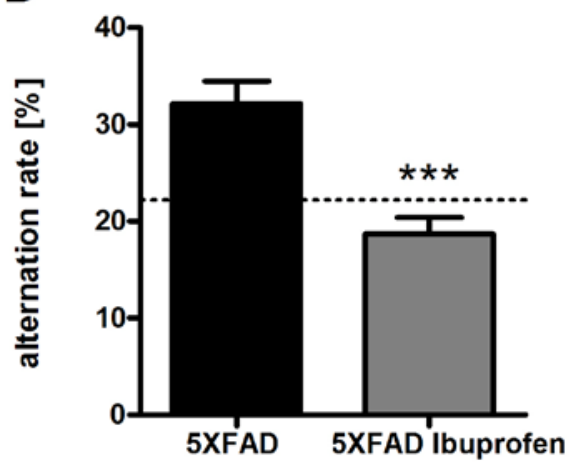

C

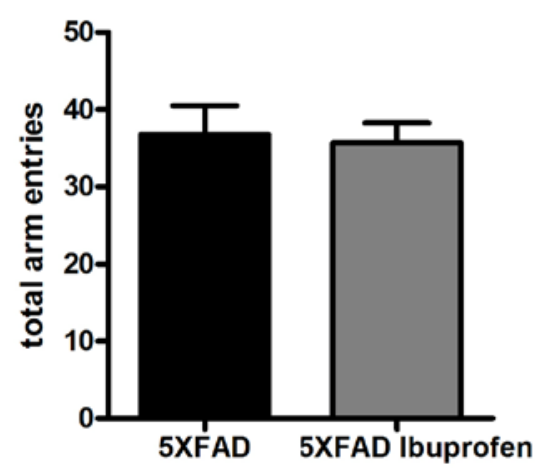

E

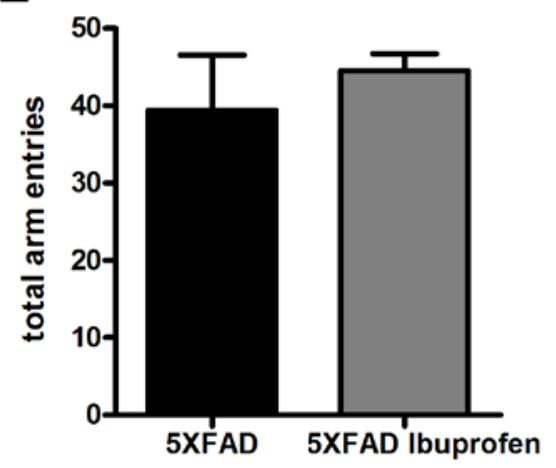

Fig. 14 Effect of ibuprofen-treatment on behavioral performance in 5XFAD mice: Ibuprofen treated 5XFAD mice displayed an impaired motor performance in the balance beam task (A). No changes were seen in the Y-maze (B). However, mice demonstrated a significantly reduced alternation frequency in the cross-maze task, which is around chance level (dotted line, D). This reduction was not due to reduced exploratory behavior as no difference in the total arm entries has been detected in both tasks (C, E). All error bars represent SEM. Unpaired t-test; ${ }^{* * *}, p<0.001 . \mathrm{n}=7$ (5XFAD-Ibu) and 12 (5XFAD). 
In addition, anxiety behavior was analyzed using the elevated plus maze paradigm. No effect of ibuprofen treatment could be seen, as both groups spent similar time in the open arms of the maze (Fig. 15 B). Also, the number of arm entries, indicating the activity level of the mice, was nearly the same in both groups (Fig. $15 \mathrm{~A}$ ).

Furthermore, the open field paradigm was used to assess exploratory and spontaneous locomotor activity and anxiety. As expected, there were no significant differences in the time the mice spent in the center of the maze (Fig. 15 C). This confirms the data from the elevated plus maze that ibuprofen treatment has apparently no influence on anxiety levels of the mice.

Locomotor activity in ibuprofen-treated 5XFAD mice was reduced compared to untreated 5XFAD mice (Fig. $15 \mathrm{D} ; p<0.01$ ). This finding is also displayed in a nearly significant decrease in the speed of ibuprofen mice during the test period (Fig. $15 \mathrm{~F} ; p=0.05$ ). Distance traveled during the test was decreased but did not reach significance (Fig. $15 \mathrm{E} ; p=$ $0.072)$. 
A

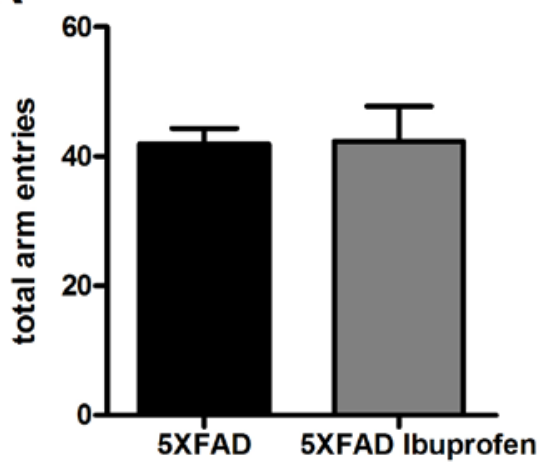

C

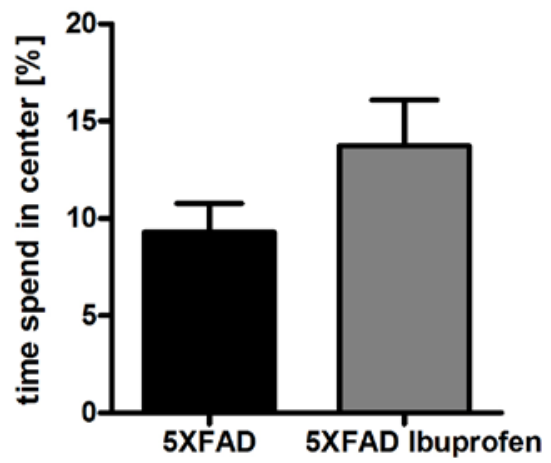

E

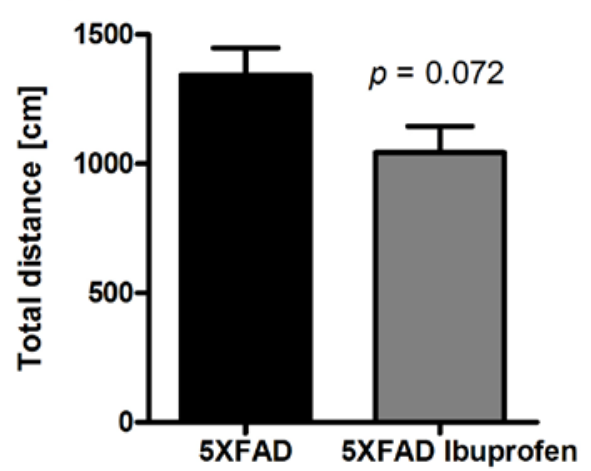

B

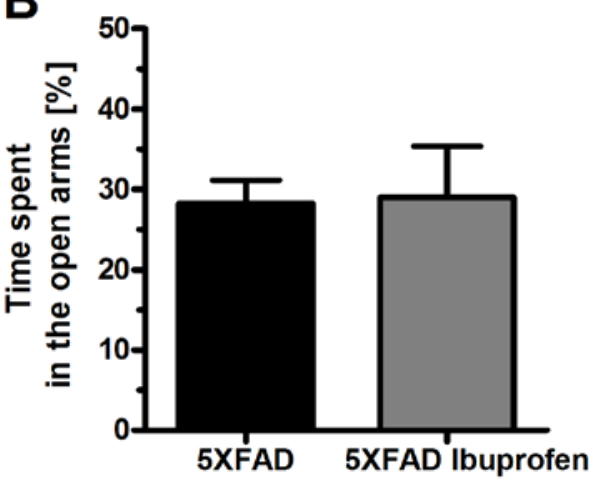

D

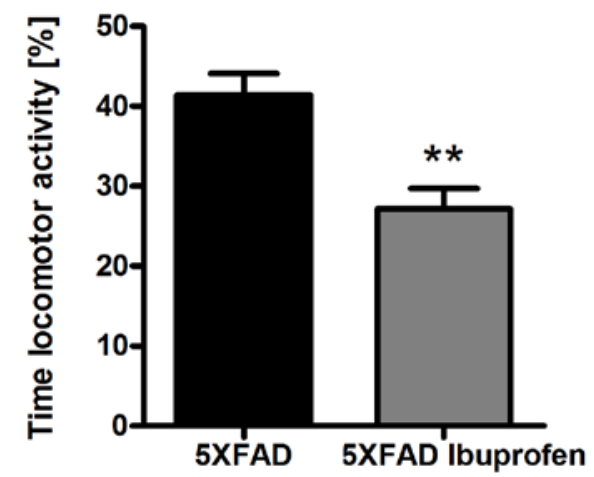

$\mathbf{F}$

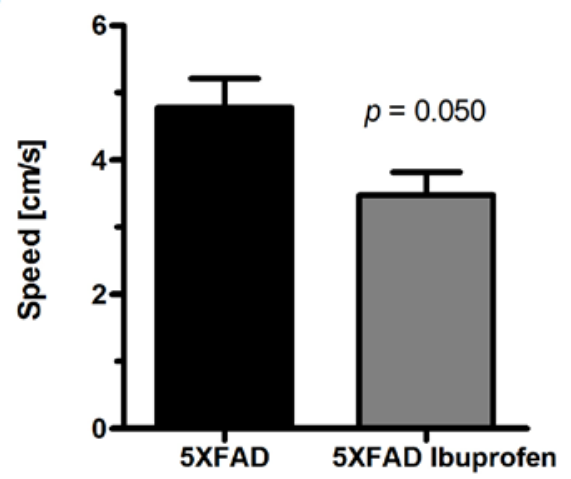

Fig. 15 Influence of ibuprofen-treatment on behavioral performance in 5XFAD mice: Ibuprofen treatment had no effect on anxiety performance in the 5XFAD mice tested in the elevated plus maze and open field paradigms (A and C). Exploratory activity was similar in both groups in the elevated plus maze (B). Ibuprofentreated 5XFAD mice showed a significant reduction in overall locomotor activity (D) and a trend towards reduced path-length and speed in the open field task (E, F). All error bars represent SEM. Unpaired t-test; **, $p<$ 0.01. $\mathrm{n}=7$ (5XFAD-Ibu) and 12 (5XFAD). 


\subsection{Project II: Analysis of oligomeric pyroglutamate Abeta in CAA}

Within the last decade, immunotherapy has gained considerable attention as an AD treatment. However, clinical studies have been facing some drawbacks as patients receiving an active vaccination had a strong autoimmune reaction causing meningoencephalitis (Orgogozo et al., 2003). Furthermore, microhemorrhages within the brain vasculature have been reported and are believed to be caused by anti-A $\beta$ antibody binding to CAA (Racke et al., 2005). For safer therapeutic approaches, it is necessary to study the association of promising antibodies with the vasculature in the human brain.

The CAA staining pattern of the 9D5 antibody was assessed and the question was addressed whether the 9D5 antibody recognizes the same amount of CAA as other A $\beta$ antibodies. In addition, a possible correlation between CAA staining and gender, age, Braak stage and ApoE genotype was studied.

\subsubsection{Screening for CAA}

Sections of the gyrus temporalis superior from 99 AD patients were stained with a generic $A \beta$ (NT244) antibody and a conformational-specific antibody for pyroglutamate oligomers (9D5). Then, they were used to screen for CAA.

Data regarding diagnosis, gender, age, Braak stage, ApoE genotype and plaque load in the brain were available for each patient. The cohort used in this study consisted of samples of 76 females and 23 males with a mean age of $77.1 \pm 12$ years. Braak stages ranged from 4 to 6 with an average of 5.1. Fifty-seven of the patients were carriers for at least one ApoE4 allele. Of these, 46 patients were heterozygous for ApoE4 and 11 patients were homozygous for ApoE4. Staining with the NT244 antibody, detecting general A $\beta$, demonstrated CAA in 24 patients (24\%). 9D5 positive blood vessels were found in 13 patients (13\%). The majority of the samples showed a heavy plaque load deposition. Only nine patients had minor plaque accumulation in the brain. Statistical analysis revealed no correlation of the occurrence of 9D5-positive CAA staining with gender, age, Braak stage, ApoE genotype and plaque deposition (data not shown). 


\subsubsection{Comparative CAA staining of 9D5 versus NT244}

For further analysis of the 9D5 staining pattern, a comparative staining between 9D5 and a generic A $\beta 1-16$ antibody (NT244) was conducted. Analysis revealed a high degree of variation in the staining pattern. Blood vessels positive for NT244 rarely lacked immunoreactivity for 9D5 (Fig. 16 A, B). Sometimes blood vessels showed a complete overlap in the staining pattern for both antibodies (Fig. 16 E, F). However, the majority of the blood vessels showed a positive immunoreactivity for NT244 over the complete vessel wall area while the 9D5 demonstrated only a partial overlap (Fig. 16 C, D). Therefore, 9D5 occupied a subfraction of NT244-positive blood vessel areas.

9D5
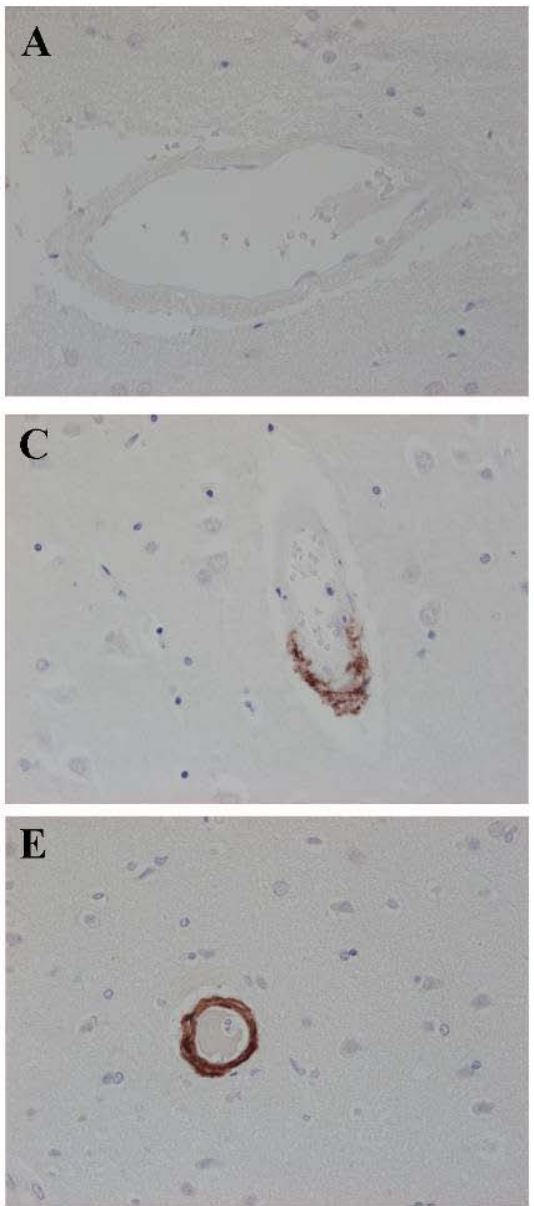

NT244
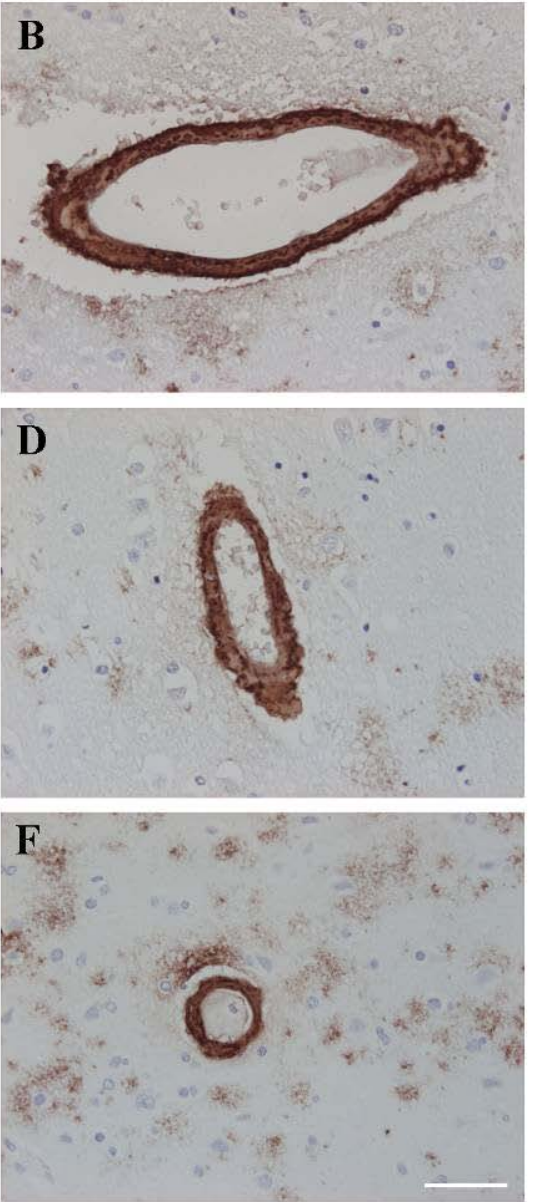

Fig. 16 Comparative CAA staining of 9D5 versus NT244: NT244 stained all blood vessels and always covered the entire vessel area (B, D, F). In contrast, 9D5 stained none of the vessel (A), part of the vessel area (C) or, very rarely, the entire vessel area $(\mathrm{E})$. Scale bar $=50 \mu \mathrm{m}$. 


\subsubsection{Quantitative analysis of blood vessels stained by diverse $A \beta$ - specific antibodies}

Tissues from all 13 cases which demonstrated CAA staining with the 9D5 antibody in the initial screening were further analyzed in detail. Analysis of the staining intensity was performed using different antibodies targeting the $\mathrm{N}$-terminus $(\mathrm{A} \beta 1-\mathrm{x})$ or $\mathrm{C}$-terminus of $\mathrm{A} \beta$ $(A \beta x-40)$, generic $A \beta$ and the linear $N$-terminus of pyroglutamate $A \beta(A \beta p E 3-x)$. In addition, the monoclonal antibody OC was used. The OC antibody is also a conformation dependent antibody and detects fibrillar oligomers.

All antibodies besides the 9D5 showed a comparable immunoreactivity for the blood vessel area (Fig. 17 A-F). A significant difference compared to the 9D5 staining intensity was discovered in all other antibodies. 9D5 staining covered only 37\% of the blood vessel area in comparison to $73 \%$ for $2-48$; $80 \%$ for NT244; $81 \%$ for $A \beta[N]$; $84 \%$ for $\mathrm{G} 2-10$ and $79 \%$ for OC (Fig. 17 G). 

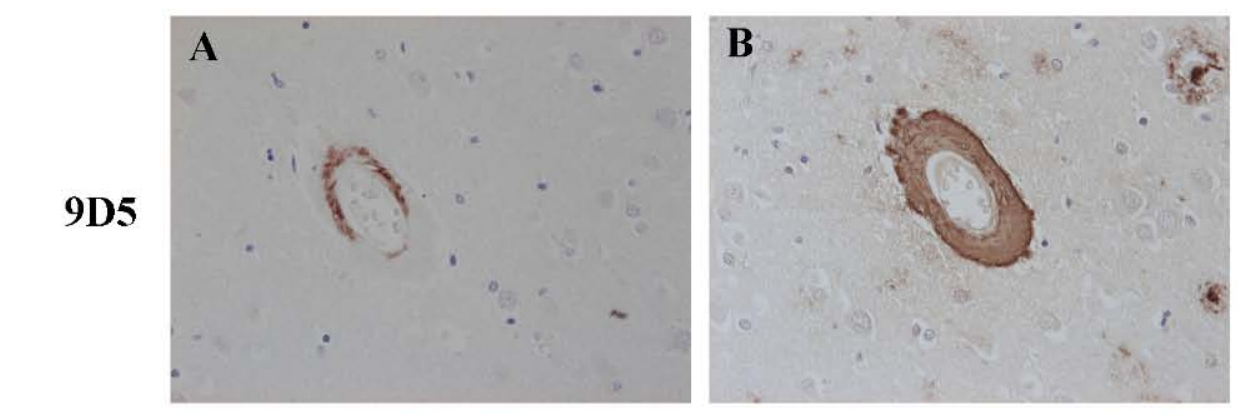

\section{2-48}
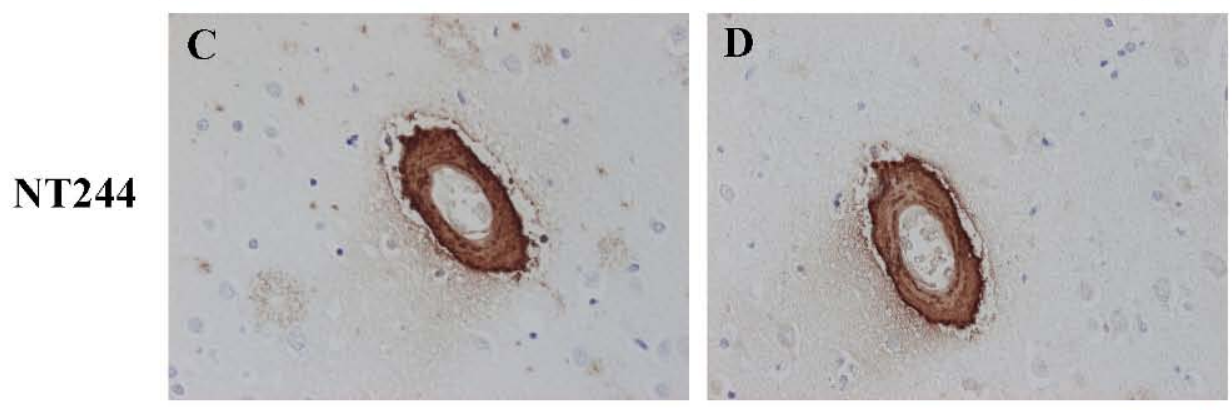

\section{Abeta[N]}
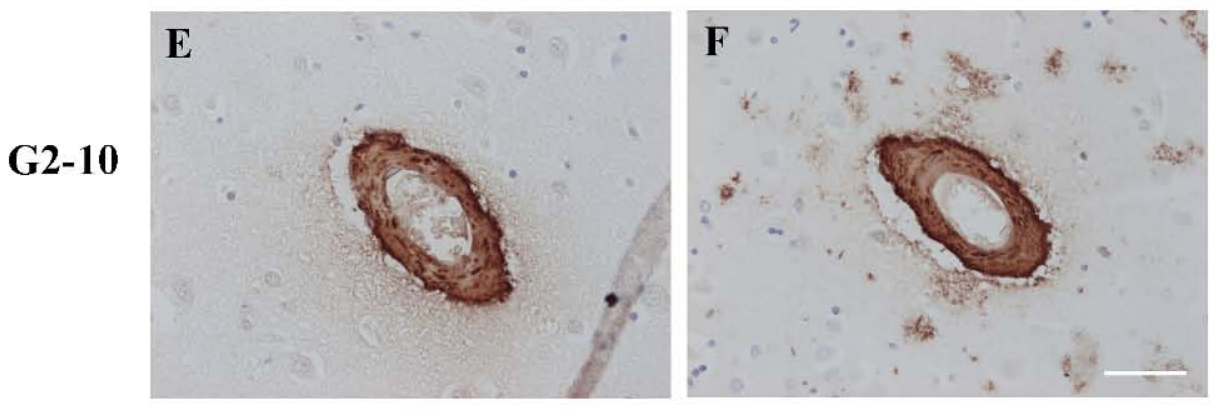

OC

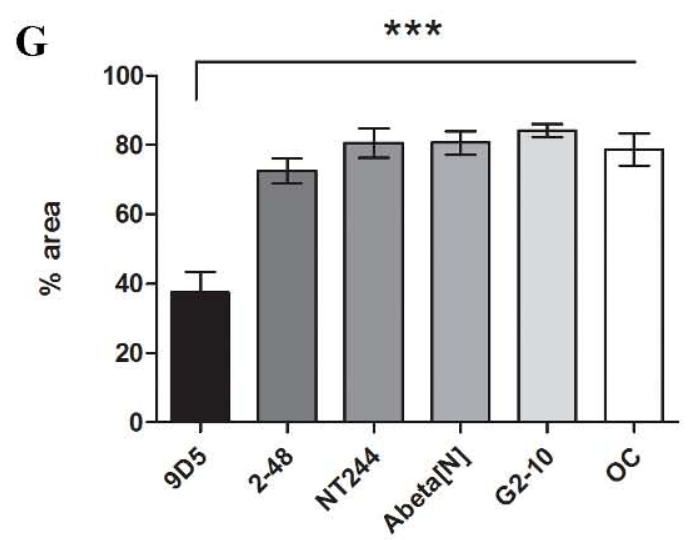

Fig. 17 Representative images of various $A \beta$ antibodies staining CAA and quantitative analysis of positively stained areas in blood vessels: (A-F) 9D5 only partially stained the vessel area, while all other antibodies stained the entire area with 2-48 against N-terminus of pyroglutamate A $\beta$ (B); NT244 against generic $\mathrm{A} \beta(\mathrm{C})$; Abeta[N] targeting the N-terminus $\mathrm{A} \beta 1-\mathrm{x}(\mathrm{D})$; G2-10 against C-terminus of $\mathrm{A} \beta \mathrm{x}-40$ (E) and $\mathrm{OC}$ that selectively labels amyloid fibrils (F). Quantitative analysis of the stained blood vessel showed a significant reduction in the staining intensity of the 9D5 compared to all other antibodies (G). All error bars represent SEM, One-way-ANOVA; ${ }^{* * *}, p<0.001$. Scale bar $=50 \mu \mathrm{m}$. 


\subsection{Project III: Study of synuclein and $A \beta$ interaction in the cortex of 5XFAD mice}

An increasing number of reports demonstrated an overlapping pathology of AD and PD, termed as dementia with Lewy-bodies (DLB) (Lippa et al., 2007). Patients with DLB typically exhibited a more aggressive disease course and more pronounced cognitive dysfunction than patients with pure AD (Hansen et al., 1990; Kraybill et al., 2005). Furthermore, studies in transgenic mice supported the hypothesis that $\alpha$-synuclein and A $\beta$ interact and may enhance aggregation of each other (Masliah et al., 2001; Clinton et al., 2010). Therefore, studying the effects of synuclein and $A \beta$ coexpression provides the possibility to gain more insight into the pathogenic processes of DLB.

The objective of this study was to establish the procedure of stereotactic injection of synuclein AVV-constructs into the brains of 5XFAD mice and analyze the developing pathology pattern. Injections were performed into the frontal cortex targeting the fifth cortical layer, an area that has been shown to exhibit a high abundance of intracellular $A \beta$ in the 5XFAD mouse model (Jawhar et al., 2012). The question raised by this project was whether an additional expression of synuclein variants might lead to the development of Lewy-bodies in the neurons harboring intraneuronal $A \beta$ and if the synuclein overexpression influences the $\mathrm{A} \beta$ pathology in the mice.

\subsubsection{Establishment of stereotactic injection of AVV into mouse brain}

In initial experiments, stereotactic surgery was established in the laboratory. To control the accuracy of injection and the distribution of the virus in the cortex, EGFP fluorescence signal was checked for each injected mouse.

EGFP signal from the virus was mainly found localized to the injection site (Fig. 18 A). In rare cases, a more widespread distribution could be seen. Virus expression occurred in neurons throughout all layers of the cortex (Fig. 18 B). 

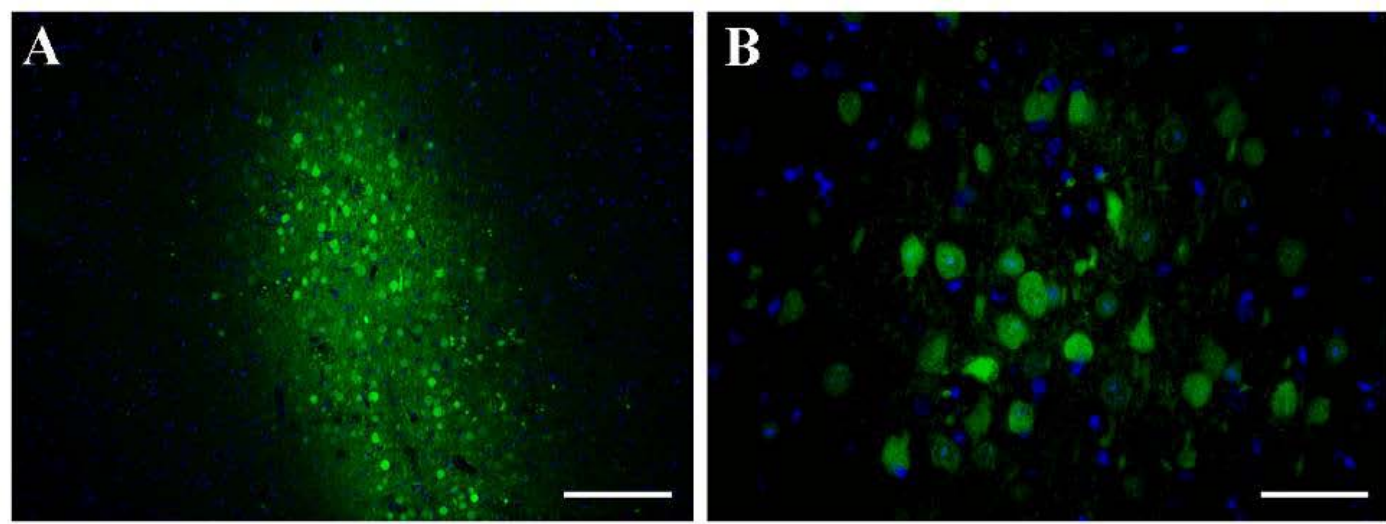

Fig. 18 Representative images of the expression pattern of injected AVV in the frontal cortex of 5XFAD mice: EGFP signal was found mainly localized around the injection site in the frontal cortex of the mice (A). Virus expression occurred intraneuronaly (B). Scale bars $=500 \mu \mathrm{m}$ (A); $50 \mu \mathrm{m}$ (B).

\subsubsection{Analysis of specificity of synuclein antibody used in the study}

In order to rule out cross-reactivity of the human-specific synuclein antibody LB509 with the endogenous murine-synuclein or $\beta$-synuclein, sections from injected and uninjected 5XFAD mice were stained. In addition, antibody reactivity for the $\alpha$-synuclein A30P mutant was confirmed. The LB509 antibody specifically detected both $\alpha$-synuclein WT and the A30P mutant (Fig. 19 A, B). No positive immunoreaction was seen for $\beta$-synuclein injected mice (Fig. 19 C). Also, cross-reactivity was not detected with murine synuclein in uninjected 5XFAD mice (Fig. 19 D).

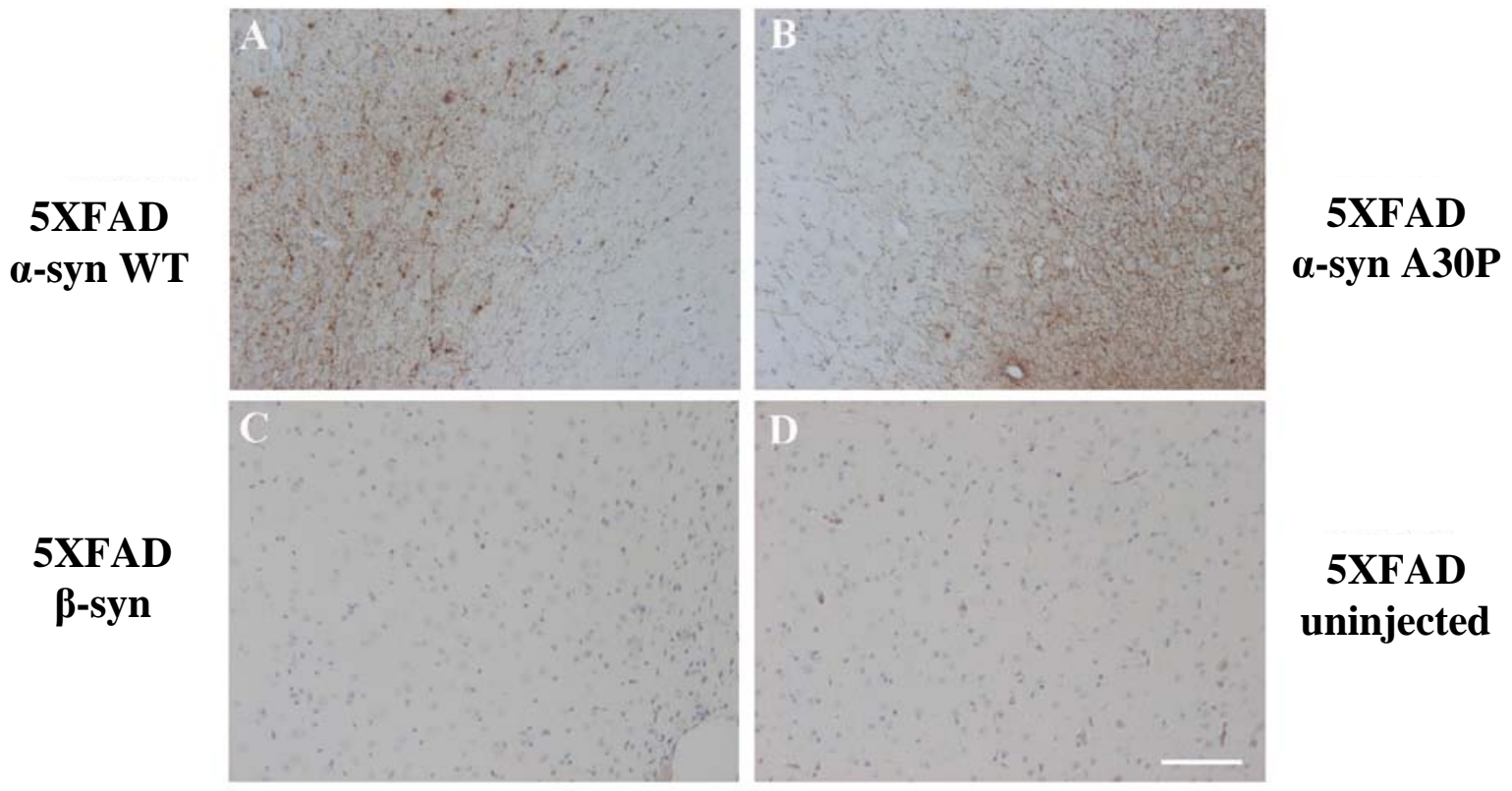

Fig. 19 Analysis of LB509 antibody specificity: Positive immunoreactivity was only seen in $\alpha$-synuclein injected mice (A, B). No staining was detectable in $\beta$-synuclein injected mice or uninjected 5XFAD mice (C, D). Scale bar $=100 \mu \mathrm{m}$. 


\subsubsection{Expression of different synuclein variants in 5XFAD and wild-type mice}

The aim of this study was to analyse the aggregation pattern of $\alpha$ - and $\beta$-synuclein variants overexpressed in the cortex of 5XFAD mice. Therefore, sections of AAV injected animals were stained with the LB509 antibody. Furthermore, $\beta$-synuclein aggregation was studied with an antibody specific for human $\alpha$ - and $\beta$-synuclein.

Synuclein aggregation could be seen in the form of Lewy neurites in $\alpha$-synuclein WT and $\alpha$-synuclein A30P injected 5XFAD mice. No Lewy body formation was seen in injected mice (Fig. 20 A, B, D, E). In the cortices of $\beta$-synuclein injected 5XFAD mice, no aggregation was seen (Fig. 20 C, F). No obvious differences in the severity or formation of neuritic aggregates between both synuclein variants were detected.

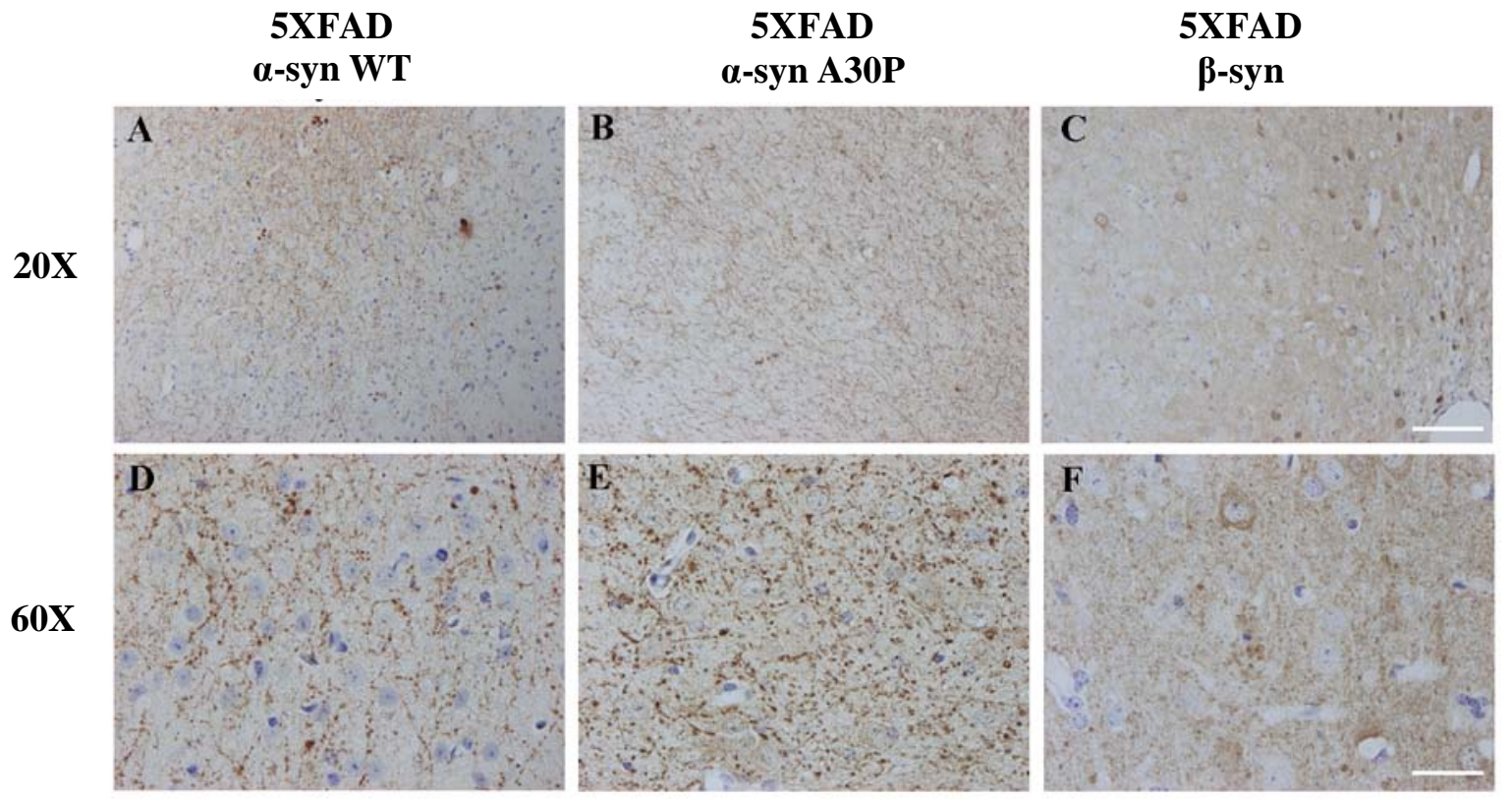

Fig. 20 Representative images of the cortices of 5XFAD mice injected with different synuclein variants: Sections were stained with LB509 antibody (A, B, D, E) and a $\beta$-synuclein specific antibody (C, F), respectively. Lewy neurites were detected in $\alpha$-synuclein WT (A, D) and $\alpha$-synuclein A30P (D, E) injected 5XFAD mice. Cortices of $\beta$-synuclein injected 5XFAD mice displayed no aggregation $(\mathrm{C}, \mathrm{F})$. Scale bars $=100 \mu \mathrm{m}(\mathrm{A}-\mathrm{C})$; $33 \mu \mathrm{m}(\mathrm{D}-\mathrm{F})$.

In order to control if the aggregation pattern seen for $\alpha$-synuclein is dependent on the AD pathology of the 5XFAD mice, non-transgenic mice were also analyzed. The three synuclein variants where therefore injected into the frontal cortex of WT animals using the same coordinates as in the 5XFAD mice. 
Immunohistological analysis revealed a similar picture as seen in the 5XFAD injected mice. Aggregation was only detectable for the $\alpha$-synuclein WT and A30P mutant (Fig. 21 D, E). Aggregation patterns were similar for both $\alpha$-synuclein variants in the mice. No neuritic pathology was detectable in the $\beta$-synuclein injected WT animals (Fig. 21 C, F).

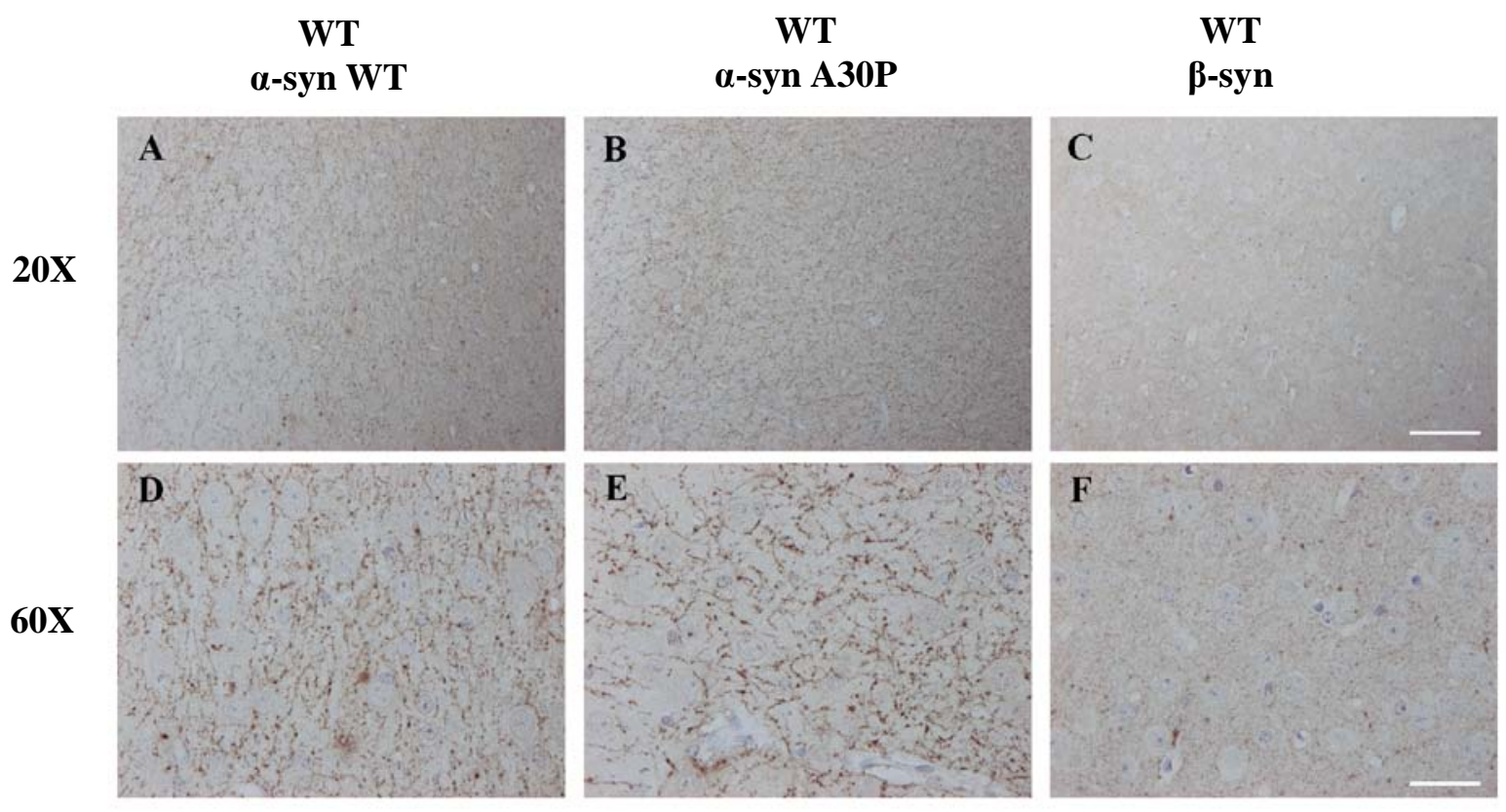

Fig. 21 Representative images of the expression of different synuclein variants in WT mice: Sections were stained with LB509 antibody (A, B, D, E) and a $\beta$-synuclein specific antibody (C, F), respectively. Lewy neurits were detected in $\alpha$-synuclein WT (A, D) and $\alpha$-synuclein A30P (D, E) injected WT mice. Cortices of $\beta$-synuclein injected WT mice displayed no aggregation (C, F). Scale bars $=100 \mu \mathrm{m}(\mathrm{A}-\mathrm{C}) ; 33 \mu \mathrm{m}(\mathrm{D}-\mathrm{F})$.

\subsubsection{Colocalization analysis of $\alpha$-synuclein aggregates with APP and $A \beta$}

It has been shown in previous studies that $\alpha$-synuclein and $\mathrm{A} \beta$ might interact with each other. An analysis of the localization of both proteins in the injected mice was therefore conducted. Immunofluorescent double-labeling revealed only a partial overlap of $\alpha$-synuclein with APP (Fig. 22). Furthermore, $\alpha$-synuclein showed no colocalization with A $\beta$. As determined by immunofluorescent double-labeling, $\alpha$-synuclein was found mainly in dystrophic structures surrounding plaques (Fig. 23). 


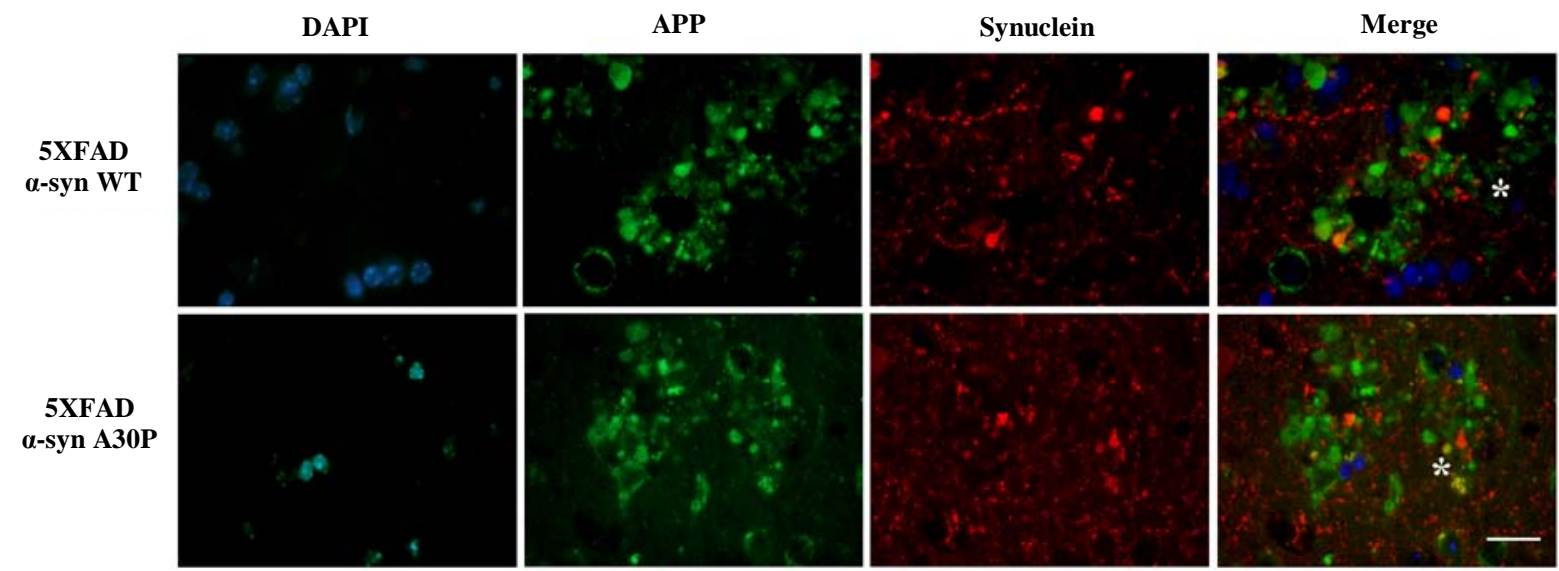

Fig. $22 \alpha$-synuclein WT and $\alpha$-synuclein A30P only partially colocalize with APP in injected 5XFAD mice: Immunofluorescent double-labeling in $\alpha$-synuclein injected mice revealed only partial colocalization of synuclein protein and APP in some dystrophic neurites (yellow, indicated by asterisk). Antibodies against APP (23850, green) and $\alpha$-synuclein (LB509, red) were used with DAPI counterstaining (blue). Scale bar $=20 \mu \mathrm{m}$.

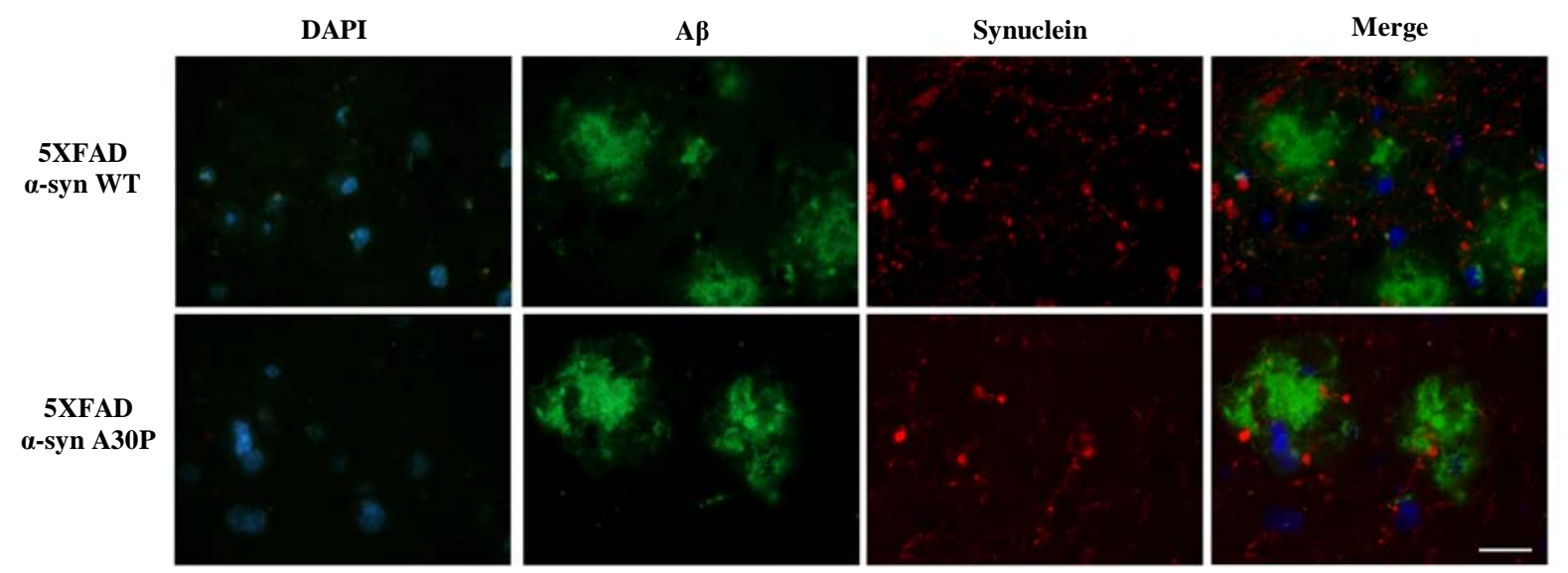

Fig. $23 \alpha$-synuclein WT and $\alpha$-synuclein A30P show no colocalization with A $\beta$ in injected 5XFAD mice: Immunofluorescent double-labeling of $\alpha$-synuclein variants and $A \beta$ displayed no colocalization of both proteins. Antibodies against $\mathrm{A} \beta(\mathrm{A} \beta[\mathrm{N}]$, green) and $\alpha$-synuclein (LB509, red) were used with DAPI counterstaining (blue). Scale bar $=20 \mu \mathrm{m}$.

\subsubsection{No influence of synuclein expression on extracellular plaque deposition in 5XFAD mice}

To assess the influence of synuclein overexpression on the $A \beta$ pathology, cortical plaque load was compared between $\alpha$-synuclein A30P and $\beta$-synuclein injected mice and non-injected mice. Sections were stained with four different $A \beta$ antibodies detecting either overall $A \beta$ (IC16), $A \beta 1-x(A \beta[N]), A \beta x-40$ (G2-10) or $A \beta x-42$ (G2-11) peptides. No significant differences were observed in the overall $A \beta$ load in the cortex of 5XFAD- $\alpha$-syn A30P (6.77 $\pm 0.96 \%), 5 X F A D-\beta$-syn $(6.97 \pm 1.52 \%)$ and non-injected 5XFAD mice (7.13 \pm 
0.76\%) (Fig. 24 A). Additionally, deposition of A $\beta 1-x$ plaques was not affected by synuclein overexpression (Fig. 24 B; 5XFAD- $\alpha$-syn A30P (1.90 \pm 0.52\%), 5XFAD- $\beta$-syn (2.26 \pm $0.44 \%)$ and non-injected 5XFAD mice (2.42 $\pm 0.38 \%))$.

C-terminal specific antibodies yielded similar results (Fig. $24 \mathrm{C}$ and D). A $\beta \mathrm{x}-40$ plaque load remained the same in all three groups (5XFAD- $\alpha$-syn A30P (3.93 $\pm 0.46 \%$ ), 5XFAD- $\beta$-syn (5.38 $\pm 0.09 \%)$ and non-injected 5XFAD mice $(4.98 \pm 1.29 \%)$ ). Also, A $\beta \mathrm{x}-42$ plaque load comparison showed no significant changes between the mice (5XFAD- $\alpha$-syn A30P (5.25 $\pm 1.03 \%)$, 5XFAD- $\beta$-syn (4.73 $\pm 0.46 \%)$ and non-injected 5XFAD mice (4.56 \pm $0.60 \%))$.

A

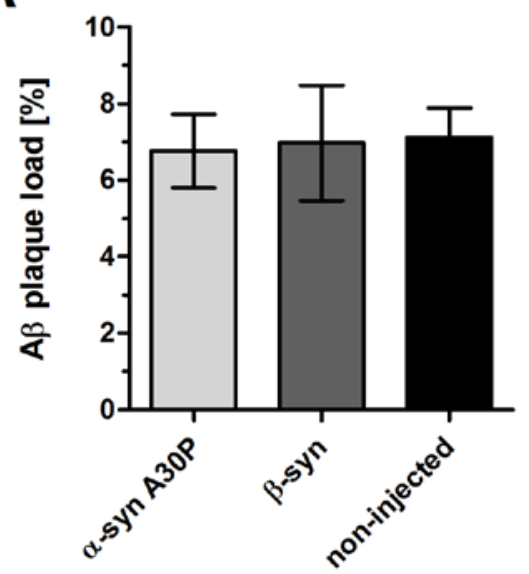

C

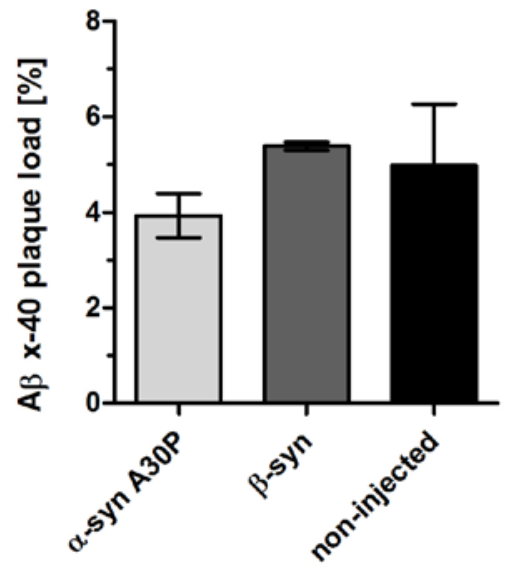

B

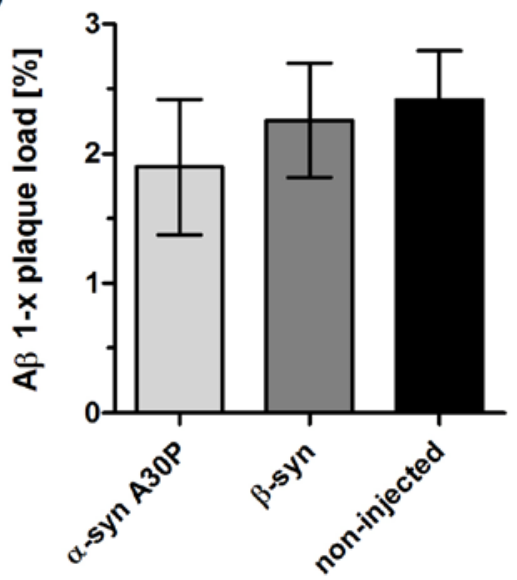

D

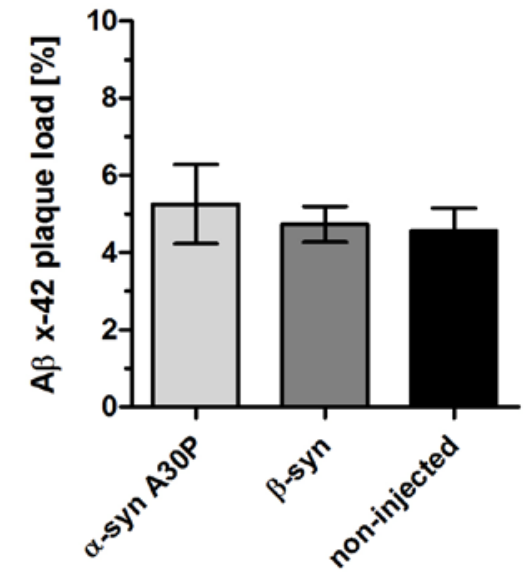

Fig. 24 Plaque load analyses revealed no differences between injected and non-injected 5XFAD groups: No changes could be detected in cortical deposition of overall $A \beta(\mathrm{IC} 16, \mathrm{~A}) ; \mathrm{A} \beta 1-\mathrm{x}(\mathrm{A} \beta[\mathrm{N}], \mathrm{B}) ; \mathrm{A} \beta 40(\mathrm{G} 2-10$, $\mathrm{C})$ and $\mathrm{A} \beta 42$ (G2-11, D) comparing $\alpha$-synuclein A30P, $\beta$-synuclein injected and non-injected mice. All error bars represent SEM. One-way ANOVA. $n=3$ (5XFAD- $\alpha$-syn A30P), 3 (5XFAD- $\beta$-syn) and 4 (5XFAD-noninjected). 


\section{Discussion}

\subsection{Project I: Chronic ibuprofen treatment in the 5XFAD mouse model}

The aim of this project was to study the influence of ibuprofen treatment on the pathology of the 5XFAD mouse model. Therefore, the first step was to characterize the agedependent inflammatory changes. Based on that, mice were treated from 3-6 months of age and studied in terms of pathology progression and cognitive changes.

\subsubsection{Inflammatory processes in the 5XFAD mouse model}

The 5XFAD mouse model develops an age-dependent pathology similar to the human situation. Plaque deposition is already seen at the age of 2-3 months and accelerates in an agedependent manner. Behavioral changes start to appear at 6 months of age in the form of spatial working memory impairment and reduced anxiety. Later on, motor deficits can also be observed (Jawhar et al., 2012).

Correlating with the marginal plaque deposition and the absence of behavioral impairments, no prominent changes in inflammatory markers were observed at the age of 3 months in the transgenic mice. Only Tlr-2, CD11B and CathD were significantly increased in comparison to age-matched WT animals.

The upregulation of these markers might indicate an early microglial activation in the mice, as CD11B is a well-known marker for activated microglia, and CathD has been shown to play a role in the mediation of microglial neurotoxicity (Akiyama et al., 2000; Kim et al., 2007). In addition, in vitro and in vivo experiments also indicated that Tlr-2 promotes microglia activation by A $\beta$ peptides (Jana et al., 2008). However, the cytokine IL-10 was strongly decreased in 3-month-old 5XFAD mice. IL-10 is an anti-inflammatory cytokine known to suppress inflammatory processes induced by $\mathrm{A} \beta$ deposition (Szczepanik et al., 2001). The down-regulation of this marker could indicate that the neuroinflammation in the 5XFAD mice is not well advanced and therefore IL-10 is not yet activated.

In 6-month-old 5XFAD mice, an activation of a broad range of microglial and astroglial markers was detected. The most prominent increase was in the expression level of 
the GFAP astrocytic marker, which was around 30-times higher in 5XFAD mice compared to WT animals.

Astrocytes have various functions such as the biochemical support of endothelial cells of the blood brain barrier (BBB), supplying nutrients to nervous tissue and maintenance of extracellular ion balance. Activated astrocytes produce chemokines, cytokines, and reactive oxygen species known to promote neuronal damage (Akiyama et al., 2000). Activation of astrocytes can be induced by amyloid plaque deposition. In brains of human AD patients, activated astrocytes occur predominantly around plaques (Dickson, 1997). The strong association of astrocytes with $A \beta$ plaques led to the hypothesis that astrocytes are also involved in the degradation and phagocytosis of $A \beta$. This point was further supported by studies showing A $\beta$ immunoreactive material within astrocytes (Nagele et al., 2003; Pihlaja et al., 2008).

In 6-month-old 5XFAD mice, markers for activated microglia, like F4/80 and MCSFR, were significantly upregulated. In addition, expression levels of CD11B and CathD, which were already increased at 3 months of age, were further raised in 6-months-old 5XFAD mice. This indicates the development of an abundant microgliosis in 5XFAD mice.

Microglia are the resident immunocompetent cells and mostly composed of mesodermally derived macrophages. They coordinate the inflammatory response in the CNS (Kato et al., 1996). In a healthy brain, microglia exhibit a deactivated state that is characterized by low expression of surface receptors, minimal secretory activity and minimal migratory behavior when in contact with astroglia or neurons (Giulian, 1999). A $\beta$ is capable of inducing an active phenotype in the microglia, resulting in proliferation of microglia and their accumulation around $A \beta$ deposits (Bolmont et al., 2008). It is assumed that activated microglia phagocytose $A \beta$, limiting the progression of amyloid deposits in the brain (Chen et al., 2006; Herber et al., 2007). On the other hand, activation of microglia is characterized by the secretion of various inflammatory cytokines and chemokines, reactive-oxygen species and complement factors, thereby inducing inflammatory processes in the brain (Akiyama et al., 2000).

Analysis of proinflammatory cytokine expression revealed an increase of IL-1 $\beta$ and TNF $\alpha$, but not IL-6, in the 6-month-old 5XFAD mice. IL-1 $\beta$ is abundantly expressed in human $\mathrm{AD}$ brain tissue and protein levels are found to be increased in homogenates from frontal cortex, parietal cortex, temporal cortex, hypothalamus, thalamus and hippocampus in AD patients in comparison to healthy controls (Cacabelos et al., 1994; Sheng et al., 2001). IL- 
$1 \beta$ expression is linked to plaque-associated microglia. Chronic overexpression of IL- $1 \beta$ seems to contribute to the neuropathological changes in $\mathrm{AD}$ as it has been shown to upregulate the expression and processing of APP (Buxbaum et al., 1992; Mrak and Griffin, 2001).

$\mathrm{TNF} \alpha$ also belongs to the group of proinflammatory cytokines. It regulates diverse processes coupled to cell viability, gene expression, synaptic integrity and ion homeostasis (Frankola et al., 2011). Its pathophysiological role is controversial, as studies reported neurotoxic effects as well as neuroprotective functions (Zhao et al., 2003; Orellana et al., 2007).

IL-6 is a pleiotropic cytokine that mediates immune responses and inflammatory reactions affecting CNS cell growth and differentiation (Akiyama et al., 2000). It is expressed during development in the nervous system and strongly induced under pathological conditions (Vallières and Rivest, 1997). Interestingly, IL-6 has also been suggested to play a role in the regulation of neuronal survival and function (Akiyama et al., 2000). Examination of AD brains revealed a strong immunostaining of IL-6 around plaques as well as around large cortical neurons (Strauss et al., 1992).

The unchanged expression of IL-6 in the 5XFAD mouse is surprising, as it has been hypothesized that levels of proinflammatory cytokines are dependent on the degree of plaque deposition in the brain (Patel et al., 2005). However, a study in APP/PS1KI mice also revealed unchanged interleukin expression levels in the transgenic mice, despite exhibition of a strong plaque pathology (Wirths et al., 2010b).

Moreover, the analysis of the inflammatory cytokine IL-10 demonstrated a strong increase at the age of 6 months in the 5XFAD mice. The major function of IL-10 is to limit inflammation by reducing proinflammatory cytokine synthesis, suppressing cytokine receptor expression and inhibiting receptor activation (Strle et al., 2001). The upregulation of this marker further underlines the severity of inflammatory processes ongoing in the 5XFAD model.

In addition, expression levels of toll-like receptors have been studied in the 5XFAD mice. At 6 months of age Tlr-2, Tlr-7 and Tlr-9 were significantly elevated in comparison to WT mice, while Tlr-4 remained unaltered. Tlrs are pattern recognition receptors in the innate immune system of the brain and respond to pathogenic insults and damaged host cells by activation of phagocytes and dendritic cells, leading to secretion of chemokines and cytokines. They secrete molecules for protective immune responses, efficient clearance of damaged tissues and activating adaptive immunity (Tahara et al., 2006). 
Transcription levels of Tlr-2 and Tlr-7 have been shown to be increased in the AD mouse model TgCRND8 in comparison to age-matched controls, while Tlr-4 was unchanged (Letiembre et al., 2009), supporting observations in the current study. Interestingly, Tlr expression has been recently associated with microglial activation. Fibrillar $A \beta$ deposition seems to stimulate a "host defense" mechanism, resulting in proinflammatory activation of microglia (Landreth and Reed-Geaghan, 2009). Interestingly, it was also shown that microglia (BV-2 cell) activation with ligands for Tlr-2, Tlr-4 or Tlr-9, markedly boosted ingestion of A $\beta$ in vitro (Tahara et al., 2006), also supporting a neuroprotective feature of Tlr upregulation.

The 5XFAD mouse model displays a robust activation of astroglial and microglial markers, similar to findings in other transgenic mouse models (Benzing et al., 1999; Gordon et al., 2002; Köhler et al., 2005; Wirths et al., 2010b). In addition to this, the mouse model has been shown to display a pathology development similar to the human situation including severe plaque pathology, cognitive decline and neuron loss. Therefore, the 5XFAD mouse model can be considered a suitable model to study the effect of anti-inflammatory interventions.

\subsubsection{Ibuprofen treatment reduces gliosis in the 5XFAD mouse model}

Based on the previous findings, treatment with ibuprofen began at 3 months of age, as this seems to be the time point were pathology development begins, and lasted until 6 months of age.

Three month treatment with ibuprofen resulted in a decrease of inflammation in the 5XFAD mice, confirming the anti-inflammatory activity of ibuprofen and the effectiveness of the treatment paradigm. A reduction in the number of GFAP and Iba- 1 positive cells was observed in the cortex and hippocampus of ibuprofen treated 5XFAD mice, accompanied by diminished expression of interleukins (IL-6 and IL-10) and microglial and astroglial markers, such as MCSF-R and GFAP, respectively.

These results are in good agreement with previous ibuprofen studies. In the Tg2576 mouse, an oral ibuprofen treatment with similar dosing led to a decrease of IL-1 $\beta$ levels and diminished the proliferation of activated microglia associated with plaques (Lim et al., 2000). Additionally, in the R1.40 mouse model, a reduction in oxidative stress was reported after ibuprofen treatment (Wilkinson et al., 2010).

Interestingly, the monocyte-chemoattractant protein 1 (MCP-1) protein level was strongly decreased in the treated mice. MCP-1 has been associated with the recruitment of astrocytes to the $A \beta$ deposits, enhancing their degradation (Wyss-Coray et al., 2003). The 
cellular source of MCP-1 in the AD brain is not clear. In vitro experiments showed that neonatal astrocytes from various species stimulated with A $\beta 1-42$ produced MCP-1 (Johnstone et al., 1999). However, contradicting results were found in vivo: no MCP-1 production could be detected in plaque associated astrocytes in an AD mouse model (Mehlhorn et al., 2000), but MCP-1 immunoreactivity was found in astrocytes of AD patients (Sokolova et al., 2009).

The strong parallel decrease of both the astroglial marker GFAP and the MCP-1 protein levels in the current study argues further for astrocytes as the main source of MCP-1.

\subsubsection{XFAD mutations attenuate $A \beta 42$ lowering activity of ibuprofen}

In addition to their anti-inflammatory properties, a subgroup of NSAIDs is also able to directly influence APP processing through $\gamma$-secretase modulation. The exact mechanism is not fully understood, but analyses suggested that NSAIDs directly interact with the $\gamma$ secretase complex. Small molecules with this activity have now been termed $\gamma$-secretase modulators (GSM) (Czirr and Weggen, 2006).

In cell based assays, treatment with either ibuprofen, sulindac sulfide or indomethacin lead to a $70-80 \%$ reduction of the amyloidogenic $A \beta 42$ peptides with a parallel increase of the less toxic $\mathrm{A} \beta 38$ peptides, while $\mathrm{A} \beta 40$ levels remained unchanged. This effect was independent of the inhibition of the COX enzymes (Weggen et al., 2001). These findings were corroborated by in vivo data demonstrating that ibuprofen, sulindac and indomethacin also reduced A $\beta 42$ levels in the brains of transgenic mice (Eriksen et al., 2003).

Recently, it has been shown that PS1 mutations can modulate the A $\beta 42$-reducing effects of NSAIDs. Overexpression of the PS1 mutation M146L enhanced the A $\beta 42$ reduction, while the PS1 $\triangle$ Exon9 mutation strongly diminished the $A \beta 42$ response in a cell culture assay using sulindac sulfide treatment (Weggen et al., 2003). Several aggressive PS1 mutations, causing early onset of $\mathrm{AD}$, have been identified to be less sensitive towards the Aß42 lowering effect of NSAIDs (Czirr et al., 2007; Page et al., 2008). This insensitivity was also confirmed in vivo, in a mouse model of $\mathrm{AD}$ with transgenic expression of mutant PS2, which was entirely resistant to treatment with high doses of a potent GSM (Page et al., 2008).

Importantly, a systematic cell culture study revealed that the PS1 double-mutation (M146L/L286V) present in the 5XFAD model, attenuates the $A \beta 42$ reducing activity of the potent GSM BB25 (Hahn et al., 2011). In the current study, dose response experiments using CHO cells with stable expression of the 5XFAD mutations confirmed the expected insensitivity of the cells towards the A $\beta 42$ lowering activity of ibuprofen. This, together with 
the pathology seen in the 5XFAD mice, prompted the use of this model to study the effects of ibuprofen independent of its $\gamma$-secretase-modulating features.

\subsubsection{Ibuprofen treatment influences $A \beta$ levels but not the deposition in the 5XFAD mouse}

Overall $A \beta$ and $A \beta 42$ plaque load were unaffected in 5XFAD mice after 3 months of oral ibuprofen treatment. This is in strong contrast with earlier reports in which oral ibuprofen treatment for 4 to 6 months in the Tg2576 model of AD with transgenic expression of Swedish-mutant APP resulted in dramatic reductions (50\%-60\%) of the number and area of A $\beta$ deposits (Lim et al., 2000; Yan et al., 2003). Another study in APP transgenic mice with the Swedish and London mutations treated with ibuprofen for 6 months showed only nonsignificant reductions for $A \beta$ plaque area and number but reported a $60 \%$ reduction in insoluble, FA-extractable $\mathrm{A} \beta 42$ in female animals compared with the vehicle-treated group (Imbimbo et al., 2009).

Two previous studies investigated ibuprofen treatment in double-transgenic mice expressing mutant APP and PS1. Ibuprofen treatment for 6 months in mice expressing Swedish-mutant APP and the PS1- M146L mutation resulted in a reduced plaque load of 20\%- 25\% (Jantzen et al., 2002).

Taking into account, the unchanged extracellular plaque deposition, it is no surprise that SDS and formic acid soluble $A \beta 40$ and $A \beta 42$ levels were not altered after ibuprofen treatment, as plaques represent a major fraction of the insoluble $A \beta$ in the brain. Interestingly, TBS-soluble levels of A $\beta 42$ were increased in the treated 5XFAD mice, while TBS-soluble A $\beta 40$ levels were unchanged.

No increase in soluble $A \beta 42$ levels has been reported in previous studies using ibuprofen treatment in AD mouse models. However, the mouse models studied so far were susceptible to the $\gamma$-secretase modulating effect of ibuprofen.

\subsubsection{Decline in behavioral performance after ibuprofen treatment}

The 5XFAD mouse model harbors a variety of $\mathrm{AD}$ hallmarks similar to the human situation, including motor impairment, memory deficits and changes in anxiety (Jawhar et al., 2012). Changes in behavioral performance after 3 months of ibuprofen treatment were evaluated by assessing motor performance, spatial working memory, anxiety levels and general locomotor activity. 
While 5XFAD mice start to exhibit motor impairments around the age of 9 months, ibuprofen treatment led to an earlier onset of motor deficits, as indicated by decreased performance in the balance beam task in 6-month-old mice.

Furthermore, spatial working memory is affected in the 5XFAD mice. At 6 months of age, a reduction in spatial alternation percentage in the cross maze can be observed in 5XFAD mice in comparison to littermate controls. Interestingly, 5XFAD mice only demonstrate this behavior in the cross-maze, and no changes were reported for the Y-maze. The cross-maze test represents a more complex test, as it consists of four arms instead of three as in the Ymaze. It is therefore more sensitive in detecting memory impairments (Jawhar et al., 2012).

Ibuprofen treatment further aggravated the performance of 5XFAD mice in the cross maze task in comparison to untreated controls. However, the decrease in spatial alternation levels was not strong enough to influence the performance in the Y-maze. It is noteworthy to mention that all mice displayed comparable levels of explorative behavior during the tests, as shown by comparable numbers of arm entries. Reduction in spatial alternation levels was therefore not caused by reduced activity.

The 5XFAD mice display a strongly reduced anxiety level starting from the age of 6 months (Jawhar et al., 2012). Ibuprofen treatment had no influence on anxiety behavior in the mice. Treated mice spent the same amount of time on the open arms of the elevated plus maze as the untreated controls. Correlating well with elevated plus maze behavior, no significant differences were found for the percentage of time spend in the center of the open field.

Interestingly, ibuprofen treated mice demonstrated a reduced locomotor activity percentage in comparison to untreated controls. Reduced activity was also confirmed by trends in distance and speed reduction for the ibuprofen treated group.

The reduced locomotor activity in the open field in ibuprofen treated 5XFAD mice concurs with a previous study in which significantly reduced open field activity, as measured by number of grid crossings, was reported in female Tg2576 mice treated for six months with a similar dose of ibuprofen (Lim et al., 2001). The replication of this behavioral effect and the suppression of inflammatory markers verify the dosing paradigm in the current study and indicate that ibuprofen was centrally effective.

The outcome of behavioral studies suggests that the intervention with ibuprofen did not improve the phenotype in 5XFAD mice and was potentially harmful. 


\subsubsection{Detrimental effects in 5XFAD mice might be caused by increase of soluble Aß42 after gliosis suppression}

The surprisingly worsened behavior in ibuprofen treated 5XFAD mice might be due to the observed elevation of soluble $A \beta 42$ in the mice. The accumulation of soluble $A \beta$ is believed to contribute strongly to the $\mathrm{AD}$ pathology. In $\mathrm{AD}$ patients, the soluble pool of $\mathrm{A} \beta 42$ correlates tightly with disease severity (McLean et al., 1999). Moreover, soluble A $\beta$ oligomers have been demonstrated to inhibit hippocampal long-term potentiation (LTP) and disrupt synaptic plasticity (Lambert et al., 1998; Walsh et al., 2002).

The reasons for the increase of soluble A $\beta 42$ level after ibuprofen treatment are currently unclear. Based on the results of the present study, one could hypothesize that ibuprofen induced the reduction of microglia and astrocytes. This resulted in a diminished phagocytosis of $A \beta$ and thereby caused an increase in soluble $A \beta$.

Microglia have been shown to degrade soluble as well as fibrillar A $\beta$. Mandrekar et al. demonstrated that microglia internalize soluble $A \beta$ through fluid-phase macropinocytosis and degrade it in endo-lysosomal compartments (Mandrekar et al., 2009). Additionally, a study showed evidence for the uptake of fibrillar $A \beta$, as microglia internalized systemically injected amyloid-binding dye in the vicinity of plaques (Bolmont et al., 2008). In addition, astrocytes have been postulated to play a role in $A \beta$ clearance. Mouse astrocytes were able to take up and degrade fibrillar $A \beta$ deposits from brain slices of transgenic animals expressing the human APP (Wyss-Coray et al., 2003).

Importantly, Grathwohl et al. observed a 3- to 4-fold increase of soluble A $\beta 40$ and A 342 levels after microglia ablation in an APP/PS1 mouse model, strongly underlining the role of microglia for clearance of soluble $A \beta$ (Grathwohl et al., 2009).

Furthermore, a general neurotoxic effect of ibuprofen can be excluded. Ibuprofen treatment in similar doses as used in the current study did not lead to behavioral deterioration in a previous experiment with Tg2576 mice. Treatment of Tg2576 mice with ibuprofen resulted in significantly higher mean probe scores in the Morris water-maze performance of Tg2576 mice fed with ibuprofen in comparison to Tg2576 mice fed with control chow. Most importantly, treatment with ibuprofen did not lead to any memory impairment in nontransgenic control mice treated with the same paradigm (Kotilinek et al., 2008). 


\subsubsection{Conclusions of project I}

Based on the results of the current work:

- Three-month-old 5XFAD mice display no prominent changes in inflammatory markers.

- 6-month-old 5XFAD mice show an upregulation of a broad range of inflammatory markers, indicating a strong astrogliosis and microgliosis in the mice.

- Cells with stable expression of the 5XFAD combination of APP and PS1 mutations are resistant to the $\mathrm{A} \beta 42$ lowering activity of ibuprofen.

- A $\beta$ plaque load deposition was not affected by ibuprofen treatment. Interestingly, a strong increase in soluble A $\beta 42$ protein levels was observed, while insoluble levels remained unchanged

- Ibuprofen treatment resulted in the reduction of some inflammatory markers on the RNA and protein level, such as GFAP

- Ibuprofen treatment could not rescue the behavior deficits of the 5XFAD mice. Instead, an aggravation of some behavioral parameters was noted. 


\subsection{Project II: Analysis of oligomeric pyroglutamate Abeta in CAA}

Immunotherapy has gained considerable attention in the last years, as it was shown that active and passive $A \beta$ immunization lower cerebral $A \beta$ levels and improve cognition in animal models of AD (Schenk et al., 1999; Janus et al., 2000). However, severe side effects were observed in animal and human trials. Removal of $A \beta$ plaques resulted in an increase of $A \beta$ in the cerebral blood vessels, hindering the clearance of $A \beta$ from the brain (Weller et al., 2009). Furthermore, microhemorrhages within the brain vasculature have been reported in transgenic mouse models and are believed to be caused by anti-A $\beta$ antibody binding to CAA (Racke et al., 2005). Deposition of amyloid in cerebral blood vessels is believed to result in a loss of smooth muscle cells and to weaken the vessels walls, resulting in cerebral hemorrhages (Maeda et al., 1993). For safer therapeutic approaches, it is therefore necessary to study the association of promising antibodies with the vasculature in the human brain.

Our group has recently developed a conformation-dependent monoclonal antibody, 9D5, which only recognizes low-molecular weight pyroglutamate A $\beta$ oligomers. Sizeexclusion chromatography followed by dot blot analysis revealed that 9D5 does not crossreact with $\mathrm{A} \beta 1-42$ variants (monomers to fibrils) and selectively detects a neoepitope generated by low-molecular weight $\mathrm{A} \beta \mathrm{pE} 3-\mathrm{x}$ oligomers (4-10mer), but not monomers or dimers (Wirths et al., 2010c). Moreover, the 9D5 antibody is specific for A $\beta$. Immunohistochemistry illustrated that 9D5 does not cross-react with aggregated protein deposits of other neurodegenerative diseases, including Pick's disease, Parkinson's disease, dementia with Lewy bodies, frontotemporal lobar degeneration, and Creutzfeldt-Jakob disease (Venkataramani et al., 2012).

Passive immunization with the 9D5 antibody for 10 weeks stabilized the the ADassociated neuropathology and behavioral deficit of the 5XFAD mouse model. This is of special interest, as this antibody detects only a small subpopulation of the $A \beta$ variants present in the 5XFAD mouse brain (Wirths et al., 2010c).

The objective of this study was to further elucidate the staining properties of the 9D5 antibody by assessing its abundance and staining pattern of CAA in sporadic AD cases in comparison to other $A \beta$ antibodies. In addition, a possible correlation between 9D5-positive CAA staining and gender, age, Braak stage and ApoE genotype was studied.

CAA was first assessed using the general A $\beta$ antibody, NT244, to confirm the occurrence of CAA in the cohort. In $24 \%$ of the patients, NT244 positive staining for CAA was found, while only $13 \%$ of the total cases demonstrated 9D5 positive CAA. As the 9D5 
antibody detects a highly specific conformational epitope, the reduced number of CAA cases in comparison to the general $A \beta$ antibody is not unexpected.

Studies with C-terminal specific antibodies have shown that the vascular amyloid is predominantly composed of $A \beta 40$ in contrast to the parenchymal deposits which mostly consist of Aß42 (Gravina et al., 1995; Herzig et al., 2004). In addition, vascular amyloid demonstrated a strong immunoreactivity with antibodies targeting the N-terminus (AßN1) and pyroglutamate A $\beta$ in DS brains (Iwatsubo et al., 1996). Therefore, antibodies targeting general $A \beta$, the N-terminus, the N-terminus of pyroglutamate $A \beta(A \beta p E-x)$, and the Cterminus of $\mathrm{A} \beta 40$ were employed to compare the CAA staining intensity of the 9D5 antibody. In addition, the monoclonal antibody OC against another conformation-dependent $\mathrm{A} \beta$ variant was used.

Quantitative analysis revealed that the 9D5 immunolabeled only a fraction of the total $A \beta$ immunoreactivity that was visualized by the generic antibody NT244. 9D5immunoreactivity only partially overlapped with the other $A \beta$ antibodies, implicating differences in the molecular protein composition of amyloid in CAA. In addition, all other antibodies showed CAA loads of $70-80 \%$, in contrast to 9D5 detecting only approximately $37 \%$.

No conclusive correlation between development of CAA and AD pathology has been found so far. Analysis of CAA and plaque deposition revealed positive and negative results (Thal et al., 2003; Tian et al., 2003). Interestingly, human ApoE4 has been found to promote CAA development in a transgenic mouse model (Fryer et al., 2005). In the present study, the statistical analysis of 99 cases revealed no correlation between 9D5 positive CAA staining and gender, age or Braak stage of the patients. ApoE genotypes were also assessed in particular, but they showed no correlation to the abundance of 9D5 CAA. It should be mentioned that only sections from the gyrus temporalis superior were used in the study. A possible correlation between CAA and AD pathology in other brain regions cannot be excluded.

Taken together, the 9D5 antibody seems to be a promising tool for therapeutic studies. It exhibits a highly specific recognition of an epitope found only in oligomeric assemblies of $\mathrm{A} \beta \mathrm{pE} 3$ and shows no cross-reaction to other aggregated proteins (Venkataramani et al., 2012). Despite the selective binding of only a minor fraction of $A \beta$ deposits, it has been shown to be highly effective in passive immunization (Wirths et al., 2010c). The reduced detection of CAA indicates that passive immunization with 9D5 will likely yield fewer side effects due to possible cerebral hemorrhages in sporadic AD patients. Future passive 
immunization studies of other CAA bearing mouse models, such as the APP23 model, might shed light on this theory.

\subsubsection{Conclusion of project II}

Based on the current work:

- No correlation between 9D5 CAA staining and the gender, age, Braak stage or ApoE genotype of $\mathrm{AD}$ patients was found.

- 9D5 detected fewer instances of CAA in comparison to a general A $\beta$ antibody.

- 9D5-immunoreactivity only partially overlapped the CAA staining pattern of other A $\beta$ antibodies. 9D5 positive CAA load was significantly reduced in comparision to all other antibodies tested. 


\subsection{Project III: Study of synuclein and $A \beta$ interaction in the cortex of 5XFAD mice}

Up to two-thirds of the $\mathrm{AD}$ patients also show a development of Lewy bodies and Lewy neurites, the major pathological hallmarks of PD. Lewy bodies and Lewy neurites are aggregations in the neuronal perikaya and cellular processes and have been shown to consist mostly of aggregated $\alpha$-synuclein. The interaction of $\alpha$-synuclein and A $\beta$ and the impact of $\alpha$ synuclein on pathology progression has been a matter of scientific debate. The objective of this pilot study was to analyze the effect of intracellular $\alpha$-synuclein overexpression on the pathology development in the 5XFAD mouse model.

In initial experiments, the procedure for stereotactic injections of AVV in the mouse cortex was established. Afterwards, synuclein AVV-constructs were injected in to the fifth cortical layer of a small cohort of 5XFAD mice, an area known to have a high abundance of intracellular $\mathrm{A} \beta$.

AVV injections have been established as a valuable tool for targeted gene transfer. Constructs using the hsyn-promoter have been shown to promote long-term gene expression in neurons (Kügler et al., 2003). In the present study, a strong EGFP signal of the injected virus throughout all cortical layers was detectable 3.5 months after injection, underlining the long-term expression efficiency of the hsyn-promoter and the accuracy of the injection.

5XFAD and WT mice were injected with three different constructs overexpressing $\alpha$ synuclein WT, $\alpha$-synuclein A30P and $\beta$-synuclein. The mutant $\alpha$-synuclein A30P, a missense mutation linked to familial $\mathrm{AD}$, has been shown to aggregate into fibrils faster than $\alpha$-syn WT (Narhi et al., 1999). In addition, $\beta$-synuclein injection was used as a negative control, as this synuclein homologue does not occur in Lewy bodies and does not aggregate (George, 2002).

Overexpression of $\alpha$-synuclein WT and $\alpha$-synuclein A30P mutant in the cortex of the 5XFAD mouse resulted in the development of $\alpha$-synuclein positive Lewy-neurites, while no cytoplasmic inclusions, like Lewy bodies, could be seen. No aggregation was found in the $\beta$ synuclein mice. These results indicate that the pathological changes are due to the $\alpha$-synuclein protein rather than just general protein overexpression.

Surprisingly, the same pattern of protein aggregation was also seen in AAV injected WT mice. $\alpha$-synuclein WT and $\alpha$-synuclein A30P injected WT mice exhibited Lewy neurites in the cortex. As expected, no aggregation was found in the $\beta$-synuclein injected WT mice.

No obvious differences in the pattern and severity of aggregation were seen in the $\alpha$ synuclein WT and $\alpha$-synuclein A30P mutant injected groups. It is noteworthy to mention that 
this finding is based on a qualitative analysis of light microscopy pictures. It cannot be excluded that a more detailed structural analysis by electron microscopy could reveal more subtle changes. The occurrence of $\alpha$-synuclein positive neurites in both the transgenic and WT mice indicates that $A \beta$ does not influence the formation of Lewy bodies and Lewy neurites.

Based on recent research data, it has been hypothesized that $A \beta$ and $\alpha$-synuclein have synergistic effects and enhance the aggregation of each other. In vitro studies using nuclear magnetic resonance (NMR) spectroscopy have shown that membrane-assoicated $\alpha$-synuclein interacts with $A \beta 40$ and $A \beta 42$ (Mandal et al., 2006). Furthermore it was demonstrated that aggregation of soluble $\alpha$-synuclein is enhanced by A $\beta 1-42$ in an in vitro cell free system. In this study, it was also shown that under in vitro cell-free conditions $\mathrm{A} \beta$ directly interacts with $\alpha$-synuclein, forming hybrid pore-like oligomers which can alter neuronal activity (Tsigelny et al., 2008).

Double-transgenic $\alpha$-synuclein and APP mice demonstrated an increased deposition of $\alpha$-synulcein in comparison to $\alpha$-synuclein single transgenic mice (Masliah et al., 2001). In addition, overexpression of mutant $\alpha$-synuclein in the 3xTg mouse model resulted in a change of $A \beta$ solubility and accumulation with an dramatic increase in A $\beta 42$ (Clinton et al., 2010). On the other hand, Tg2576 mice overexpressing human $\alpha$-synuclein A53T did not show an enhancement of $\alpha$-synuclein pathology (Emmer et al., 2012).

In the present study, the possible overlap of synuclein and $\mathrm{AD}$ pathology was assessed by employing fluorescent double staining. $\alpha$-synuclein demonstrated an overlap with APP in some dystrophic neurites surrounding plaques.

APP and synuclein are both axonally transported proteins. While APP undergoes fast axonal transport (Koo et al., 1990), $\alpha$-syunclein has been shown to move primarily in the slow components. Only a smaller fraction is transported by fast components in the axons (Jensen et al., 1999). Dystrophic neurites represent axonal swellings harboring abnormal accumulation of microtubule-associated and molecular motor proteins, organelles, and vesicles and develop due to disturbances in the axonal transport system (Stokin et al., 2005).

Contact of both proteins during transport seems unlikely; however, the colocalization of synuclein and APP in axonal swellings might promote a possible interaction.

No colocalization of $A \beta$ and $\alpha$-synuclein was found in the current study. $\alpha$-synuclein aggregation was mostly found in dystrophic neurites surrounding the plaques and no immunoreactivity in plaques was found.

Early studies also reported synuclein immunoreactivity within the plaque cores. However, development of more specific antibodies revised this finding, showing no 
association of $\alpha$-synuclein with mature amyloid plaques (Bayer et al., 1999). Occurrence of synuclein in dystrophic neurites has also been demonstrated by a histological analysis in patients with mixed AD and Lewy body pathology (Wirths et al., 2000).

Additionally, changes in extracellular plaque deposition after synuclein injection were assessed. No effect of $\alpha$-synuclein expression on the amount of extracellular A $\beta$ deposits was found. This stands in contrast to the study by Clinton et al, who reported an increase in plaque deposition in $\alpha$-synuclein overexpressing 3xTg mice in comparison to control animals (Clinton et al., 2010). Furthermore, a study using PET scanning also reported an elevation of amyloid load in patients with DLB (Edison et al., 2008).

5XFAD mice display strong plaque pathology; therefore, it might be possible that the localized expression of $\alpha$-synuclein in the cortex was insufficient to promote changes in extracellular $A \beta$ pathology.

The interaction of $\mathrm{A} \beta$ and $\alpha$-synuclein and possible synergistic effects might be dependent on their aggregation state. Both proteins are able to adopt different conformation states, ranging from soluble monomers/oligomers to insoluble fibrils (Wood et al., 1999; Roychaudhuri et al., 2009).

It should be noted that immuohistochemistry analysis only detects aggregated proteins, and the majority of oligomeric species cannot be directly observed. Effects of $\alpha$-synuclein oligomers as well as the possible interaction with $\mathrm{A} \beta$ oligomers need further elucidation.

Recently, it was shown that a small subset of $\alpha$-synuclein localizes to the lumen of the endoplasmatic reticulum (ER)/microsome in vivo (Colla et al., 2012b). Accumulation of $\alpha$ synuclein oligomers caused chronic ER stress and thereby promoted cell dysfunction (Colla et al., 2012a). Interestingly, the ER also exhibits a high accumulation of $A \beta$ peptides, which have been shown to also induce stress responses (Cook et al., 1997; Ferreiro et al., 2006). Assessment of stress markers, such as caspase activation, chaperone expression and changes in calcium homeostasis might give an indication of whether $\mathrm{A} \beta$ and $\alpha$-synuclein interact on a cellular level.

In summary, this pilot study showed that injection of $\alpha$-synuclein led to development of Lewy neurites in transgenic as well as WT mice. An overlap between AD and $\alpha$-synuclein pathology was only detectable to a minor degree in plaque associated dystrophic neurites, and no changes in $A \beta$ depositions were found. Additional analyses assessing the influence of soluble synuclein peptides on cell stress and apoptosis are necessary to gain further insight into disease mechanisms and the possible interaction of $\alpha$-synuclein with $\mathrm{AD}$ pathology. 


\subsubsection{Conclusion of project III}

Based on the current work:

- The stereotactic injection procedure for AAV injection into the mouse cortex was successfully established.

- Formation of $\alpha$-synulein positive Lewy neurites was observed in transgenic mice as well as in WT mice, while $\beta$-synuclein showed no aggregation formation.

- No obvious differences in the expression pattern and severity of aggregation were observed between $\alpha$-synuclein WT and $\alpha$-synuclein A30P mutant.

- No colocalization of $\alpha$-synuclein with $A \beta$ was found.

- A partial colocalization of $\alpha$-synuclein with APP was found in dystrophic neurites surrounding plaques. 


\section{Summary and Conclusions}

Alzheimer's disease $(\mathrm{AD})$ is the most common neurodegenerative disease in the elderly. It is mainly characterized by the deposition of amyloid plaques and neurofibrillary tangles. In this thesis, additional neuropathological features such as inflammation, amyloid deposition in blood vessels and the interaction of amyloid with other proteins were examined.

Inflammatory processes in the brain are a well described feature of AD. Their contribution to the pathological progression is still under debate. Epidemiological studies have shown that treatment with non-steroidal anti-inflammatory drugs (NSAIDs) leads to a decreased risk of $\mathrm{AD}$. However, the results of pharmacological studies in both mice and humans are inconsistent. In addition to anti-inflammatory activity, a subgroup of NSAIDs, including ibuprofen, has been shown to directly influence $A \beta$ production, leading to the reduction of $A \beta 42$. This raised the question of whether the observed beneficial effects were due to a reduction of $A \beta$ or the influence of the NSAIDs on inflammatory processes. Based on in vitro work, the $5 \mathrm{XFAD}$ mouse model has been shown to attenuate the A $\beta 42$ lowering feature of ibuprofen due to the mutations used. The presence of these mutations therefore makes it possible to study the exclusive effects of ibuprofen on inflammation.

It was thus important to characterize the inflammatory processes in the 5XFAD mouse model in detail as this has not been previously examined. 5XFAD mice displayed only minor inflammation at three months of age. At 6 months of age, an upregulation of a broad range of microglial and astrocyte markers was observed. This validates the suitability of the model for studying anti-inflammatory therapeutics.

5XFAD mice were treated for three months with ibuprofen. As expected, ibuprofen treatment resulted in a decrease in diverse inflammatory markers, suggesting that the treatment paradigm was effective. Surprisingly, ibuprofen treatment resulted in a decline in some behavioral parameters and lead to an increase in soluble $A \beta 42$ levels. No difference in $\mathrm{A} \beta$ plaque deposition was detected between ibuprofen-treated and control mice. Together, these data suggest that suppression of inflammation might not be beneficial for the treatment of $\mathrm{AD}$ as it seems to worsen pathology. This raises the question of whether treatment using NSAIDs without $A \beta 42$ lowering properties is an effective therapeutic strategy.

Accumulation of $\mathrm{A} \beta$ in blood vessels (cerebral amyloid angiopathy, CAA) is a common neuropathological feature of AD. The occurrence of CAA is associated with an increased number of hemorrhages during passive immunizations. It is believed that 
microhemorrhages within the brain vasculature result from direct binding of anti-A $\beta$ antibodies to vascular amyloid. Assessment of antibody association with the vasculature in the human brain is therefore necessary for safer therapeutic approaches.

In the second project, the CAA staining pattern of a new conformation-dependent antibody was assessed. Our group has generated a conformation-dependent monoclonal antibody, 9D5, that selectively recognizes low-molecular weight pyroglutamate A $\beta$ pE3 oligomers, and demonstrated its diagnostic and therapeutic potential. The 9D5 antibody exhibited a unique CAA staining pattern and showed significantly less immunoreactivity in blood vessels relative to all other antibodies tested. This indicates that passive immunization with 9D5 antibodies will likely cause fewer side effects due to possible cerebral hemorrhages in sporadic $\mathrm{AD}$ patients.

$\alpha$-synuclein is considered the main compound of Lewy bodies and Lewy neurites, the major pathological hallmarks of Parkinson's disease. Interestingly, Lewy bodies are found in up to $60 \%$ of $\mathrm{AD}$ cases. The interaction of $\alpha$-synuclein and $\mathrm{A} \beta$ and the impact of $\alpha$-synuclein on pathology progression has been a matter of scientific debate. In the third project, the effect $\alpha$-synuclein overexpression on the pathology development in the 5XFAD mouse model was analyzed in a small pilot study.

As the first step, the procedure of stereotactic injection of adeno associated viruses (AAV) was established in the lab. Later on, overexpression of $\alpha$-synuclein via AAV injection in the cortex of the mice was analyzed. Formation of $\alpha$-synulein-positive Lewy neurites was observed in transgenic mice as well as in WT mice. In addition, a partial colocalization of $\alpha-$ synuclein with APP was found in dystrophic neurites surrounding plaques, while no colocalization of $\alpha$-synuclein with $\mathrm{A} \beta$ was detected. These findings indicate that $\alpha$-synuclein and $\mathrm{A} \beta$ pathology only have very limited overlap and are less likely to interact. However, more detailed analyses of protein aggregation states and changes in cellular processes are necessary to clarify this point. 


\section{Bibliography}

Aisen PS, Schafer KA, Grundman M, Pfeiffer E, Sano M, Davis KL, Farlow MR, Jin S, Thomas RG, Thal LJ (2003) Effects of rofecoxib or naproxen vs placebo on Alzheimer disease progression: a randomized controlled trial. JAMA: the journal of the American Medical Association 289:2819-2826.

Akiyama $\mathrm{H}$ et al. (2000) Inflammation and Alzheimer's disease. Neurobiology of aging 21:383-421.

Allinson TMJ, Parkin ET, Turner AJ, Hooper NM (2003) ADAMs family members as amyloid precursor protein alpha-secretases. Journal of neuroscience research 74:342352.

Arendash GW, Gordon MN, Diamond DM, Austin LA, Hatcher JM, Jantzen P, DiCarlo G, Wilcock D, Morgan D (2001) Behavioral assessment of Alzheimer's transgenic mice following long-term Abeta vaccination: task specificity and correlations between Abeta deposition and spatial memory. DNA and cell biology 20:737-744.

Arnaud L, Robakis NK, Figueiredo-Pereira ME (2006) It may take inflammation, phosphorylation and ubiquitination to "tangle" in Alzheimer's disease. Neurodegenerative diseases 3:313-319.

Arnáiz E, Almkvist O (2003) Neuropsychological features of mild cognitive impairment and preclinical Alzheimer's disease. Acta neurologica Scandinavica Supplementum 179:3441.

Ballard C, Waite J (2006) The effectiveness of atypical antipsychotics for the treatment of aggression and psychosis in Alzheimer's disease. Cochrane database of systematic reviews (Online):CD003476.

Ballatore C, Lee VM-Y, Trojanowski JQ (2007) Tau-mediated neurodegeneration in Alzheimer's disease and related disorders. Nature reviews Neuroscience 8:663-672.

Basun H, Bogdanovic N, Ingelsson M, Almkvist O, Näslund J, Axelman K, Bird TD, Nochlin D, Schellenberg GD, Wahlund L-O, Lannfelt L (2008) Clinical and neuropathological features of the arctic APP gene mutation causing early-onset Alzheimer disease. Archives of neurology 65:499-505.

Baumann K, Mandelkow EM, Biernat J, Piwnica-Worms H, Mandelkow E (1993) Abnormal Alzheimer-like phosphorylation of tau-protein by cyclin-dependent kinases cdk2 and cdk5. FEBS letters 336:417-424.

Bayer TA, Jakala P, Hartmann T, Havas L, McLean C, Culvenor JG, Li QX, Masters CL, Falkai P, Beyreuther K (1999) Alpha-synuclein accumulates in Lewy bodies in Parkinson's disease and dementia with Lewy bodies but not in Alzheimer's disease betaamyloid plaque cores. Neurosci Lett 266:213-216. 
Bayer TA, Wirths O (2010) Intracellular accumulation of amyloid-Beta - a predictor for synaptic dysfunction and neuron loss in Alzheimer's disease. Frontiers in aging neuroscience 2:8.

Benzing WC, Wujek JR, Ward EK, Shaffer D, Ashe KH, Younkin SG, Brunden KR (1999) Evidence for glial-mediated inflammation in aged APP(SW) transgenic mice. Neurobiology of aging 20:581-589.

Bertram L, Lill CM, Tanzi RE (2010) The genetics of Alzheimer disease: back to the future. Neuron 68:270-281.

Birks J (2006) Cholinesterase inhibitors for Alzheimer's disease. Cochrane database of systematic reviews (Online):CD005593.

Blennow K, de Leon MJ, Zetterberg H (2006) Alzheimer’s disease. Lancet 368:387-403.

Bobinski M, Wegiel J, Wisniewski HM, Tarnawski M, Reisberg B, De Leon MJ, Miller DC (1996) Neurofibrillary pathology--correlation with hippocampal formation atrophy in Alzheimer disease. Neurobiology of aging 17:909-919.

Boche D, Nicoll JAR (2008) The role of the immune system in clearance of Abeta from the brain. Brain pathology (Zurich, Switzerland) 18:267-278.

Bolmont T, Haiss F, Eicke D, Radde R, Mathis CA, Klunk WE, Kohsaka S, Jucker M, Calhoun ME (2008) Dynamics of the microglial/amyloid interaction indicate a role in plaque maintenance. The Journal of neuroscience 28:4283-4292.

Bottino CMC, Castro CC, Gomes RLE, Buchpiguel CA, Marchetti RL, Neto MRL (2002) Volumetric MRI measurements can differentiate Alzheimer's disease, mild cognitive impairment, and normal aging. International psychogeriatrics / IPA 14:59-72.

Braak H, Braak E (1991) Neuropathological stageing of Alzheimer-related changes. Acta neuropathologica 82:239-259.

Van Broeckhoven C, Haan J, Bakker E, Hardy JA, Van Hul W, Wehnert A, Vegter-Van der Vlis M, Roos RA (1990) Amyloid beta protein precursor gene and hereditary cerebral hemorrhage with amyloidosis (Dutch). Science (New York, NY) 248:1120-1122.

Buxbaum JD, Oishi M, Chen HI, Pinkas-Kramarski R, Jaffe EA, Gandy SE, Greengard P (1992) Cholinergic agonists and interleukin 1 regulate processing and secretion of the Alzheimer beta/A4 amyloid protein precursor. Proceedings of the National Academy of Sciences of the United States of America 89:10075-10078.

Bäckman L, Jones S, Berger A-K, Laukka EJ, Small BJ (2004) Multiple cognitive deficits during the transition to Alzheimer's disease. Journal of internal medicine 256:195-204.

Cacabelos R, Alvarez XA, Fernández-Novoa L, Franco A, Mangues R, Pellicer A, Nishimura $\mathrm{T}$ (1994) Brain interleukin-1 beta in Alzheimer's disease and vascular dementia. Methods and findings in experimental and clinical pharmacology 16:141-151. 
Chandrasekharan NV, Dai H, Roos KLT, Evanson NK, Tomsik J, Elton TS, Simmons DL (2002) COX-3, a cyclooxygenase-1 variant inhibited by acetaminophen and other analgesic/antipyretic drugs: cloning, structure, and expression. Proceedings of the National Academy of Sciences of the United States of America 99:13926-13931.

Chen F, David D, Ferrari A, Götz J (2004) Posttranslational modifications of tau--role in human tauopathies and modeling in transgenic animals. Current drug targets 5:503-515.

Chen K, Iribarren P, Hu J, Chen J, Gong W, Cho EH, Lockett S, Dunlop NM, Wang JM (2006) Activation of Toll-like receptor 2 on microglia promotes cell uptake of Alzheimer disease-associated amyloid beta peptide. The Journal of biological chemistry 281:36513659.

Citron M, Oltersdorf T, Haass C, McConlogue L, Hung AY, Seubert P, Vigo-Pelfrey C, Lieberburg I, Selkoe DJ (1992) Mutation of the beta-amyloid precursor protein in familial Alzheimer's disease increases beta-protein production. Nature 360:672-674.

Clinton LK, Blurton-Jones M, Myczek K, Trojanowski JQ, LaFerla FM (2010) Synergistic Interactions between Abeta, tau, and alpha-synuclein: acceleration of neuropathology and cognitive decline. The Journal of neuroscience 30:7281-7289.

Colla E, Coune P, Liu Y, Pletnikova O, Troncoso JC, Iwatsubo T, Schneider BL, Lee MK (2012a) Endoplasmic Reticulum Stress Is Important for the Manifestations of $\alpha$ Synucleinopathy In Vivo. The Journal of neuroscience 32:3306-3320.

Colla E, Jensen PH, Pletnikova O, Troncoso JC, Glabe C, Lee MK (2012b) Accumulation of Toxic $\alpha$-Synuclein Oligomer within Endoplasmic Reticulum Occurs in $\alpha$ Synucleinopathy In Vivo. The Journal of neuroscience 32:3301-3305.

Cook DG, Forman MS, Sung JC, Leight S, Kolson DL, Iwatsubo T, Lee VM, Doms RW (1997) Alzheimer's A beta(1-42) is generated in the endoplasmic reticulum/intermediate compartment of NT2N cells. Nature medicine 3:1021-1023.

Corder EH, Saunders AM, Strittmatter WJ, Schmechel DE, Gaskell PC, Small GW, Roses AD, Haines JL, Pericak-Vance MA (1993) Gene dose of apolipoprotein E type 4 allele and the risk of Alzheimer's disease in late onset families. Science (New York, NY) 261:921-923.

Cruts M, Van Broeckhoven C (1998) Presenilin mutations in Alzheimer's disease. Human mutation 11:183-190.

Czirr E, Leuchtenberger S, Dorner-Ciossek C, Schneider A, Jucker M, Koo EH, Pietrzik CU, Baumann K, Weggen S (2007) Insensitivity to Abeta42-lowering nonsteroidal antiinflammatory drugs and gamma-secretase inhibitors is common among aggressive presenilin-1 mutations. The Journal of biological chemistry 282:24504-24513.

Czirr E, Weggen S (2006) Gamma-secretase modulation with Abeta42-lowering nonsteroidal anti-inflammatory drugs and derived compounds. Neurodegenerative Disease 3:298304. 
Davies CA, Mann DM, Sumpter PQ, Yates PO (1987) A quantitative morphometric analysis of the neuronal and synaptic content of the frontal and temporal cortex in patients with Alzheimer's disease. Journal of the neurological sciences 78:151-164.

DeKosky ST, Scheff SW (1990) Synapse loss in frontal cortex biopsies in Alzheimer's disease: correlation with cognitive severity. Annals of neurology 27:457-464.

Delacourte A (1990) General and dramatic glial reaction in Alzheimer brains. Neurology 40:33-37.

Van Den Heuvel C, Thornton E, Vink R (2007) Traumatic brain injury and Alzheimer's disease: a review. Progress in brain research 161:303-316.

Dickson DW (1997) The pathogenesis of senile plaques. Journal of neuropathology and experimental neurology 56:321-339.

Dixit R, Ross JL, Goldman YE, Holzbaur ELF (2008) Differential regulation of dynein and kinesin motor proteins by tau. Science (New York, NY) 319:1086-1089.

Duff K, Eckman C, Zehr C, Yu X, Prada CM, Perez-tur J, Hutton M, Buee L, Harigaya Y, Yager D, Morgan D, Gordon MN, Holcomb L, Refolo L, Zenk B, Hardy J, Younkin S (1996) Increased amyloid-beta42(43) in brains of mice expressing mutant presenilin 1. Nature 383:710-713.

Duyckaerts C, Delatour B, Potier M-C (2009) Classification and basic pathology of Alzheimer disease. Acta neuropathologica 118:5-36.

Eckman CB, Mehta ND, Crook R, Perez-tur J, Prihar G, Pfeiffer E, Graff-Radford N, Hinder P, Yager D, Zenk B, Refolo LM, Prada CM, Younkin SG, Hutton M, Hardy J (1997) A new pathogenic mutation in the APP gene (I716V) increases the relative proportion of A beta 42(43). Human molecular genetics 6:2087-2089.

Edison P, Rowe CC, Rinne JO, Ng S, Ahmed I, Kemppainen N, Villemagne VL, O’Keefe G, Någren K, Chaudhury KR, Masters CL, Brooks DJ (2008) Amyloid load in Parkinson's disease dementia and Lewy body dementia measured with [11C]PIB positron emission tomography. Journal of neurology, neurosurgery, and psychiatry 79:1331-1338.

Ellis RJ, Olichney JM, Thal LJ, Mirra SS, Morris JC, Beekly D, Heyman A (1996) Cerebral amyloid angiopathy in the brains of patients with Alzheimer's disease: the CERAD experience, Part XV. Neurology 46:1592-1596.

Emmer KL, Covy JP, Giasson BI (2012) Studies of protein aggregation in A53T $\alpha$-synuclein transgenic, Tg2576 transgenic, and P246L presenilin-1 knock-in cross bred mice. Neuroscience letters 507:137-142.

Eriksen JL, Sagi SA, Smith TE, Weggen S, Das P, McLendon DC, Ozols VV, Jessing KW, Zavitz KH, Koo EH, Golde TE (2003) NSAIDs and enantiomers of flurbiprofen target gamma-secretase and lower Abeta 42 in vivo. J Clin Invest 112:440-449. 
Ferreiro E, Resende R, Costa R, Oliveira CR, Pereira CMF (2006) An endoplasmicreticulum-specific apoptotic pathway is involved in prion and amyloid-beta peptides neurotoxicity. Neurobiology of disease 23:669-678.

Ferri CP, Prince M, Brayne C, Brodaty H, Fratiglioni L, Ganguli M, Hall K, Hasegawa K, Hendrie H, Huang Y, Jorm A, Mathers C, Menezes PR, Rimmer E, Scazufca M (2005) Global prevalence of dementia: a Delphi consensus study. Lancet 366:2112-2117.

Frankola KA, Greig NH, Luo W, Tweedie D (2011) Targeting TNF- $\alpha$ to elucidate and ameliorate neuroinflammation in neurodegenerative diseases. CNS \& neurological disorders drug targets 10:391-403.

Fryer JD, Simmons K, Parsadanian M, Bales KR, Paul SM, Sullivan PM, Holtzman DM (2005) Human apolipoprotein E4 alters the amyloid-beta 40:42 ratio and promotes the formation of cerebral amyloid angiopathy in an amyloid precursor protein transgenic model. The Journal of neuroscience 25:2803-2810.

Förstl H, Kurz A (1999) Clinical features of Alzheimer's disease. European archives of psychiatry and clinical neuroscience 249:288-290.

George JM (2002) The synucleins. Genome biology 3:REVIEWS3002.

Gilman S, Koller M, Black RS, Jenkins L, Griffith SG, Fox NC, Eisner L, Kirby L, Rovira MB, Forette F, Orgogozo J-M (2005) Clinical effects of Abeta immunization (AN1792) in patients with AD in an interrupted trial. Neurology 64:1553-1562.

Giulian D (1999) Microglia and the immune pathology of Alzheimer disease. American journal of human genetics 65:13-18.

Goate A, Chartier-Harlin MC, Mullan M, Brown J, Crawford F, Fidani L, Giuffra L, Haynes A, Irving N, James L (1991) Segregation of a missense mutation in the amyloid precursor protein gene with familial Alzheimer's disease. Nature 349:704-706.

Goedert M, Spillantini MG, Jakes R, Rutherford D, Crowther RA (1989) Multiple isoforms of human microtubule-associated protein tau: sequences and localization in neurofibrillary tangles of Alzheimer's disease. Neuron 3:519-526.

Goldgaber D, Lerman MI, McBride OW, Saffiotti U, Gajdusek DC (1987) Characterization and chromosomal localization of a cDNA encoding brain amyloid of Alzheimer's disease. Science (New York, NY) 235:877-880.

Gordon MN, Holcomb LA, Jantzen PT, DiCarlo G, Wilcock D, Boyett KW, Connor K, Melachrino J, O’Callaghan JP, Morgan D (2002) Time course of the development of Alzheimer-like pathology in the doubly transgenic PS1+APP mouse. Experimental neurology 173:183-195.

Gouras GK, Tsai J, Naslund J, Vincent B, Edgar M, Checler F, Greenfield JP, Haroutunian V, Buxbaum JD, Xu H, Greengard P, Relkin NR (2000) Intraneuronal Abeta42 accumulation in human brain. The American journal of pathology 156:15-20. 
Grathwohl S a, Kälin RE, Bolmont T, Prokop S, Winkelmann G, Kaeser S a, Odenthal J, Radde R, Eldh T, Gandy S, Aguzzi A, Staufenbiel M, Mathews PM, Wolburg H, Heppner FL, Jucker M (2009) Formation and maintenance of Alzheimer's disease betaamyloid plaques in the absence of microglia. Nature neuroscience 12:1357-1360.

Gravina SA, Ho L, Eckman CB, Long KE, Otvos L, Younkin LH, Suzuki N, Younkin SG (1995) Amyloid beta protein (A beta) in Alzheimer's disease brain. Biochemical and immunocytochemical analysis with antibodies specific for forms ending at A beta 40 or A beta 42(43). The Journal of biological chemistry 270:7013-7016.

Guo Q, Fu W, Sopher BL, Miller MW, Ware CB, Martin GM, Mattson MP (1999) Increased vulnerability of hippocampal neurons to excitotoxic necrosis in presenilin-1 mutant knock-in mice. Nature medicine 5:101-106.

Gyure KA, Durham R, Stewart WF, Smialek JE, Troncoso JC (2001) Intraneuronal abetaamyloid precedes development of amyloid plaques in Down syndrome. Archives of pathology \& laboratory medicine 125:489-492.

Gómez-Isla T, Hollister R, West H, Mui S, Growdon JH, Petersen RC, Parisi JE, Hyman BT (1997) Neuronal loss correlates with but exceeds neurofibrillary tangles in Alzheimer's disease. Annals of neurology 41:17-24.

Hahn S, Brüning T, Ness J, Czirr E, Baches S, Gijsen H, Korth C, Pietrzik CU, Bulic B, Weggen S (2011) Presenilin-1 but not amyloid precursor protein mutations present in mouse models of Alzheimer's disease attenuate the response of cultured cells to $\gamma$ secretase modulators regardless of their potency and structure. Journal of neurochemistry 116:385-395.

Hamilton RL (2000) Lewy bodies in Alzheimer's disease: a neuropathological review of 145 cases using alpha-synuclein immunohistochemistry. Brain Pathol 10:378-384.

Hansen L, Salmon D, Galasko D, Masliah E, Katzman R, DeTeresa R, Thal L, Pay MM, Hofstetter R, Klauber M, et al. (1990) The Lewy body variant of Alzheimer's disease: a clinical and pathologic entity. Neurology 40:1-8.

Hardy J, Allsop D (1991) Amyloid deposition as the central event in the aetiology of Alzheimer's disease. Trends in pharmacological sciences 12:383-388.

Harigaya Y, Saido TC, Eckman CB, Prada CM, Shoji M, Younkin SG (2000) Amyloid beta protein starting pyroglutamate at position 3 is a major component of the amyloid deposits in the Alzheimer's disease brain. Biochemical and biophysical research communications 276:422-427.

Herber DL, Mercer M, Roth LM, Symmonds K, Maloney J, Wilson N, Freeman MJ, Morgan D, Gordon MN (2007) Microglial activation is required for Abeta clearance after intracranial injection of lipopolysaccharide in APP transgenic mice. Journal of neuroimmune pharmacology 2:222-231.

Herzig MC, Van Nostrand WE, Jucker M (2006) Mechanism of cerebral beta-amyloid angiopathy: murine and cellular models. Brain pathology 16:40-54. 
Herzig MC, Winkler DT, Burgermeister P, Pfeifer M, Kohler E, Schmidt SD, Danner S, Abramowski D, Stürchler-Pierrat C, Bürki K, van Duinen SG, Maat-Schieman MLC, Staufenbiel M, Mathews PM, Jucker M (2004) Abeta is targeted to the vasculature in a mouse model of hereditary cerebral hemorrhage with amyloidosis. Nature neuroscience 7:954-960.

Heston LL, Mastri AR (1977) The genetics of Alzheimer's disease: associations with hematologic malignancy and Down's syndrome. Archives of general psychiatry 34:976981.

Holcomb L, Gordon MN, McGowan E, Yu X, Benkovic S, Jantzen P, Wright K, Saad I, Mueller R, Morgan D, Sanders S, Zehr C, O’Campo K, Hardy J, Prada CM, Eckman C, Younkin S, Hsiao K, Duff K (1998) Accelerated Alzheimer-type phenotype in transgenic mice carrying both mutant amyloid precursor protein and presenilin 1 transgenes. Nature medicine 4:97-100.

Honer WG (2003) Pathology of presynaptic proteins in Alzheimer's disease: more than simple loss of terminals. Neurobiology of aging 24:1047-1062.

Hoogendijk WJ, Pool CW, Troost D, van Zwieten E, Swaab DF (1995) Image analyserassisted morphometry of the locus coeruleus in Alzheimer's disease, Parkinson's disease and amyotrophic lateral sclerosis. Brain 118 ( Pt 1:131-143.

Hsiao K, Chapman P, Nilsen S, Eckman C, Harigaya Y, Younkin S, Yang F, Cole G (1996) Correlative memory deficits, Abeta elevation, and amyloid plaques in transgenic mice. Science (New York, NY) 274:99-102.

Imbimbo BP (2004) The potential role of non-steroidal anti-inflammatory drugs in treating Alzheimer's disease. Expert opinion on investigational drugs 13:1469-1481.

Imbimbo BP (2009) An update on the efficacy of non-steroidal anti-inflammatory drugs in Alzheimer's disease. Expert opinion on investigational drugs 18:1147-1168.

Imbimbo BP, Hutter-Paier B, Villetti G, Facchinetti F, Cenacchi V, Volta R, Lanzillotta a, Pizzi M, Windisch M (2009) CHF5074, a novel gamma-secretase modulator, attenuates brain beta-amyloid pathology and learning deficit in a mouse model of Alzheimer's disease. British journal of pharmacology 156:982-993.

Iwatsubo T, Saido TC, Mann DM, Lee VM, Trojanowski JQ (1996) Full-length amyloid-beta (1-42(43)) and amino-terminally modified and truncated amyloid-beta 42(43) deposit in diffuse plaques. The American journal of pathology 149:1823-1830.

Jana M, Palencia CA, Pahan K (2008) Fibrillar amyloid-beta peptides activate microglia via TLR2: implications for Alzheimer's disease. Journal of immunology 181:7254-7262.

Janssen JC, Beck JA, Campbell TA, Dickinson A, Fox NC, Harvey RJ, Houlden H, Rossor MN, Collinge J (2003) Early onset familial Alzheimer's disease: Mutation frequency in 31 families. Neurology 60:235-239.

Jantzen PT, Connor KE, DiCarlo G, Wenk GL, Wallace JL, Rojiani AM, Coppola D, Morgan D, Gordon MN (2002) Microglial activation and beta -amyloid deposit reduction caused 
by a nitric oxide-releasing nonsteroidal anti-inflammatory drug in amyloid precursor protein plus presenilin-1 transgenic mice. The Journal of neuroscience 22:2246-2254.

Janus C, Pearson J, McLaurin J, Mathews PM, Jiang Y, Schmidt SD, Chishti MA, Horne P, Heslin D, French J, Mount HT, Nixon RA, Mercken M, Bergeron C, Fraser PE, St George-Hyslop P, Westaway D (2000) A beta peptide immunization reduces behavioural impairment and plaques in a model of Alzheimer's disease. Nature 408:979-982.

Jarrett JT, Berger EP, Lansbury PT (1993) The C-terminus of the beta protein is critical in amyloidogenesis. Annals of the New York Academy of Sciences 695:144-148.

Jawhar S, Trawicka A, Jenneckens C, Bayer TA, Wirths O (2012) Motor deficits, neuron loss, and reduced anxiety coinciding with axonal degeneration and intraneuronal $A \beta$ aggregation in the 5XFAD mouse model of Alzheimer's disease. Neurobiology of aging 33:196.e29-40.

Jawhar S, Wirths O, Bayer T a (2011a) Pyroglutamate amyloid- $\beta$ (A $\beta$ ): a hatchet man in Alzheimer disease. The Journal of biological chemistry 286:38825-38832.

Jawhar S, Wirths O, Schilling S, Graubner S, Demuth H-U, Bayer T a (2011b) Overexpression of glutaminyl cyclase, the enzyme responsible for pyroglutamate A \{beta\} formation, induces behavioral deficits, and glutaminyl cyclase knock-out rescues the behavioral phenotype in 5XFAD mice. The Journal of biological chemistry 286:4454-4460.

Jellinger KA (2002) Alzheimer disease and cerebrovascular pathology: an update. Journal of neural transmission 109:813-836.

Jellinger KA (2007) The enigma of vascular cognitive disorder and vascular dementia. Acta neuropathologica 113:349-388.

Jensen PH, Li JY, Dahlström A, Dotti CG (1999) Axonal transport of synucleins is mediated by all rate components. The European journal of neuroscience 11:3369-3376.

Johnstone M, Gearing AJ, Miller KM (1999) A central role for astrocytes in the inflammatory response to beta-amyloid; chemokines, cytokines and reactive oxygen species are produced. Journal of neuroimmunology 93:182-193.

de Jong D, Jansen R, Hoefnagels W, Jellesma-Eggenkamp M, Verbeek M, Borm G, Kremer B (2008) No effect of one-year treatment with indomethacin on Alzheimer's disease progression: a randomized controlled trial. PloS one 3:e1475.

Kalinin S, Richardson JC, Feinstein DL (2009) A PPARdelta agonist reduces amyloid burden and brain inflammation in a transgenic mouse model of Alzheimer's disease. Current Alzheimer research 6:431-437.

Kang J, Lemaire HG, Unterbeck A, Salbaum JM, Masters CL, Grzeschik KH, Multhaup G, Beyreuther K, Müller-Hill B (1987) The precursor of Alzheimer's disease amyloid A4 protein resembles a cell-surface receptor. Nature 325:733-736. 
Karl T, Pabst R, von Hörsten S (2003) Behavioral phenotyping of mice in pharmacological and toxicological research. Experimental and toxicologic pathology 55:69-83.

Kashon ML, Ross GW, O’Callaghan JP, Miller DB, Petrovitch H, Burchfiel CM, Sharp DS, Markesbery WR, Davis DG, Hardman J, Nelson J, White LR (2004) Associations of cortical astrogliosis with cognitive performance and dementia status. Journal of Alzheimer's disease 6:595-604.

Kato H, Kogure K, Liu XH, Araki T, Itoyama Y (1996) Progressive expression of immunomolecules on activated microglia and invading leukocytes following focal cerebral ischemia in the rat. Brain research 734:203-212.

Kim S, Ock J, Kim AK, Lee HW, Cho J-Y, Kim DR, Park J-Y, Suk K (2007) Neurotoxicity of microglial cathepsin $\mathrm{D}$ revealed by secretome analysis. Journal of neurochemistry 103:2640-2650.

Kok EH, Luoto T, Haikonen S, Goebeler S, Haapasalo H, Karhunen PJ (2011) CLU, CR1 and PICALM genes associate with Alzheimer's-related senile plaques. Alzheimer's research \& therapy 3:12.

Koo EH, Sisodia SS, Archer DR, Martin LJ, Weidemann A, Beyreuther K, Fischer P, Masters CL, Price DL (1990a) Precursor of amyloid protein in Alzheimer disease undergoes fast anterograde axonal transport. Proceedings of the National Academy of Sciences of the United States of America 87:1561-1565.

Kotilinek L a, Westerman M a, Wang Q, Panizzon K, Lim GP, Simonyi A, Lesne S, Falinska A, Younkin LH, Younkin SG, Rowan M, Cleary J, Wallis RA, Sun GY, Cole G, Frautschy S, Anwyl R, Ashe KH (2008) Cyclooxygenase-2 inhibition improves amyloidbeta-mediated suppression of memory and synaptic plasticity. Brain 131:651-664.

Kotzbauer PT, Trojanowsk JQ, Lee VM (2001) Lewy body pathology in Alzheimer's disease. J Mol Neurosci 17:225-232.

Kraybill ML, Larson EB, Tsuang DW, Teri L, McCormick WC, Bowen JD, Kukull WA, Leverenz JB, Cherrier MM (2005) Cognitive differences in dementia patients with autopsy-verified AD, Lewy body pathology, or both. Neurology 64:2069-2073.

Köhler C, Ebert U, Baumann K, Schröder H (2005) Alzheimer's disease-like neuropathology of gene-targeted APP-SLxPS1mut mice expressing the amyloid precursor protein at endogenous levels. Neurobiology of disease 20:528-540.

Kügler S, Lingor P, Schöll U, Zolotukhin S, Bähr M (2003) Differential transgene expression in brain cells in vivo and in vitro from AAV-2 vectors with small transcriptional control units. Virology 311:89-95.

Lambert J-C et al. (2009) Genome-wide association study identifies variants at CLU and CR1 associated with Alzheimer's disease. Nature genetics 41:1094-1099.

Lambert MP, Barlow AK, Chromy BA, Edwards C, Freed R, Liosatos M, Morgan TE, Rozovsky I, Trommer B, Viola KL, Wals P, Zhang C, Finch CE, Krafft GA, Klein WL (1998) Diffusible, nonfibrillar ligands derived from Abeta1-42 are potent central nervous 
system neurotoxins. Proceedings of the National Academy of Sciences of the United States of America 95:6448-6453.

Landreth GE, Reed-Geaghan EG (2009) Toll-like receptors in Alzheimer's disease. Current topics in microbiology and immunology 336:137-153.

Lazarov VK, Fraering PC, Ye W, Wolfe MS, Selkoe DJ, Li H (2006) Electron microscopic structure of purified, active gamma-secretase reveals an aqueous intramembrane chamber and two pores. Proceedings of the National Academy of Sciences of the United States of America 103:6889-6894.

Letiembre M, Liu Y, Walter S, Hao W, Pfander T, Wrede A, Schulz-Schaeffer W, Fassbender K (2009) Screening of innate immune receptors in neurodegenerative diseases: a similar pattern. Neurobiology of aging 30:759-768.

Li L, Fei Z, Ren J, Sun R, Liu Z, Sheng Z, Wang L, Sun X, Yu J, Wang Z, Fei J (2008) Functional imaging of interleukin 1 beta expression in inflammatory process using bioluminescence imaging in transgenic mice. BMC Immunol 9:49.

Lim GP, Yang F, Chu T, Chen P, Beech W, Teter B, Tran T, Ubeda O, Ashe KH, Frautschy SA, Cole GM (2000) Ibuprofen suppresses plaque pathology and inflammation in a mouse model for Alzheimer's disease. The Journal of neuroscience 20:5709-5714.

Lim GP, Yang F, Chu T, Gahtan E, Ubeda O, Beech W, Overmier JB, Hsiao-Ashec K, Frautschy S a, Cole GM (2001) Ibuprofen effects on Alzheimer pathology and open field activity in APPsw transgenic mice. Neurobiology of aging 22:983-991.

Lippa CF et al. (2007) DLB and PDD boundary issues: diagnosis, treatment, molecular pathology, and biomarkers. Neurology 68:812-819.

Lyness SA, Zarow C, Chui HC (2003) Neuron loss in key cholinergic and aminergic nuclei in Alzheimer disease: a meta-analysis. Neurobiology of aging 24:1-23.

Mackenzie IR, Munoz DG (1998) Nonsteroidal anti-inflammatory drug use and Alzheimertype pathology in aging. Neurology 50:986-990.

Maeda A, Yamada M, Itoh Y, Otomo E, Hayakawa M, Miyatake T (1993) Computer-assisted three-dimensional image analysis of cerebral amyloid angiopathy. Stroke; a journal of cerebral circulation 24:1857-1864.

Mandal PK, Pettegrew JW, Masliah E, Hamilton RL, Mandal R (2006) Interaction between Abeta peptide and alpha synuclein: molecular mechanisms in overlapping pathology of Alzheimer's and Parkinson's in dementia with Lewy body disease. Neurochem Res 31:1153-1162.

Mandelkow EM, Biernat J, Drewes G, Steiner B, Lichtenberg-Kraag B, Wille H, Gustke N, Mandelkow E (1993) Microtubule-associated protein tau, paired helical filaments, and phosphorylation. Annals of the New York Academy of Sciences 695:209-216. 
Mandrekar S, Jiang Q, Lee CYD, Koenigsknecht-Talboo J, Holtzman DM, Landreth GE (2009) Microglia mediate the clearance of soluble Abeta through fluid phase macropinocytosis. The Journal of neuroscience 29:4252-4262.

Maroon JC, Bost JW, Borden MK, Lorenz KM, Ross NA (2006) Natural antiinflammatory agents for pain relief in athletes. Neurosurgical focus 21:E11.

Masliah E, Rockenstein E, Veinbergs I, Sagara Y, Mallory M, Hashimoto M, Mucke L (2001) beta-amyloid peptides enhance alpha-synuclein accumulation and neuronal deficits in a transgenic mouse model linking Alzheimer's disease and Parkinson's disease. Proc Natl Acad Sci U S A 98:12245-12250.

Masters CL, Multhaup G, Simms G, Pottgiesser J, Martins RN, Beyreuther K (1985) Neuronal origin of a cerebral amyloid: neurofibrillary tangles of Alzheimer's disease contain the same protein as the amyloid of plaque cores and blood vessels. The EMBO journal 4:2757-2763.

Mayeux R (2003) Epidemiology of neurodegeneration. Annual review of neuroscience 26:81-104.

McGeer PL, McGeer E, Rogers J, Sibley J (1990) Anti-inflammatory drugs and Alzheimer disease. Lancet 335:1037.

McGeer PL, McGeer EG (2007) NSAIDs and Alzheimer disease: epidemiological, animal model and clinical studies. Neurobiology of aging 28:639-647.

McKee AC, Carreras I, Hossain L, Ryu H, Klein WL, Oddo S, LaFerla FM, Jenkins BG, Kowall NW, Dedeoglu A (2008) Ibuprofen reduces Abeta, hyperphosphorylated tau and memory deficits in Alzheimer mice. Brain research 1207:225-236.

McLean CA, Cherny RA, Fraser FW, Fuller SJ, Smith MJ, Beyreuther K, Bush AI, Masters CL (1999) Soluble pool of Abeta amyloid as a determinant of severity of neurodegeneration in Alzheimer’s disease. Annals of neurology 46:860-866.

Mehlhorn G, Hollborn M, Schliebs R (2000) Induction of cytokines in glial cells surrounding cortical beta-amyloid plaques in transgenic Tg2576 mice with Alzheimer pathology. International journal of developmental neuroscience 18:423-431.

Melnikova T, Savonenko A, Wang Q, Liang X, Hand T, Wu L, Kaufmann WE, Vehmas A, Andreasson KI (2006) Cycloxygenase-2 activity promotes cognitive deficits but not increased amyloid burden in a model of Alzheimer's disease in a sex-dimorphic pattern. Neuroscience 141:1149-1162.

Morrissette D a, Parachikova A, Green KN, LaFerla FM (2009) Relevance of transgenic mouse models to human Alzheimer disease. The Journal of biological chemistry 284:6033-6037.

Mortimer JA, Snowdon DA, Markesbery WR (2003) Head circumference, education and risk of dementia: findings from the Nun Study. Journal of clinical and experimental neuropsychology 25:671-679. 
Mrak RE, Griffin WS (2001) Interleukin-1, neuroinflammation, and Alzheimer's disease. Neurobiology of aging 22:903-908.

Mullan M, Crawford F, Axelman K, Houlden H, Lilius L, Winblad B, Lannfelt L (1992) A pathogenic mutation for probable Alzheimer's disease in the APP gene at the N-terminus of beta-amyloid. Nature genetics 1:345-347.

Murphy DD, Rueter SM, Trojanowski JQ, Lee VM (2000) Synucleins are developmentally expressed, and alpha-synuclein regulates the size of the presynaptic vesicular pool in primary hippocampal neurons. Journal Neuroscience 20:3214-3220.

Nagele RG, D’Andrea MR, Lee H, Venkataraman V, Wang H-Y (2003) Astrocytes accumulate A beta 42 and give rise to astrocytic amyloid plaques in Alzheimer disease brains. Brain research 971:197-209.

Narhi L, Wood SJ, Steavenson S, Jiang Y, Wu GM, Anafi D, Kaufman SA, Martin F, Sitney K, Denis P, Louis JC, Wypych J, Biere AL, Citron M (1999) Both familial Parkinson's disease mutations accelerate alpha-synuclein aggregation. The Journal of biological chemistry 274:9843-9846.

Nicoll JAR, Wilkinson D, Holmes C, Steart P, Markham H, Weller RO (2003) Neuropathology of human Alzheimer disease after immunization with amyloid-beta peptide: a case report. Nature medicine 9:448-452.

Oakley H, Cole SL, Logan S, Maus E, Shao P, Craft J, Guillozet-Bongaarts A, Ohno M, Disterhoft J, Van Eldik L, Berry R, Vassar R (2006) Intraneuronal beta-amyloid aggregates, neurodegeneration, and neuron loss in transgenic mice with five familial Alzheimer's disease mutations: potential factors in amyloid plaque formation. Journal Neuroscience 26:10129-10140.

Oddo S, Caccamo A, Shepherd JD, Murphy MP, Golde TE, Kayed R, Metherate R, Mattson MP, Akbari Y, LaFerla FM (2003) Triple-transgenic model of Alzheimer's disease with plaques and tangles: intracellular Abeta and synaptic dysfunction. Neuron 39:409-421.

Orellana DI, Quintanilla RA, Maccioni RB (2007) Neuroprotective effect of TNFalpha against the beta-amyloid neurotoxicity mediated by CDK5 kinase. Biochimica et biophysica acta 1773:254-263.

Orgogozo J-M, Gilman S, Dartigues J-F, Laurent B, Puel M, Kirby LC, Jouanny P, Dubois B, Eisner L, Flitman S, Michel BF, Boada M, Frank A, Hock C (2003) Subacute meningoencephalitis in a subset of patients with AD after Abeta42 immunization. Neurology 61:46-54.

Page RM, Baumann K, Tomioka M, Perez-Revuelta BI, Fukumori A, Jacobsen H, Flohr A, Luebbers T, Ozmen L, Steiner H, Haass C (2008) Generation of Abeta38 and Abeta42 is independently and differentially affected by familial Alzheimer disease-associated presenilin mutations and gamma-secretase modulation. The Journal of biological chemistry 283:677-683. 
Patel NS, Paris D, Mathura V, Quadros AN, Crawford FC, Mullan MJ (2005) Inflammatory cytokine levels correlate with amyloid load in transgenic mouse models of Alzheimer's disease. Journal of neuroinflammation 2:9.

Perry EK, Kerwin J, Perry RH, Blessed G, Fairbairn AF (1990) Visual hallucinations and the cholinergic system in dementia. Journal of neurology, neurosurgery, and psychiatry 53:88.

Pfaffl MW, Horgan GW, Dempfle L (2002) Relative expression software tool (REST) for group-wise comparison and statistical analysis of relative expression results in real-time PCR. Nucleic Acids Research 30:e36.

Pfeifer M, Boncristiano S, Bondolfi L, Stalder A, Deller T, Staufenbiel M, Mathews PM, Jucker M (2002) Cerebral hemorrhage after passive anti-Abeta immunotherapy. Science (New York, NY) 298:1379.

Pihlaja R, Koistinaho J, Malm T, Sikkilä H, Vainio S, Koistinaho M (2008) Transplanted astrocytes internalize deposited beta-amyloid peptides in a transgenic mouse model of Alzheimer's disease. Glia 56:154-163.

Pike CJ, Overman MJ, Cotman CW (1995) Amino-terminal deletions enhance aggregation of beta-amyloid peptides in vitro. The Journal of biological chemistry 270:23895-23898.

Portelius E, Bogdanovic N, Gustavsson MK, Volkmann I, Brinkmalm G, Zetterberg H, Winblad B, Blennow K (2010) Mass spectrometric characterization of brain amyloid beta isoform signatures in familial and sporadic Alzheimer's disease. Acta neuropathologica 120:185-193.

Racke MM, Boone LI, Hepburn DL, Parsadainian M, Bryan MT, Ness DK, Piroozi KS, Jordan WH, Brown DD, Hoffman WP, Holtzman DM, Bales KR, Gitter BD, May PC, Paul SM, DeMattos RB (2005) Exacerbation of cerebral amyloid angiopathy-associated microhemorrhage in amyloid precursor protein transgenic mice by immunotherapy is dependent on antibody recognition of deposited forms of amyloid beta. The Journal of neuroscience 25:629-636.

Richter L, Munter L-M, Ness J, Hildebrand PW, Dasari M, Unterreitmeier S, Bulic B, Beyermann M, Gust R, Reif B, Weggen S, Langosch D, Multhaup G (2010) Amyloid beta 42 peptide (Abeta42)-lowering compounds directly bind to Abeta and interfere with amyloid precursor protein (APP) transmembrane dimerization. Proceedings of the National Academy of Sciences of the United States of America 107:14597-14602.

Rogers J, Kirby LC, Hempelman SR, Berry DL, McGeer PL, Kaszniak AW, Zalinski J, Cofield M, Mansukhani L, Willson P (1993) Clinical trial of indomethacin in Alzheimer's disease. Neurology 43:1609-1611.

Roychaudhuri R, Yang M, Hoshi MM, Teplow DB (2009) Amyloid beta-protein assembly and Alzheimer disease. The Journal of biological chemistry 284:4749-4753.

Scarmeas N, Hadjigeorgiou GM, Papadimitriou A, Dubois B, Sarazin M, Brandt J, Albert M, Marder K, Bell K, Honig LS, Wegesin D, Stern Y (2004) Motor signs during the course of Alzheimer disease. Neurology 63:975-982. 
Scarpini E, Scheltens P, Feldman H (2003) Treatment of Alzheimer's disease: current status and new perspectives. Lancet neurology 2:539-547.

Scheff SW, Price DA, Schmitt FA, DeKosky ST, Mufson EJ (2007) Synaptic alterations in CA1 in mild Alzheimer disease and mild cognitive impairment. Neurology 68:15011508.

Schenk D et al. (1999) Immunization with amyloid-beta attenuates Alzheimer-disease-like pathology in the PDAPP mouse. Nature 400:173-177.

Selkoe DJ (2001) Alzheimer's disease: genes, proteins, and therapy. Physiological reviews 81:741-766.

Sheng JG, Jones RA, Zhou XQ, McGinness JM, Van Eldik LJ, Mrak RE, Griffin WS (2001) Interleukin-1 promotion of MAPK-p38 overexpression in experimental animals and in Alzheimer's disease: potential significance for tau protein phosphorylation. Neurochemistry international 39:341-348.

Sherrington R, Rogaev EI, Liang Y, Rogaeva EA, Levesque G, Ikeda M, Chi H, Lin C, Li G, Holman K, et al. (1995) Cloning of a gene bearing missense mutations in early-onset familial Alzheimer's disease. Nature 375:754-760.

Sinha S et al. (1999) Purification and cloning of amyloid precursor protein beta-secretase from human brain. Nature 402:537-540.

Smith RP, Higuchi DA, Broze GJ (1990) Platelet coagulation factor XIa-inhibitor, a form of Alzheimer amyloid precursor protein. Science (New York, NY) 248:1126-1128.

Snowdon DA (1997) Aging and Alzheimer's disease: lessons from the Nun Study. The Gerontologist 37:150-156.

Soininen H, West C, Robbins J, Niculescu L (2007) Long-term efficacy and safety of celecoxib in Alzheimer's disease. Dementia and geriatric cognitive disorders 23:8-21.

Sokolova A, Hill MD, Rahimi F, Warden LA, Halliday GM, Shepherd CE (2009) Monocyte chemoattractant protein-1 plays a dominant role in the chronic inflammation observed in Alzheimer’s disease. Brain pathology (Zurich, Switzerland) 19:392-398.

Stewart WF, Kawas C, Corrada M, Metter EJ (1997) Risk of Alzheimer's disease and duration of NSAID use. Neurology 48:626-632.

Stokin GB, Lillo C, Falzone TL, Brusch RG, Rockenstein E, Mount SL, Raman R, Davies P, Masliah E, Williams DS, Goldstein LSB (2005) Axonopathy and transport deficits early in the pathogenesis of Alzheimer's disease. Science (New York, NY) 307:1282-1288.

Strauss S, Bauer J, Ganter U, Jonas U, Berger M, Volk B (1992) Detection of interleukin-6 and alpha 2-macroglobulin immunoreactivity in cortex and hippocampus of Alzheimer's disease patients. Laboratory investigation 6:223-230.

Strittmatter WJ, Weisgraber KH, Huang DY, Dong LM, Salvesen GS, Pericak-Vance M, Schmechel D, Saunders AM, Goldgaber D, Roses AD (1993) Binding of human 
apolipoprotein E to synthetic amyloid beta peptide: isoform-specific effects and implications for late-onset Alzheimer disease. Proceedings of the National Academy of Sciences of the United States of America 90:8098-8102.

Strle K, Zhou JH, Shen WH, Broussard SR, Johnson RW, Freund GG, Dantzer R, Kelley KW (2001) Interleukin-10 in the brain. Critical reviews in immunology 21:427-449.

De Strooper B, Iwatsubo T, Wolfe MS (2012) Presenilins and $\gamma$-Secretase: Structure, Function, and Role in Alzheimer Disease. Cold Spring Harbor perspectives in medicine 2:a006304.

Sung S, Yang H, Uryu K, Lee EB, Zhao L, Shineman D, Trojanowski JQ, Lee VM-Y, Praticò D (2004) Modulation of nuclear factor-kappa B activity by indomethacin influences A beta levels but not A beta precursor protein metabolism in a model of Alzheimer's disease. The American journal of pathology 165:2197-2206.

Suzuki N, Cheung TT, Cai XD, Odaka A, Otvos L, Eckman C, Golde TE, Younkin SG (1994) An increased percentage of long amyloid beta protein secreted by familial amyloid beta protein precursor (beta APP717) mutants. Science (New York, NY) 264:1336-1340.

Szczepanik AM, Funes S, Petko W, Ringheim GE (2001) IL-4, IL-10 and IL-13 modulate A beta(1--42)-induced cytokine and chemokine production in primary murine microglia and a human monocyte cell line. Journal of neuroimmunology 113:49-62.

Tahara K, Kim H-D, Jin J-J, Maxwell JA, Li L, Fukuchi K-ichiro (2006) Role of toll-like receptor signalling in Abeta uptake and clearance. Brain 129:3006-3019.

Tanzi RE, McClatchey AI, Lamperti ED, Villa-Komaroff L, Gusella JF, Neve RL (1988) Protease inhibitor domain encoded by an amyloid protein precursor mRNA associated with Alzheimer's disease. Nature 331:528-530.

Terry RD, Masliah E, Salmon DP, Butters N, DeTeresa R, Hill R, Hansen LA, Katzman R (1991) Physical basis of cognitive alterations in Alzheimer's disease: synapse loss is the major correlate of cognitive impairment. Annals of neurology 30:572-580.

Thal DR, Ghebremedhin E, Orantes M, Wiestler OD (2003) Vascular pathology in Alzheimer disease: correlation of cerebral amyloid angiopathy and arteriosclerosis/lipohyalinosis with cognitive decline. Journal of neuropathology and experimental neurology 62:12871301.

Thies W, Bleiler L (2011) 2011 Alzheimer's disease facts and figures. Alzheimer's \& dementia 7:208-244.

Thinakaran G, Koo EH (2008) Amyloid precursor protein trafficking, processing, and function. The Journal of biological chemistry 283:29615-29619.

Tian J, Shi J, Bailey K, Mann DMA (2003) Negative association between amyloid plaques and cerebral amyloid angiopathy in Alzheimer's disease. Neuroscience letters 352:137140. 
Tomimoto H, Akiguchi I, Akiyama H, Ikeda K, Wakita H, Lin JX, Budka H (1999) Vascular changes in white matter lesions of Alzheimer's disease. Acta neuropathologica 97:629634.

Tsigelny IF, Crews L, Desplats P, Shaked GM, Sharikov Y, Mizuno H, Spencer B, Rockenstein E, Trejo M, Platoshyn O, Yuan JX, Masliah E (2008) Mechanisms of hybrid oligomer formation in the pathogenesis of combined Alzheimer's and Parkinson's diseases. PLoS One 3:e3135.

Vallières L, Rivest S (1997) Regulation of the genes encoding interleukin-6, its receptor, and gp130 in the rat brain in response to the immune activator lipopolysaccharide and the proinflammatory cytokine interleukin-1beta. Journal of neurochemistry 69:1668-1683.

Vane JR, Botting RM (1998) Mechanism of action of antiinflammatory drugs. International journal of tissue reactions 20:3-15.

Vassar R et al. (1999) Beta-secretase cleavage of Alzheimer's amyloid precursor protein by the transmembrane aspartic protease BACE. Science (New York, NY) 286:735-741.

in t' Veld BA, Ruitenberg a, Hofman a, Launer LJ, van Duijn CM, Stijnen T, Breteler MM, Stricker BH (2001) Nonsteroidal antiinflammatory drugs and the risk of Alzheimer's disease. N Engl J Med 345:1515-1521.

Venkataramani V, Wirths O, Budka H, Härtig W, Kovacs GG, Bayer TA (2012) Antibody 9D5 Recognizes Oligomeric Pyroglutamate Amyloid- $\beta$ in a Fraction of Amyloid- $\beta$ Deposits in Alzheimer's Disease without Cross-Reactivity with other Protein Aggregates. Journal of Alzheimer's disease 29:361-371.

Walsh DM, Klyubin I, Fadeeva JV, Cullen WK, Anwyl R, Wolfe MS, Rowan MJ, Selkoe DJ (2002) Naturally secreted oligomers of amyloid beta protein potently inhibit hippocampal long-term potentiation in vivo. Nature 416:535-539.

Walsh DM, Lomakin A, Benedek GB, Condron MM, Teplow DB (1997) Amyloid betaprotein fibrillogenesis. Detection of a protofibrillar intermediate. The Journal of biological chemistry 272:22364-22372.

Walsh DM, Selkoe DJ (2007) A beta oligomers - a decade of discovery. Journal of neurochemistry 101:1172-1184.

Weggen S, Eriksen JL, Das P, Sagi SA, Wang R, Pietrzik CU, Findlay KA, Smith TE, Murphy MP, Bulter T, Kang DE, Marquez-Sterling N, Golde TE, Koo EH (2001) A subset of NSAIDs lower amyloidogenic Abeta42 independently of cyclooxygenase activity. Nature 414:212-216.

Weggen S, Eriksen JL, Sagi SA, Pietrzik CU, Ozols V, Fauq A, Golde TE, Koo EH (2003) Evidence that nonsteroidal anti-inflammatory drugs decrease amyloid beta 42 production by direct modulation of gamma-secretase activity. The Journal of biological chemistry 278:31831-31837. 
Weller RO, Boche D, Nicoll J a R (2009) Microvasculature changes and cerebral amyloid angiopathy in Alzheimer's disease and their potential impact on therapy. Acta neuropathologica 118:87-102.

West MJ, Coleman PD, Flood DG, Troncoso JC (1994) Differences in the pattern of hippocampal neuronal loss in normal ageing and Alzheimer's disease. Lancet 344:769772.

Whitehouse PJ, Price DL, Struble RG, Clark AW, Coyle JT, Delon MR (1982) Alzheimer's disease and senile dementia: loss of neurons in the basal forebrain. Science (New York, NY) 215:1237-1239.

Wilkinson BL, Cramer PE, Varvel NH, Reed-Geaghan E, Jiang Q, Szabo A, Herrup K, Lamb BT, Landreth GE (2010) Ibuprofen attenuates oxidative damage through NOX2 inhibition in Alzheimer's disease. Neurobiology of aging.

Wimo A, Prince M (2010) World Alzheimer Report. Alzheimer’s disease international.

Wirths O, Bayer TA (2010) Neuron loss in transgenic mouse models of Alzheimer's disease. International journal of Alzheimer's disease 2010.

Wirths O, Bethge T, Marcello A, Harmeier A, Jawhar S, Lucassen PJ, Multhaup G, Brody DL, Esparza T, Ingelsson M, Kalimo H, Lannfelt L, Bayer TA (2010a) Pyroglutamate Abeta pathology in APP/PS1KI mice, sporadic and familial Alzheimer's disease cases. Journal of neural transmission 117:85-96.

Wirths O, Breyhan H, Marcello A, Cotel M-C, Brück W, Bayer TA (2010b) Inflammatory changes are tightly associated with neurodegeneration in the brain and spinal cord of the APP/PS1KI mouse model of Alzheimer's disease. Neurobiology of aging 31:747-757.

Wirths O, Breyhan H, Schafer S, Roth C, Bayer TA (2008) Deficits in working memory and motor performance in the APP/PS1ki mouse model for Alzheimer's disease. Neurobiology of aging 29:891-901.

Wirths O, Erck C, Martens H, Harmeier A, Geumann C, Jawhar S, Kumar S, Multhaup G, Walter J, Ingelsson M, Degerman-Gunnarsson M, Kalimo H, Huitinga I, Lannfelt L, Bayer TA (2010c) Identification of low molecular weight pyroglutamate A\{beta\} oligomers in Alzheimer disease: a novel tool for therapy and diagnosis. The Journal of biological chemistry 285:41517-41524.

Wirths O, Multhaup G, Bayer T a (2004) A modified beta-amyloid hypothesis: intraneuronal accumulation of the beta-amyloid peptide--the first step of a fatal cascade. Journal of neurochemistry 91:513-520.

Wirths O, Weickert S, Majtenyi K, Havas L, Kahle PJ, Okochi M, Haass C, Multhaup G, Beyreuther K, Bayer TA (2000) Lewy body variant of Alzheimer's disease: alphasynuclein in dystrophic neurites of A beta plaques. Neuroreport 11:3737-3741.

Wolfe MS (2009) gamma-Secretase in biology and medicine. Seminars in cell \& developmental biology 20:219-224. 
Wood SJ, Wypych J, Steavenson S, Louis JC, Citron M, Biere AL (1999) alpha-synuclein fibrillogenesis is nucleation-dependent. Implications for the pathogenesis of Parkinson's disease. The Journal of biological chemistry 274:19509-19512.

Wyss-Coray T, Loike JD, Brionne TC, Lu E, Anankov R, Yan F, Silverstein SC, Husemann J (2003) Adult mouse astrocytes degrade amyloid-beta in vitro and in situ. Nature medicine 9:453-457.

$\mathrm{Xu} X$ (2009) Gamma-secretase catalyzes sequential cleavages of the AbetaPP transmembrane domain. Journal of Alzheimer's disease 16:211-224.

Yan Q, Zhang J, Liu H, Babu-Khan S, Vassar R, Biere AL, Citron M, Landreth G (2003) Anti-inflammatory drug therapy alters beta-amyloid processing and deposition in an animal model of Alzheimer's disease. Journal of neuroscience 23:7504-7509.

Zandi PP, Anthony JC, Hayden KM, Mehta K, Mayer L, Breitner JC (2002) Reduced incidence of AD with NSAID but not $\mathrm{H} 2$ receptor antagonists: the Cache County Study. Neurology 59:880-886.

Zarow C, Lyness SA, Mortimer JA, Chui HC (2003) Neuronal loss is greater in the locus coeruleus than nucleus basalis and substantia nigra in Alzheimer and Parkinson diseases. Archives of neurology 60:337-341.

Zhao B, Stavchansky SA, Bowden RA, Bowman PD (2003) Effect of interleukin-1beta and tumor necrosis factor-alpha on gene expression in human endothelial cells. American journal of physiology Cell physiology 284:C1577-83.

Zheng H, Jiang M, Trumbauer ME, Sirinathsinghji DJ, Hopkins R, Smith DW, Heavens RP, Dawson GR, Boyce S, Conner MW, Stevens KA, Slunt HH, Sisoda SS, Chen HY, Van der Ploeg LH (1995) beta-Amyloid precursor protein-deficient mice show reactive gliosis and decreased locomotor activity. Cell 81:525-531.

Zlokovic BV (2011) Neurovascular pathways to neurodegeneration in Alzheimer's disease and other disorders. Nature reviews Neuroscience 13:1-16. 


\section{Curriculum vitae}

\section{Personal Data}

Name: Antje Hillmann

Date of birth: $\quad 30.05 .1984$

Place of birth: Halberstadt

\section{$\underline{\text { Education }}$}

02/2009 - 07/2012 Georg-August-University, Göttingen, Germany:

PhD program 'Molecular Medicine’

10/2003 - 10/2008 Georg-August-University, Göttingen, Germany:

Diploma Degree Biology

09/1994 - 06/2003 Fallstein-Gymnasium Osterwieck, Germany:

Abitur degree

\section{$\underline{\text { Publications }}$}

Hillmann A, Hahn S, Schilling S, Hoffmann T, Demuth H-U, Bulic B, Schneider-Axmann T, Bayer TA, Weggen S, Wirths O (2012)

No improvement after chronic ibuprofen treatment in the 5XFAD mouse model of Alzheimer's disease. Neurobiology of aging 33:833.e39-50

Lüttmann D, Heermann R, Zimmer B, Hillmann A, Rampp IS, Jung K, Görke B (2009) Stimulation of the potassium sensor KdpD kinase activity by interaction with the phosphotransferase protein IIANtr in Escherichia coli. Mol Microbiol 72, 978-994

Zimmer B, Hillmann A, and Görke B (2008)

Requirements for the phosphorylation of the Escherichia coli EIIANtr protein in vivo. FEMS Microbiol Lett 286: 96-102 